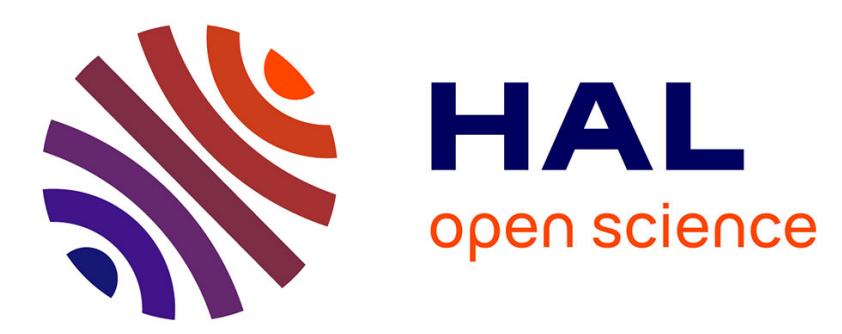

\title{
Cyclic (Alkyl)(amino)carbenes (CAACs) in Ruthenium Olefin Metathesis
}

J. Morvan, Marc Mauduit, G. Bertrand, R. Jazzar

\section{To cite this version:}

J. Morvan, Marc Mauduit, G. Bertrand, R. Jazzar. Cyclic (Alkyl)(amino)carbenes (CAACs) in Ruthenium Olefin Metathesis. ACS Catalysis, 2021, 11 (3), pp.1714-1748. 10.1021/acscatal.0c05508 . hal03164092

\section{HAL Id: hal-03164092 \\ https://hal.science/hal-03164092}

Submitted on 29 Mar 2021

HAL is a multi-disciplinary open access archive for the deposit and dissemination of scientific research documents, whether they are published or not. The documents may come from teaching and research institutions in France or abroad, or from public or private research centers.
L'archive ouverte pluridisciplinaire HAL, est destinée au dépôt et à la diffusion de documents scientifiques de niveau recherche, publiés ou non, émanant des établissements d'enseignement et de recherche français ou étrangers, des laboratoires publics ou privés. 


\section{Cyclic (Alkyl)(Amino)carbenes (CAACs) in Ruthenium Olefin Metathesis}

Jennifer Morvan, ${ }^{\mathrm{a}}$ Marc Mauduit, ${ }^{\text {a }}$ Guy Bertrand, ${ }^{* \mathrm{~b}}$ Rodolphe Jazzar*b

aUniversité de Rennes, Ecole Nationale Supérieure de Chimie de Rennes, CNRS, ISCR UMR 6226, F-35000 Rennes, France

bUCSD-CNRS Joint Research Chemistry Laboratory (UMI 3555), Department of Chemistry and Biochemistry, University of California, San Diego, La Jolla, California 92093-0358, United States

Keywords: cyclic (alkyl)(amino)carbenes (CAACs), olefin metathesis, homogeneous catalysis, ruthenium catalysts, transition metals.

TOC:

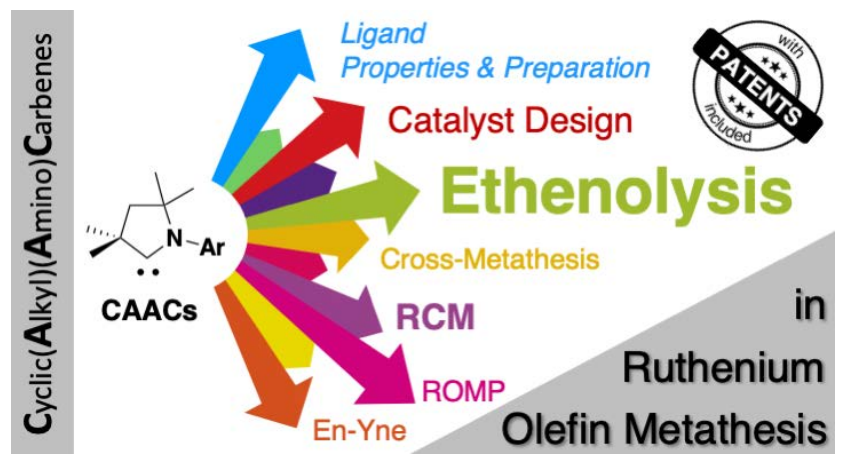

Abstract: Discovered in 2005, cyclic (alkyl)(amino)carbenes (CAACs) have led to numerous discoveries in the field of ruthenium olefin metathesis, until then largely dominated by the well-known $\mathrm{N}$-heterocyclic carbenes (NHCs). Compared to the latter, CAACs are simultaneously more nucleophilic ( $\sigma$-donating) and electrophilic ( $\pi$-accepting), which leads to very strong metal-carbene bonds. Consequently, CAAC-ruthenium complexes are very robust, which leads to enhanced catalytic activities, as exemplified by the industrially relevant ethenolysis of unsaturated fatty acids (up to of 390,000 TON). Herein, we provide a 
comprehensive overview of the impact of CAAC ligands in olefin metathesis, including results which are discribed in patents. 


\section{Table of Content}

1. Introduction 4

2. Ligand and Catalyst Design 5

2.1. CAACs: Properties and Preparation. 5

2.2. Heteroleptic (CAAC)Ruthenium Metathesis Complexes 6

2.2.1 Hoveyda-Grubbs (CAAC)Ruthenium Type Complexes 6

2.2.2 Indenylidene (CAAC)Ruthenium Type Complexes 11

2.2.3. Other Types of (CAAC)Ruthenium Complexes 14

2.2.4 Optically pure (CAAC)Ruthenium Complexes 16

3. (CAAC)Ruthenium catalysts in Olefin Metathesis 17

3.1. Application to Self- and Cross metathesis 17

$\begin{array}{lll}\text { 3.1.1. Self-metathesis } & 17\end{array}$

3.1.2. Cross metathesis 21

3.2. Application to Ring-Closing Metathesis 26

3.2.1. Small molecules 26

3.2.2. Macrocycles 34

3.3. Applications in Ethenolysis 37

3.3.1. Methyl and ethyl Oleate 37

3.3.2. Fatty acid methyl esters (FAME) mixture 45

$\begin{array}{lll}\text { 3.3.3. Other substrates } & 47\end{array}$

3.4. Application to ROCM 49

3.5. Application to Olefin Polymerization 51

3.5.1. Ring Opening Metathesis Polymerization (ROMP) 52

3.5.2. Acyclic Diene Metathesis (ADMET) Polycondensation 55

3.6. Application to En-Yne Metathesis 58

3.7. Activity in Degenerate (Nonproductive) Metathesis 59

4. Conclusions and Future Directions 61

$\begin{array}{ll}\text { References } & 63\end{array}$ 


\section{Introduction}

The discovery of stable carbenes at the end of the last century ${ }^{1,2}$ has unarguably triggered a profound revolution in transition metal catalysis. Until then, the field was largely dominated by phosphines as ancillary ligands. ${ }^{3}$ One of the most prominent examples is witnessed by the evolution of the first generation Grubbs ruthenium olefin metathesis catalyst $\mathbf{A}^{4}{ }^{4}$ The replacement of one of the two $\mathrm{PCy}_{3}$ ligands in $\mathbf{A}$, by the strong $\sigma$-donor and poor $\pi$-acceptor 1,3-dimesityl-imidazolin-2-ylidene (IMes), ${ }^{2}$ (a carbene from the family of $N$-heterocyclic carbenes; i.e. NHCs), resulted in the extremely stable, yet very reactive second-generation Grubbs catalyst B (Scheme 1). ${ }^{5,6,7,8,9,10}$ The superior catalytic activity of $\mathbf{B}$ over A, originally demonstrated in the preparation of di-, tri-, and even tetra-substituted olefins, ${ }^{4,11}$ was later established across multiple other systems. ${ }^{5,6,7}$ This breakthrough, also referenced as the 00 's of metathesis, paved the way for the development of hundreds of metathesis catalysts featuring $N$-heterocyclic carbene ligands, ${ }^{8,9,10}$ as seen with the well-known second generation HoveydaGrubbs catalysts C. ${ }^{12}$ Recently, another class of stable singlet carbenes, named cyclic (alkyl)(amino)carbenes (CAACs), have gained considerable momentum in this field and have only briefly been discussed in a few review articles. ${ }^{13,14,15,16,17}$ Herein, we provide a comprehensive summary of the impact of CAACs in olefin metathesis, since the first report in 2007, including results which were only reported in patents (the latter are highlighted in pink in the schemes and figures).

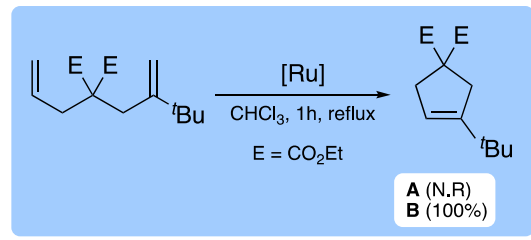

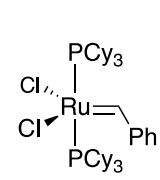

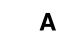

$\underset{1 \text { st Grubbs }}{\text { generation }}$ $1^{\text {st }}$ generation

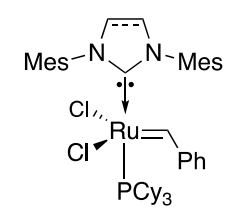

B

Grubbs
$2^{\text {nd }}$
generation

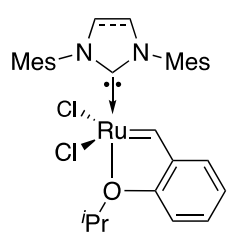

C

Hoveyda-Grubbs 
Scheme 1 The debut of $N$-heterocyclic carbenes in ruthenium olefin metathesis

\section{Ligand and Catalyst Design}

\subsection{CAACs: Properties and Preparation.}

To understand the advantages and limitations of CAACs versus NHCs in ruthenium olefin metathesis, a brief comparison of their electronic properties and steric contribution is necessary. ${ }^{18,19,20,21}$ CAACs differ from NHCs by the presence of a $\sigma$-donating quaternary carbon $\alpha$ to the carbene center instead of a $\pi$-donating and $\sigma$-attracting amino group (Figure 1). As a result, CAACs are simultaneously more nucleophilic and electrophilic than traditional NHCs (HOMO: -5.35 vs. $-5.82 \mathrm{eV}$ and LUMO: +0.06 vs. $+1.00 \mathrm{eV}$ ). Also contrasting with NHCs, where the steric contribution is best described as an umbrella with pendant $\mathrm{N}$ substituents oriented towards the metal (as opposed to phosphines), the $\mathrm{sp}^{3}$-hybridized $\alpha$ carbon of CAACs provides a wall of protection. Additionally, this quaternary carbon provides a mean to introduce chirality much closer to the metal not feasible with conventional NHCs. ${ }^{22}$

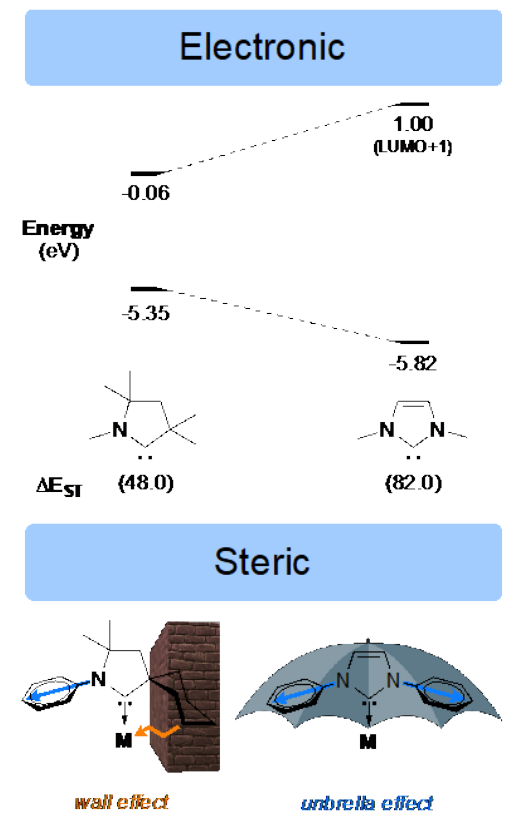

Figure 1. Electronic and steric properties of CAACs versus NHCs

The preparation of aldiminium cations, the conjugate acids of CAACs, has been achieved by two complimentary synthetic routes (Scheme 2). While both methods involve the addition of electrophiles to aza-allyl anion intermediates, followed by ring closure, they differ in the nature 
of the electrophile. For Route 1, the use of epoxides allows for introducing both alkyl and aryl groups at nitrogen but is somewhat restricted to relatively sterically uncongested $\mathrm{sp}^{3}$ hybridized carbon center. ${ }^{23,24}$ On the other hand, Route 2 is limited to $N$-aryl substituents, but more tolerant to steric congestion at the $\mathrm{sp}^{3}$ carbon. It proceeds via an allylation followed by an intramolecular hydroiminiumation reaction. ${ }^{25,26}$ In recent years, Route 2 has been used for the preparation of more ambiphilic CAAC ligands such as the bicyclic (alkyl)(amino)carbenes (BiCAACs) and the 6-membered cyclic (alkyl)(amino)carbenes (CAAC-6s). ${ }^{27,28}$ In all cases, free CAACs were obtained from the corresponding aldiminium salts by deprotonation with a strong base such as KHMDS or LDA.
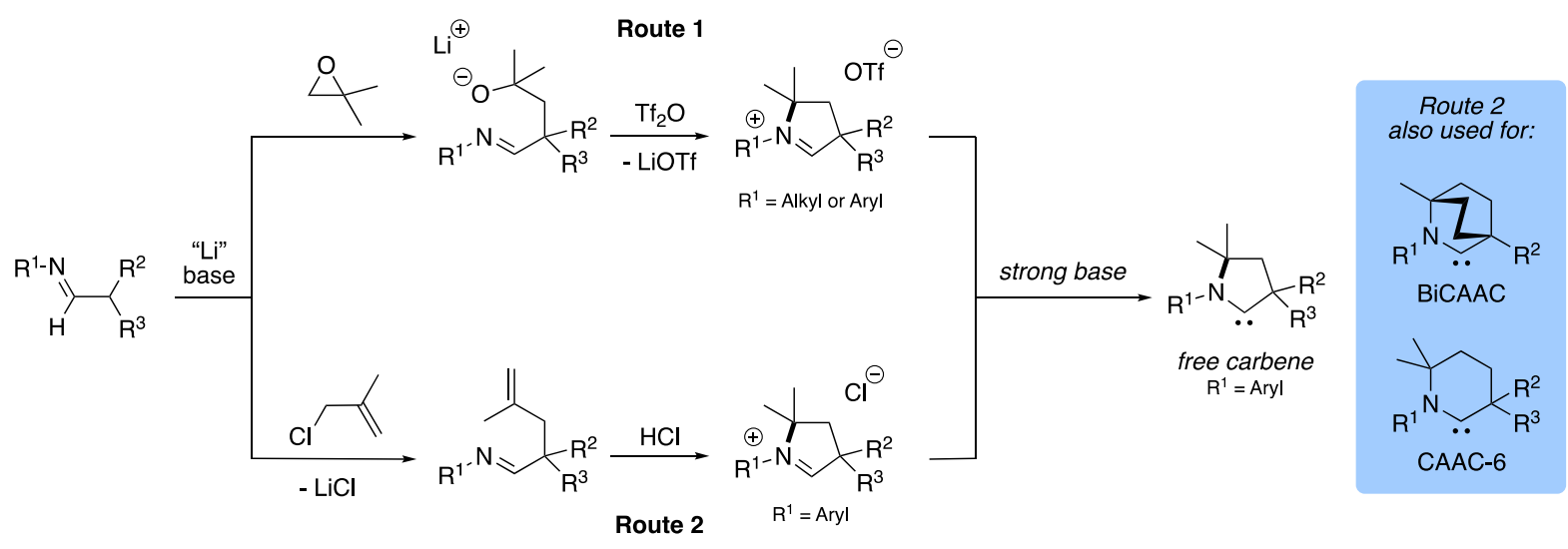

Scheme 2. Synthesis of CAACs

\subsection{Heteroleptic (CAAC)Ruthenium Metathesis Complexes}

\subsubsection{Hoveyda-Grubbs (CAAC)Ruthenium Type Complexes}

Second generation heteroleptic ruthenium metathesis complexes are typically accessed by ligand exchange, reacting the free NHC with inexpensive and readily available first-generation complexes bearing a sacrificial phosphine ligand (e.g. PCуз). With NHC, this route classically relies on in situ generation of free carbenes by treatment of various imidazolinium salts with a strong base. ${ }^{29}$ This is also the case with CAACs which can be generated in situ and undergo ligand exchange at room temperature with Hoveyda-Grubbs first generation $\mathbf{D}^{30}$ (Scheme 3). ${ }^{31,32,33}$ While yields appear counterintuitively higher with more sterically demanding 
ligands, it is likely a consequence of the propensity of some of the metal-free CAACs to degrade via intramolecular insertion into benzylic $\mathrm{C}\left(\mathrm{sp}^{3}\right)-\mathrm{H}$ bonds of aryl substituents. ${ }^{34}$ With bulky groups, the aryl moiety is forced to be perpendicular to the CAAC skeleton, which prevents its ortho-substituents from approaching the carbene center. As seen with Ru1-Ru18, most of the modifications of the CAAC ligands in ruthenium complexes have been achieved by changing substituents on the $N$-Aryl or at the quaternary carbon adjacent to the carbene center. To investigate the influence of the backbone over the catalytic performance of these complexes, Zhang, Shi and coworkers, prepared complexes Ru19-Ru21 bearing a bulky isopropyl group $\beta$ to the carbene center. ${ }^{35}$ More recently, Tóth, Tuba and coworkers extended the variety of (CAAC)Ru complexes to $\mathbf{R u}-\mathbf{2 2}$ and $\mathbf{R u}-\mathbf{2 3}$ in which the CAAC features an amino and an ammonium group on the $N$-aryl moiety. ${ }^{36}$ The latter is highly polar and was shown to be soluble in environmentally benign protic media without compromising the high catalytic activity and stability. 


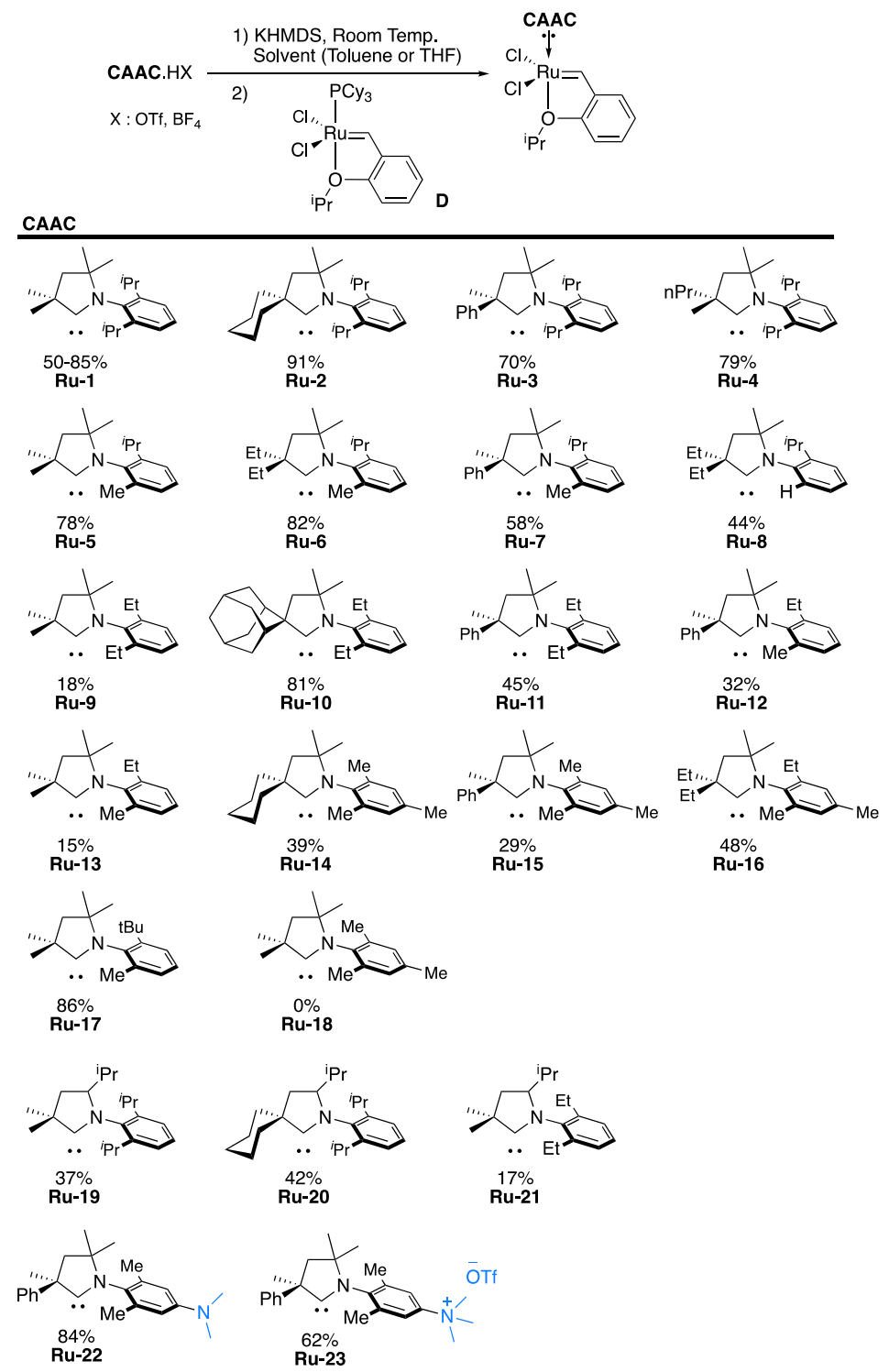

\section{Scheme 3 Synthesis of Hoveyda-Grubbs CAACs}

As shown by Olivier-Bourbigou and coworkers, the benzylidene moiety of CAAC derived Hoveyda-Grubbs complexes are readily tunable by simple addition of a chelating olefin (Scheme 4). ${ }^{37}$ These authors used this pathway to introduce an amino group on the benzylidene fragment as shown by complexes $\mathbf{R u - 2 4}$ and $\mathbf{R u - 2 5}$. In line with a report by Grela, Kirschning and coworkers, ${ }^{38}$ subsequent protonation of the amino substituent of $\mathbf{R u}-25$ with pTsOH afforded complex Ru-26 which appeared to be more active, probably due to the increased lability of the benzylidene fragment. The benzylidene variants Ru-27 have also been obtained by reacting pre-functionalized $1^{\text {st }}$ generation precursors with in situ generated CAACs. ${ }^{39}$ 


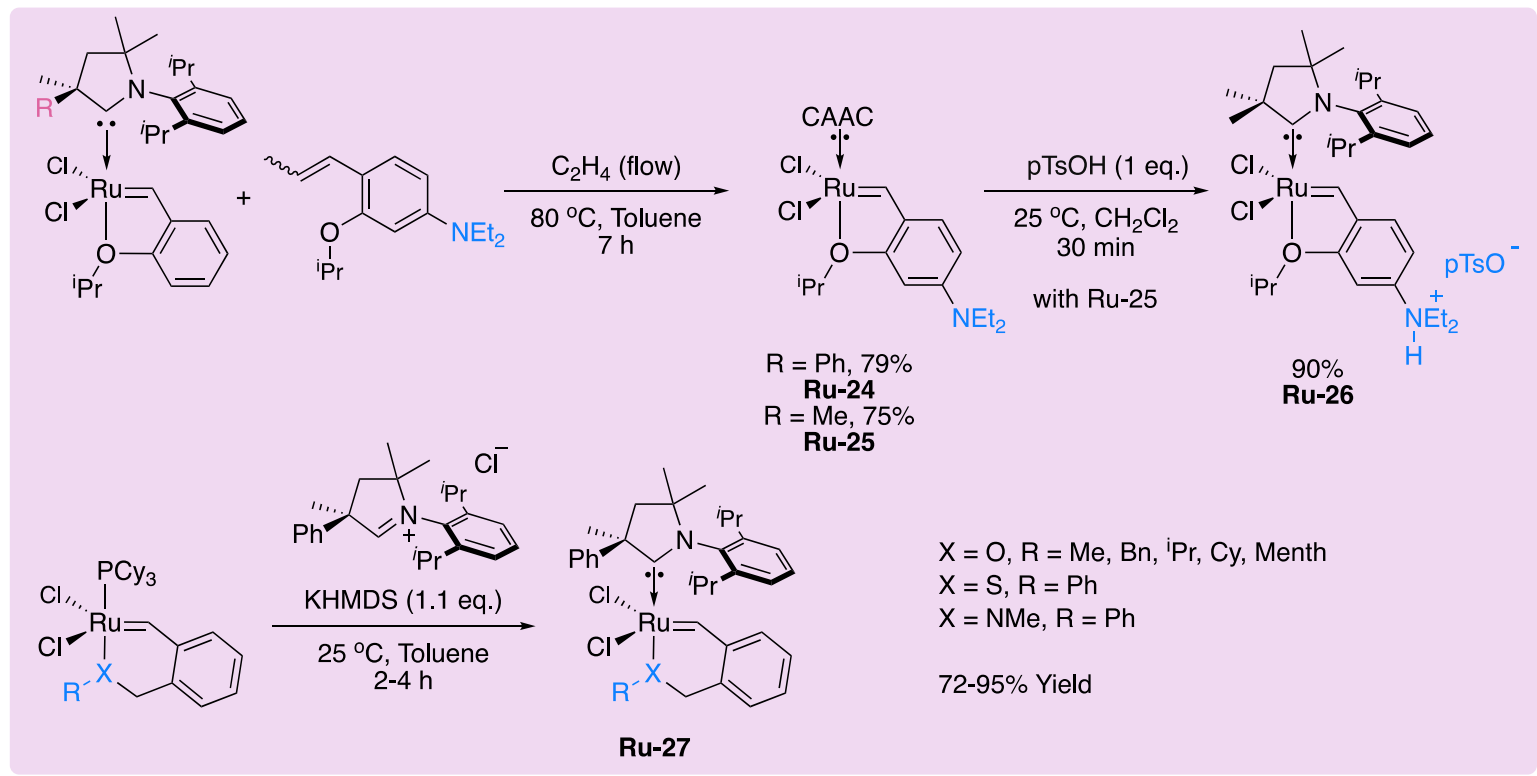

Scheme 4 Preparation of Ruthenium metathesis CAACs complexes with various benzylidene

fragments

These methodologies are not limited to CAAC-5, and can be extended to other motifs of the CAAC family. Indeed, Grubbs and coworkers have recently reported the first example of CAAC-6 ruthenium metathesis complexes Ru-28-31 (Scheme 5) ${ }^{40}$ Here also, excellent yields were obtained with the sterically hindered cyclohexyl derivatives ( $>68 \%)$, whereas less hindered ethyl derivatives resulted in much lower yields $(<30 \%)$. Note that the ethyl substituted CAAC-6 is less stable than the CAAC-5 analogues. ${ }^{28}$ Moreover, the authors stated that decreasing sterics at nitrogen (e.g., $N$-mesityl group) or at the quaternary $\alpha$-carbon (e.g., gemdimethyl) proved challenging, because of the difficulty in preparing the CAAC conjugate acids. $^{25}$

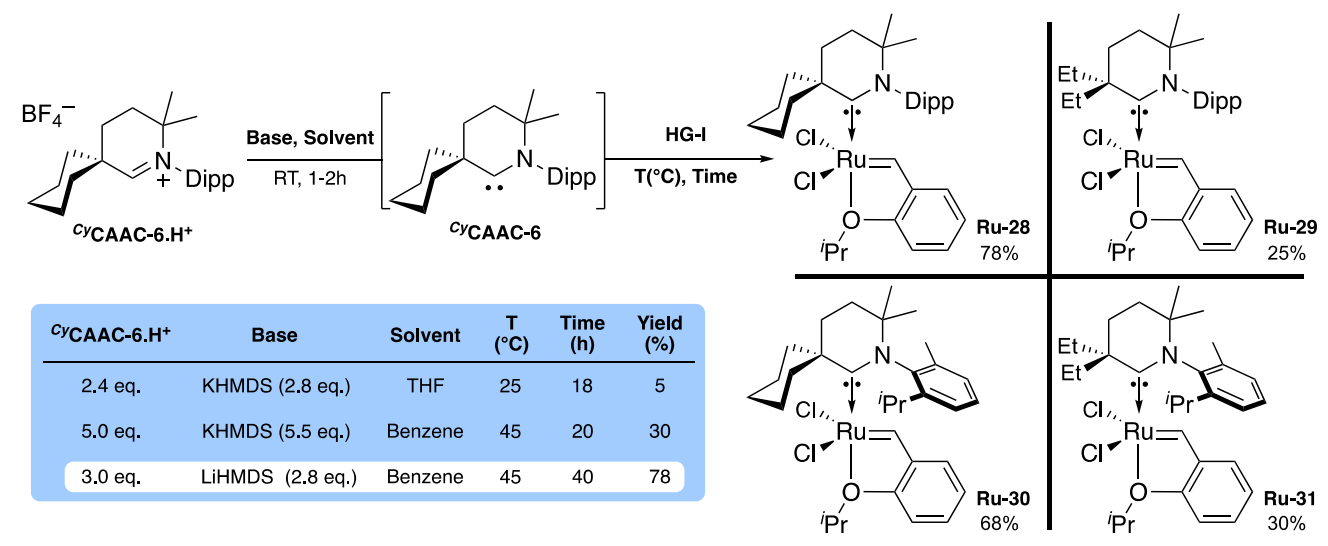




\section{Scheme 5 Preparation of Hoveyda-Grubbs CAAC-6 complexes}

As highlighted by Fogg et al., ${ }^{41}$ numerous issues have been associated with the preparation of (carbene)Ru metathesis pre-catalysts by in situ generation of the free carbene. Looking for alternatives, ${ }^{42,43,44,45}$ Grela and coworkers disclosed the use of mechanochemistry (ballmilling) as a mild and solvent free method for the preparation of CAAC Hoveyda-Grubbs complexes (Scheme 6). ${ }^{46}$ While the method compares reasonably well with the homogeneous route (55\% yield vs. $77 \%$ for $\mathbf{R u}-\mathbf{2}$ ), it arguably opens new prospects for the preparation of Hoveyda-Grubbs complexes of more challenging or low yielding CAAC motifs.
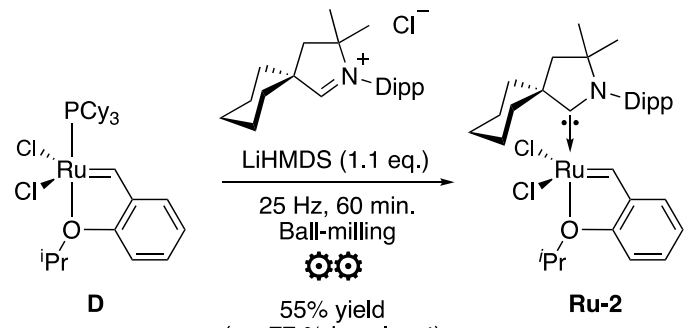

(vs. $77 \%$ in solvent)

Ru-2

Scheme 6 Mechanochemical preparation of (CAAC)Ru metathesis pre-catalysts.

For its ability to undergo facile ligand exchange with stronger donors, pyridine complex $\mathbf{E}$ has also been used as precursor for Hoveyda-Grubbs type (CAAC)Ruthenium pre-catalysts (Scheme 7). ${ }^{32}$ As expected, treatment of $\mathbf{E}$ with CAACs, generated in situ, afforded the airsensitive pyridine adducts Ru-32 and Ru-33, which were isolated in modest yields. Building upon these results, Lemcoff and coworkers have shown that $\mathbf{R u} \mathbf{u} 32$ provides a convenient route to sulfur-chelated ruthenium benzylidenes $\mathbf{R u}-\mathbf{3 4}$ and $\mathbf{R u}-35 .{ }^{47}$

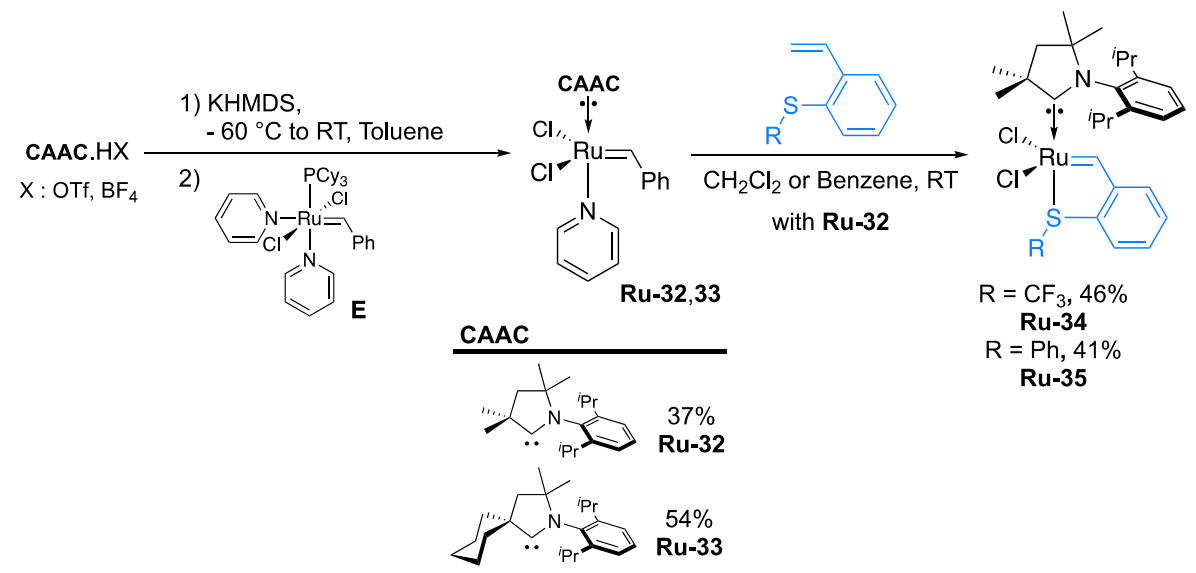




\section{Scheme 7 Preparation of sulfur-chelated ruthenium benzylidene complexes}

\subsubsection{Indenylidene (CAAC)Ruthenium Type Complexes}

Until recently, (CAAC)Ru complexes were mainly obtained using Hoveyda-Grubbs firstgeneration benzylidene complex $\mathbf{D}$ (vide supra), the preparation of which can be challenging. ${ }^{30}$ Aiming to develop a more versatile route, Skowerski and coworkers examined the preparation of CAAC olefin metathesis ruthenium catalysts from readily accessible and patent-free precursors. They considered the indenylidene complex $\mathbf{F}$ bearing two triphenyl phosphine ligands. ${ }^{48,49}$ Excitingly, in contrast with NHCs, ${ }^{50,51}$ reaction of $\mathbf{F}$ with three equivalents of in situ generated CAACs, resulted in the formation of bis(CAAC)Ru indenylidene complexes Ru-36-43 (Scheme 8). ${ }^{52,53}$ Note that higher yields were obtained with the indenylidene complex bearing two tricyclohexyl phosphines, albeit with longer reaction times. Tóth, Tuba and coworkers extended this methodology to CAAC bearing $\mathrm{NMe}_{2} \mathbf{R u}-\mathbf{4 4}$ and $\mathrm{N}-\mathrm{Me}_{3}{ }^{+}$ ammonium Ru-45 groups on the $N$-aryl moiety (Scheme 9). ${ }^{36}$

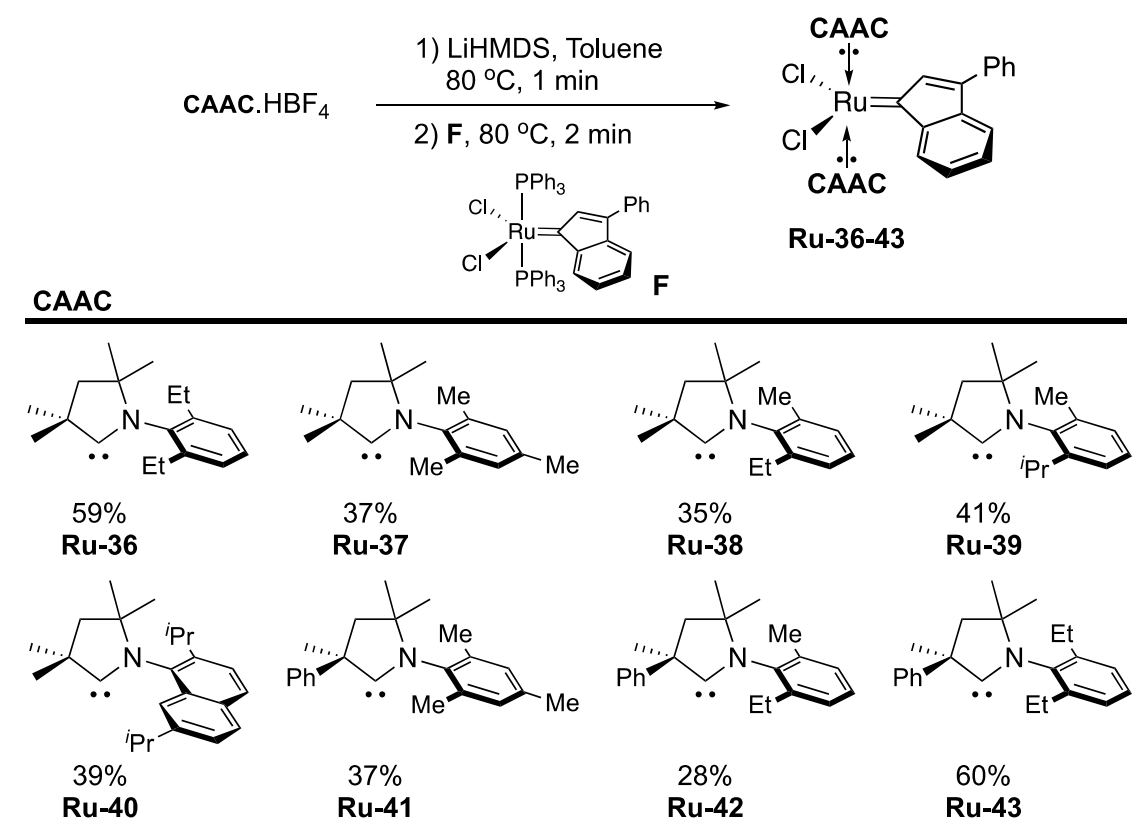

Scheme 8 Preparation of bis(CAAC)Ru indenylidene complexes 


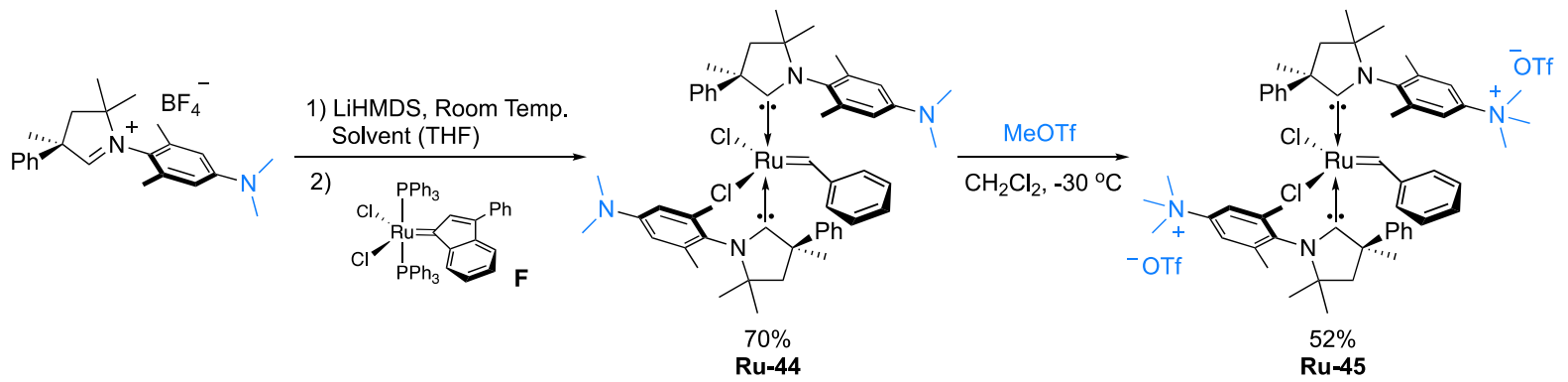

Scheme 9 Preparation of bis(CAAC)Ru complexes bearing polar amino substituents

The propensity of ruthenium bis-NHCs alkylidenes to generate active catalytic species has been discussed. ${ }^{43,51,54,55}$ To determine whether strongly $\sigma$-donating and $\pi$-accepting CAACs could impede or facilitate the activation of bis-CAAC-Ru-indenylidene complexes, Skowerski and coworkers next examined their reaction with a doubly chelating olefin. ${ }^{52}$ As shown in Scheme 10, reaction of Ru-43 with 1-isopropoxy-2-(propenyl)benzene at $60{ }^{\circ} \mathrm{C}$ in toluene led to the clean formation of the Hoveyda-Grubbs derivative Ru-11, which was isolated in $86 \%$ yield. Interestingly, the authors also noted that under the same conditions no conversion was observed with the less sterically hindered Ru-36 even after 48h. However, it was shown that simple addition of $\mathrm{CuCl}$ (2 eq.), likely acting as a carbene scavenger, is sufficient to drive the reaction forward, thus affording complex Ru-9 in good yield.

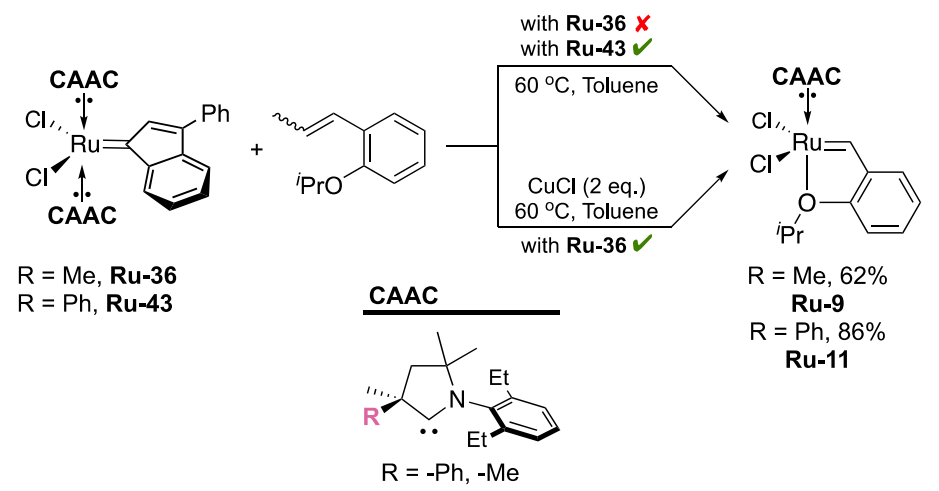

Scheme 10 Accessing Hoveyda-Grubbs type complexes from bis(CAAC)Ru indenylidenes

Capitalizing on these results the same group extended the methodology to other Grela type $\mathrm{e}^{56}$ Hoveya-Grubbs CAAC-ruthenium metathesis complexes Ru-46-52 (Scheme 11), ${ }^{57,58}$ as well as $\mathbf{R u - 5 3}$ and $\mathbf{R u - 5 4 - 5 7}$ which were only reported in a patent (Scheme 12). ${ }^{59}$ 

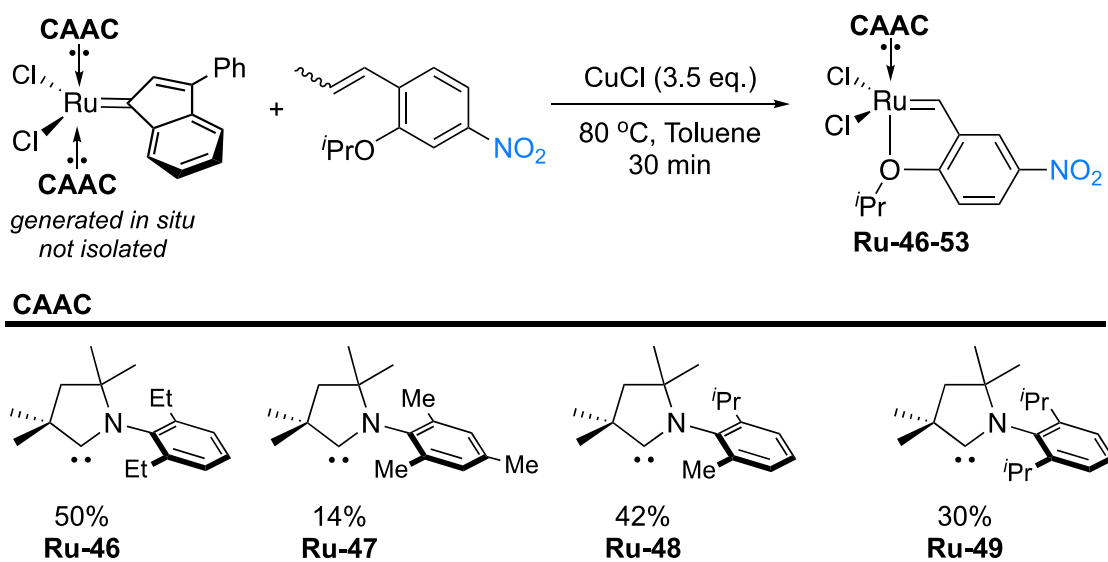

Ru-47

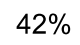

Ru-48

Ru-46-53
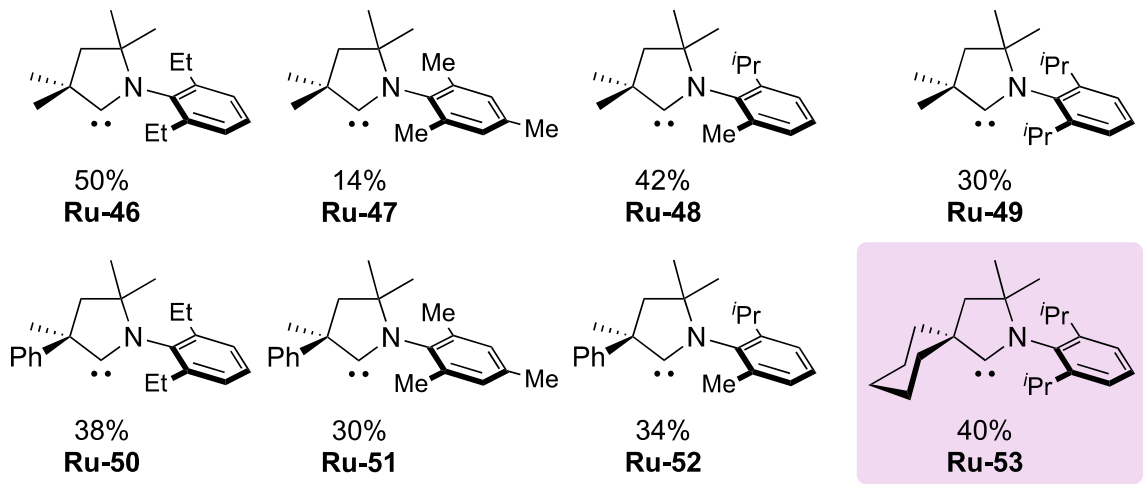

Scheme 11 Accessing nitro-Grela type complexes from bis(CAAC)Ru indenylidenes

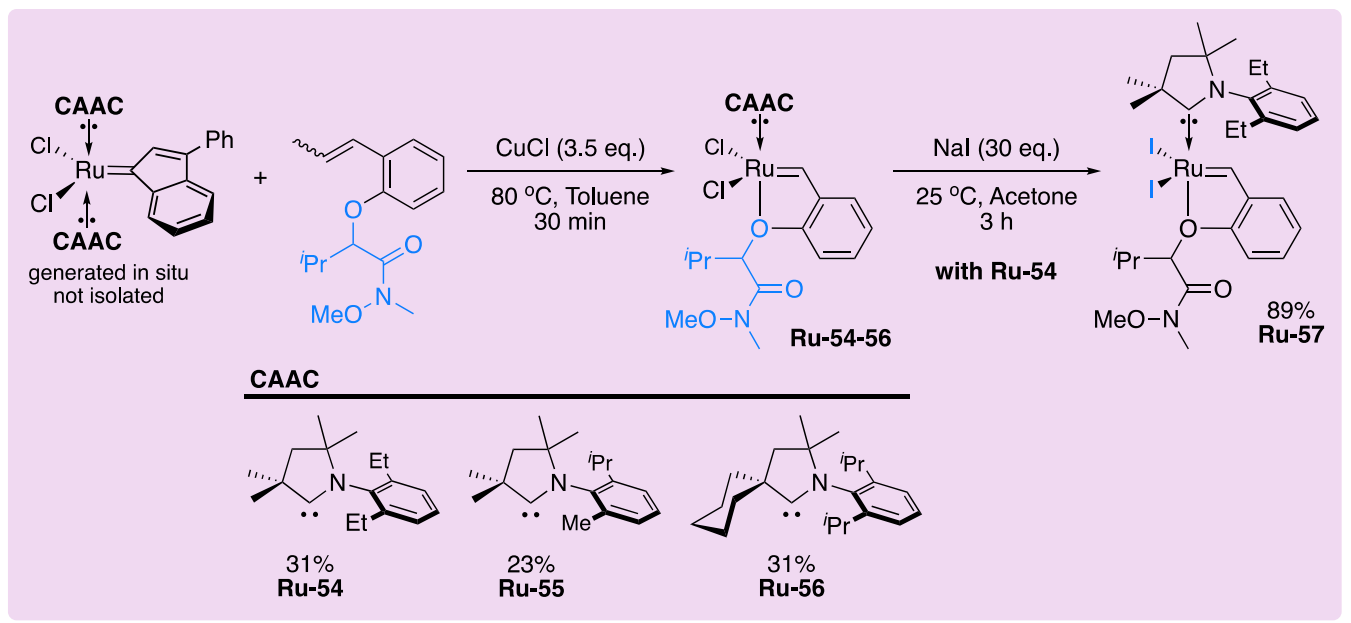

Scheme 12 Bis(CAAC)Ru indenylidenes a convenient route to mono-CAAC ruthenium metathesis complexes

Similarly, Lemcoff and coworkers showed that sulfur-chelated ruthenium benzylidenes Ru-58 and Ru-59 are also accessible by this route as a mixture of trans- and cis- isomers (Scheme 13). ${ }^{47}$ The cis/trans ratio could readily be tuned by solvent polarity and temperature, and UVA irradiation was sufficient to revert from cis to trans. 


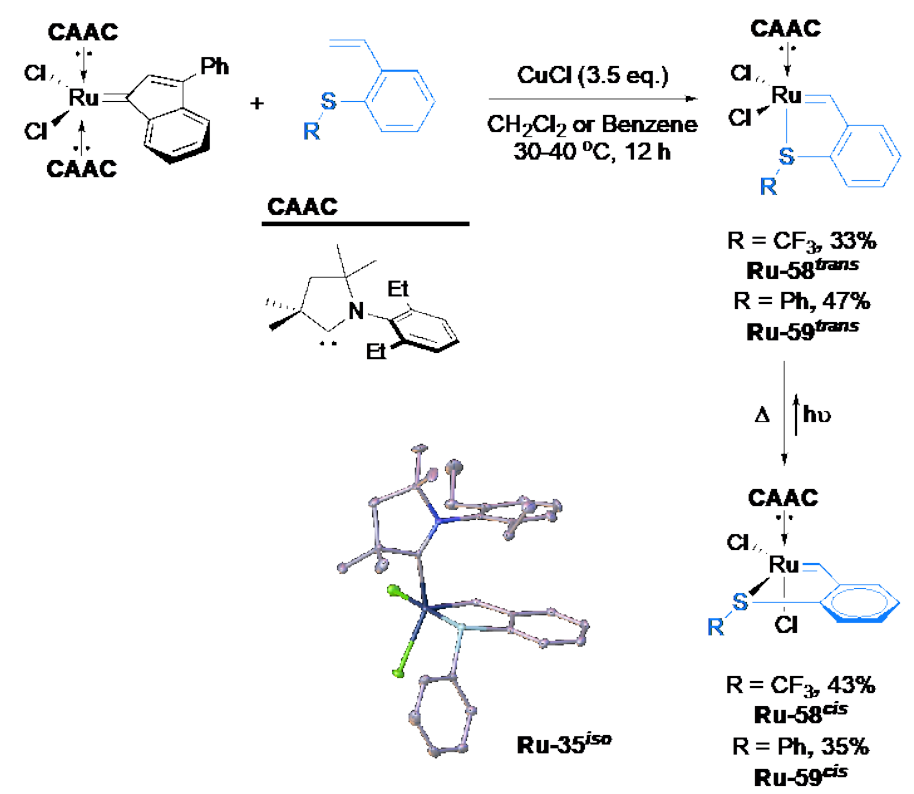

Scheme 13 Preparation and configurational behavior of sulfur-chelated ruthenium benzylidenes

\subsubsection{Other Types of (CAAC)Ruthenium Complexes}

The development of Z-selective ruthenium-based catalysts bearing cyclometalated NHC ligands ${ }^{60,61}$ has been expanded to CAAC derivatives. ${ }^{62}$ As shown in Scheme 14, the general synthetic strategy used to access the adamantyl variant Ru-60, involves the exchange of the chlorines of Hoveyda-Grubbs CAAC complex Ru-10 with sodium-pivalate. With NHCs, cyclometalated-nitrato catalyst have been shown to afford more stable and more selective catalysts. ${ }^{63}$ The CAAC analogue Ru-61 is readily available in 59\% yield by simple treatment of Ru-60 with ammonium nitrate.
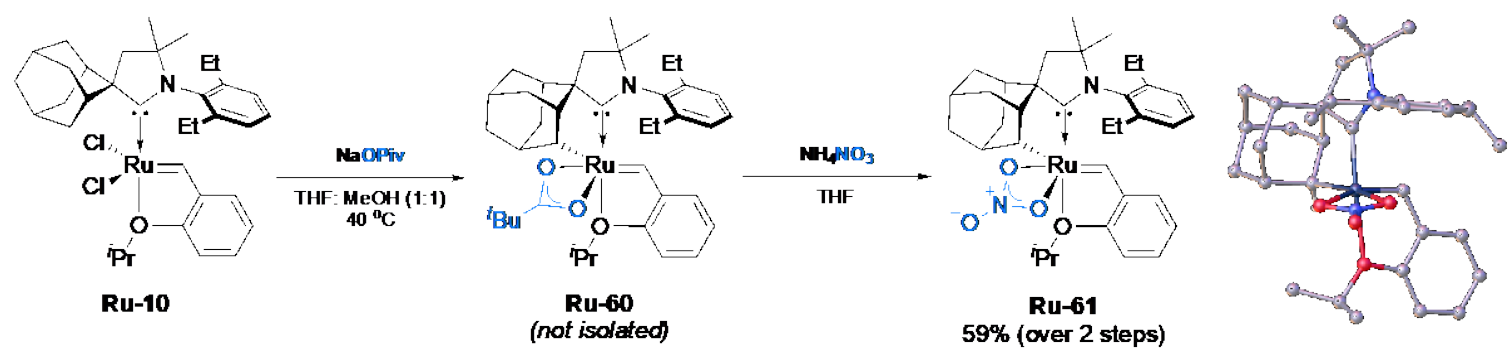

Scheme 14 Preparation of CAAC-Ru cyclometalated complexes

As previously mentioned, bis(CAAC)Ru-indenylidene pre-catalysts are rather difficult to initiate, requiring high temperatures or the use of additives such as copper chloride. This 
arguably impedes their catalytic activity under mild conditions, because of catalyst degradation. ${ }^{64,65}$ To circumvent these limitations, Fogg and coworkers reported a novel (CAAC)Ru-indenylidene dimer Ru-62, ${ }^{66}$ bridged by dative $\mathrm{Cl}$ interactions ${ }^{67}$ To access this species, the bis(CAAC)Ru indenylidene $\mathbf{R u - 4 3}$ was treated with $\mathrm{CuCl}$ in the absence of additional donors in $\mathrm{CH}_{2} \mathrm{Cl}_{2}$ (Scheme 15). Under these conditions, trapping of one of the two CAAC ligands afforded Ru-62 in 78\% isolated yield.
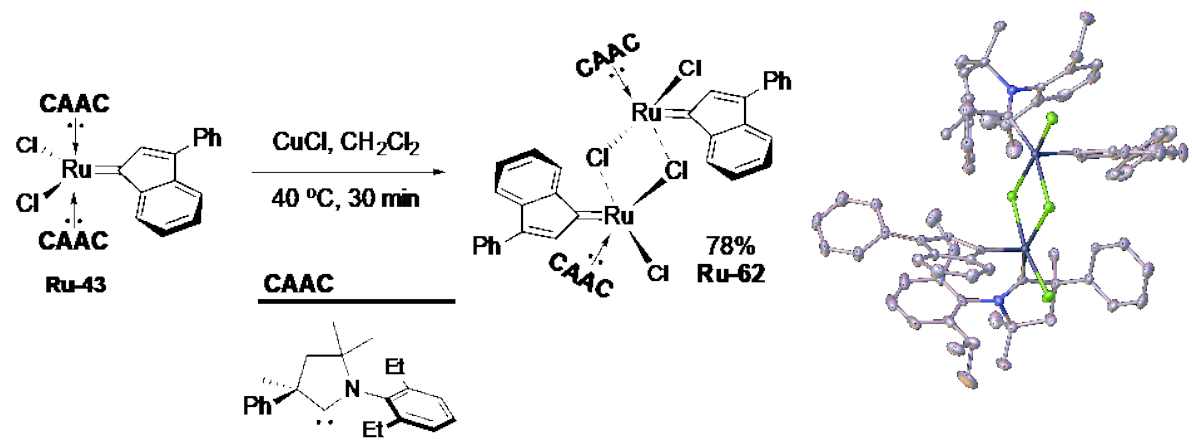

Scheme 15 Preparation of Fogg's (CAAC)Ru-indenylidene dimer Ru-62

Grubbs and coworkers sought to better understand the influence of CAACs versus NHCs on elementary steps of the RCM catalytic cycle, correlating these effects with the selectivity for either degenerate or productive olefin metathesis. ${ }^{68}$ For this purpose, they prepared CAAC ethylene ruthenacycles Ru-67,68 via a three-step procedure involving the reaction of HoveydaGrubbs type complexes Ru-1,9 with $\mathrm{P}^{i} \mathrm{Pr}_{3}$, which afforded carbides Ru-63,64 (Scheme 16). Following protonation with $\mathrm{HBF}_{4}$, the reactivity of the ensuing Piers type phosphonium alkylidene Ru-65,66 complexes was evaluated under ethene atmosphere to afford $\mathbf{R u - 6 7 , 6 8 .}{ }^{69}$ It is worth mentioning that these results show that phosphonium alkylidenes are accessible from Hoveyda-type complexes. Note that ethylene ruthenacycles can also be obtained starting from Fogg's (CAAC)Ru-indenylidene dimer Ru-62. ${ }^{70}$ 

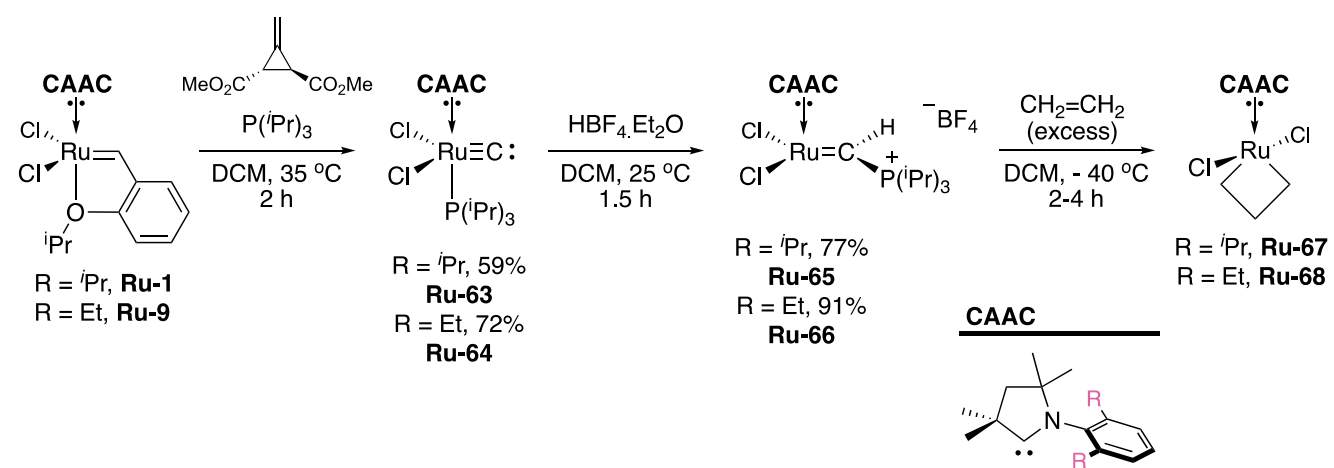

Scheme 16 Preparative sequence for accessing ethylene ruthenacycles Ru-67,68

\subsubsection{Optically pure (CAAC)Ruthenium Complexes}

Owing to their simple accessibility, optically pure NHCs have fostered numerous asymmetric applications in olefin metathesis. ${ }^{71,72,73}$ Recently, it was shown that the highly modular steric environment of CAACs could also provide potent optically pure ligands for asymmetric catalysis. $^{22}$ Eager to streamline the discovery of optically pure CAAC-ruthenium metathesis catalysts, we have shown that preparative high-performance liquid chromatography (PrepHPLC), ${ }^{74}$ provides means for bypassing problems typically associated with the synthesis of chiral catalysts (i.e. multisteps, low yielding, single enantiomers). ${ }^{75}$ Of the several columns evaluated, only amylose chiral stationary phases substituted with chloro-phenylcarbamate allowed for separations with good enantioselectivity and excellent resolution. Using Chiralpak IF® for its antipode’s separation, shorter elution time and good loading capacity, (+)-Ru-3 and (-)-Ru-3 enantiomers were isolated in excellent yields (46 and 45\%, respectively) and excellent enantiomeric purities ( $>98 \%$ ee) (Scheme 17). This method was successfully extended to Grela type complexes $\mathbf{R u}-\mathbf{5 3}$ and $\mathbf{R u}-\mathbf{6 9 - 7 3 .}{ }^{76}$ 


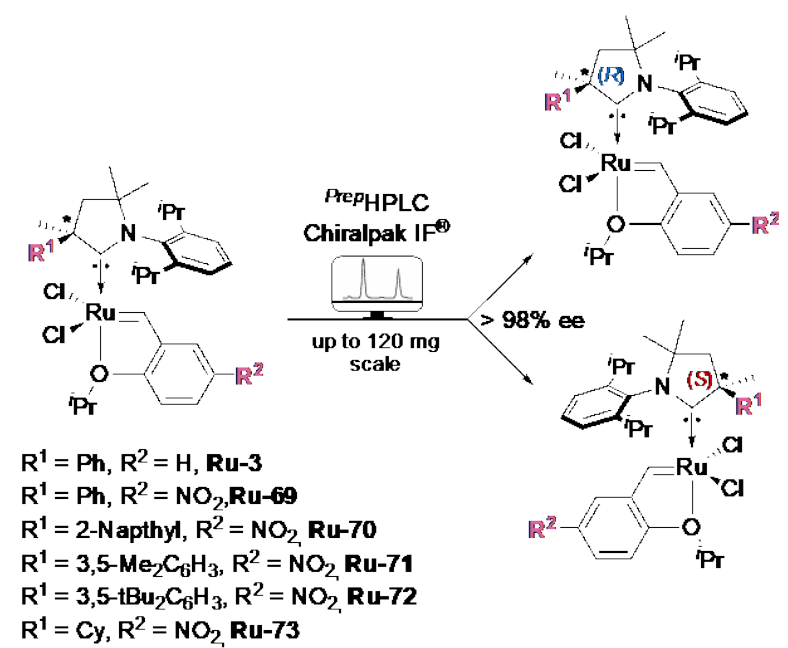

Scheme 17 Preparation of optically pure (CAAC)Ruthenium complexes

\section{3. (CAAC)Ruthenium catalysts in Olefin Metathesis}

\subsection{Application to Self- and Cross metathesis}

The cross metathesis (CM) between two different olefins or between the same olefin, known as self-metathesis (SM), offers a straightforward access to higher value, multifunctional compounds. Of course, the latter (SM) competes with the former (CM), thus both processes are often considered in parallel across the literature. To better delineate the specificities of these processes we have chosen to present them separately.

\subsubsection{Self-metathesis}

In contrast with NHC ruthenium catalysts which are generally known to be very active in selfmetathesis processes reaching up to 640,000 TONs with 1 -octene, ${ }^{77}$ CAACs variants are comparatively less efficient. This is apparent in the self-metathesis of type 1 olefins $^{78}$ such as olefin 1 which results in lower TONs in the presence of Hoveyda-Grubbs Ru-47, Ru-51 complexes (Scheme 18). ${ }^{57}$ Contrasting with this statement are bis(CAAC)-indenylidene type complexes such as Ru-43 yielding up to 315,000 (Scheme 19). ${ }^{52}$ Such differences likely results from the different initiation modes between these two families of complexes. 


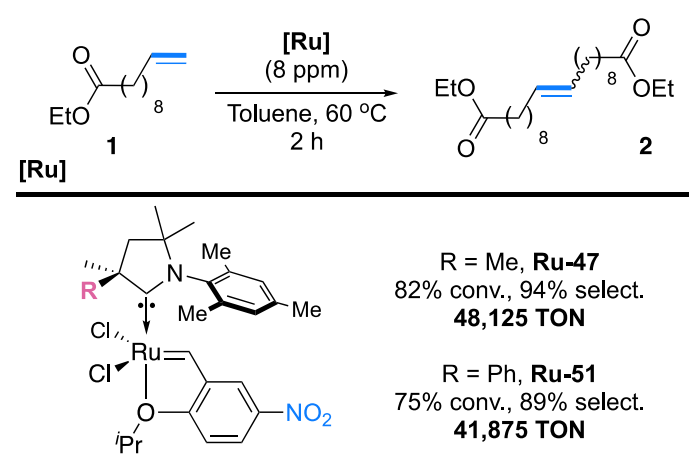

Scheme 18. Activity of CAAC-Ru Grela type complexes in self-metathesis

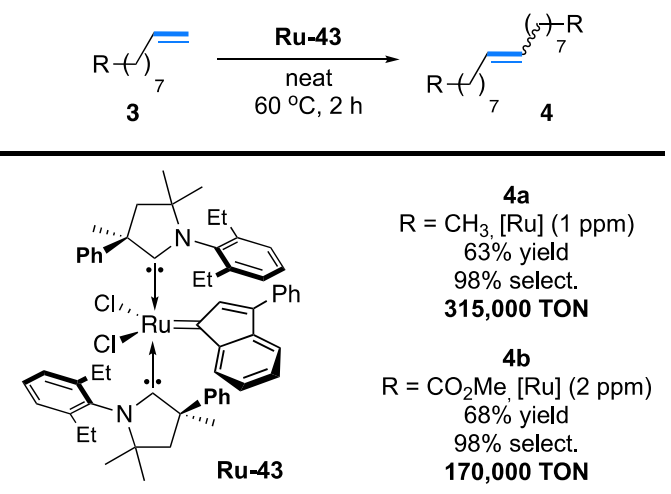

Scheme 19. Activity of bis(CAAC)Ru indenylidenes catalysts in self-metathesis

Despite the moderate activity of CAAC catalysts in the homo-dimerization of olefin, their inherent reactivity provides a convenient tool for reducing isomerization pathways. This was unambiguously established by Lemcoff and coworkers by comparing the Hoveyda-Grubbs $2^{\text {nd }}$ generation $\mathbf{C}$ to the CAAC Ru-5 in the self-metathesis of methyl oleate $\mathbf{5}$ at $100{ }^{\circ} \mathrm{C}$ in the presence of $0.1 \mathrm{~mol} \%$ catalyst loading (Scheme 20). ${ }^{79}$ These authors showed that after $1 \mathrm{~h}$, up to $40 \%$ isomerization was observed with $\mathbf{C}$, whereas it was suppressed almost completely with

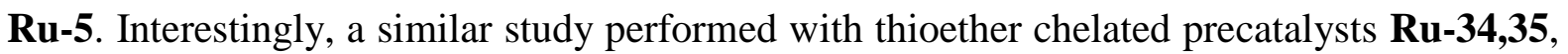
Ru-58,59 ${ }^{\text {cis }}$ supported these findings. ${ }^{47}$ Supported by DFT, this selectivity was proposed to originate from the greater difficulty of CAAC ruthenium complexes to form the rutheniumhydride- $\pi$-allyl intermediate compulsory to the isomerization mechanism. These results also suggest that the conformation of the catalyst and the nature of the benzylidene moiety should be accounted for when predicting the reactivity of these species. Indeed, marked differences where observed between $\mathbf{R u}-\mathbf{5 8}^{\text {cis }}$ and $\mathbf{R u}-\mathbf{5 9} \mathbf{c}^{\text {cis }}$ upon performing the reaction at either $100^{\circ} \mathrm{C}$ 
to $120^{\circ} \mathrm{C}$, the former yielding up to $47 \%$ increase in isomerization products. Moreover, it was shown to also impact the stability of the catalyst as seen with the lack of reactivity of Ru-35.
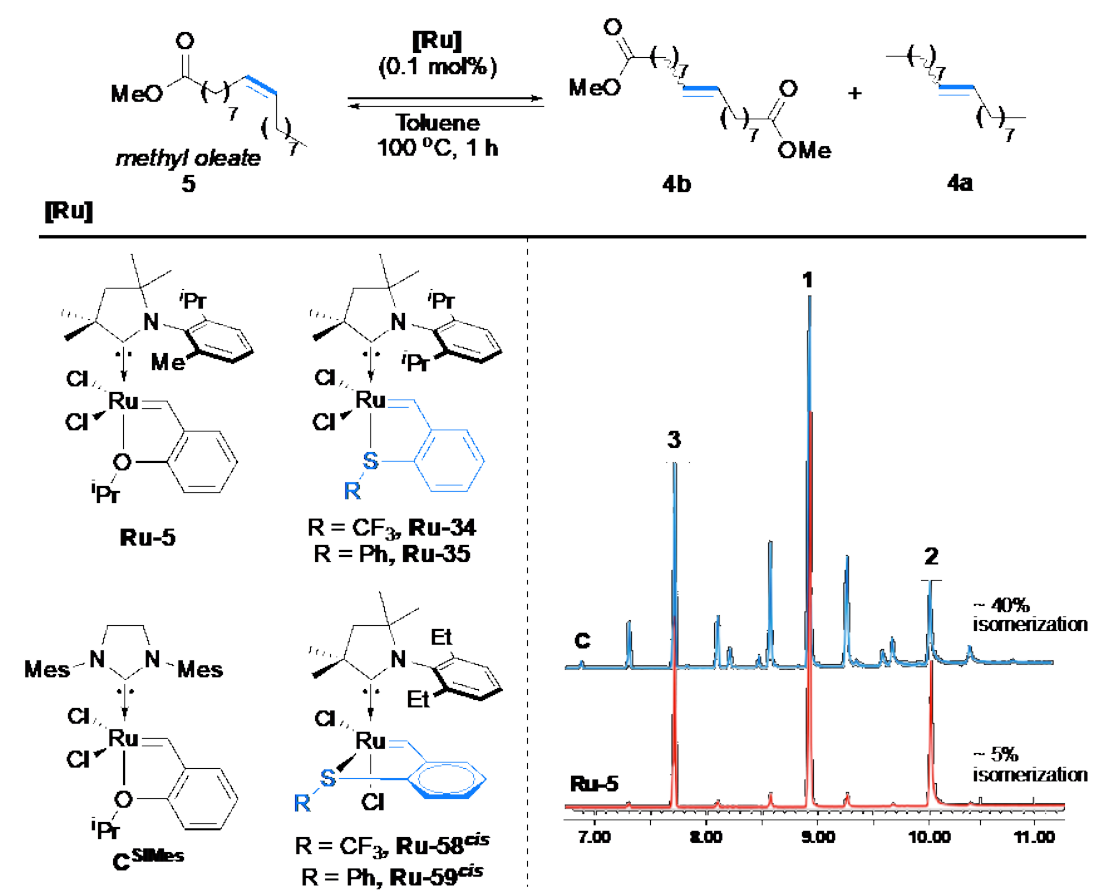

Scheme 20 CAACs catalysts appear to be more selective that their NHC variant in olefin selfmetathesis

As expected, and as highlighted by Wagener and coworkers, ${ }^{80}$ the propensity of CAAC ruthenium catalysts to completely inhibit isomerization processes remains contingent on the nature of the olefin. This was demonstrated in the homodimerization of an anthracene substituted olefin 6 in the presence of Ru-3 at $100{ }^{\circ} \mathrm{C}$, which afforded up to $29 \%$ of the isomerization product 7 (Scheme 21).

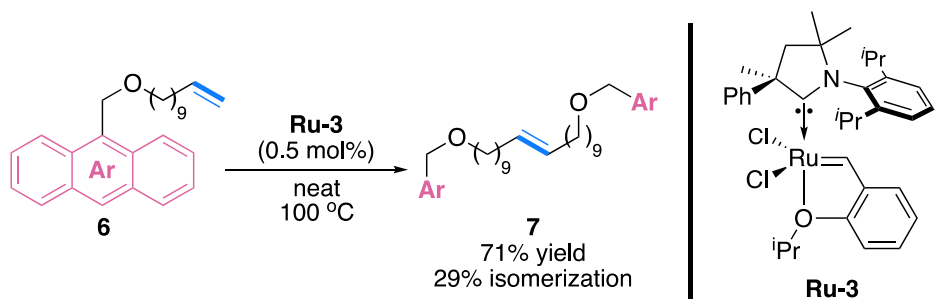

Scheme 21 CAAC catalyst selectivity is likely contingent to the nature of the olefin

The homo-dimerization of olefins by a CAAC-6 ruthenium complex has also been reported

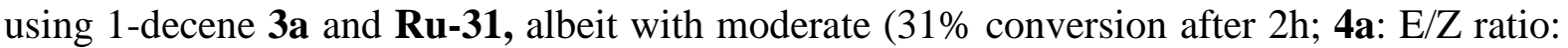


4.7/1) (Scheme 22). ${ }^{40}$ The reduced catalytic activity and selectivity were proposed to originate from the increased steric bulk of the CAAC-6 ligand. ${ }^{28}$ It is worth noting that allylbenzene resulted in significant olefin migration under the same conditions.

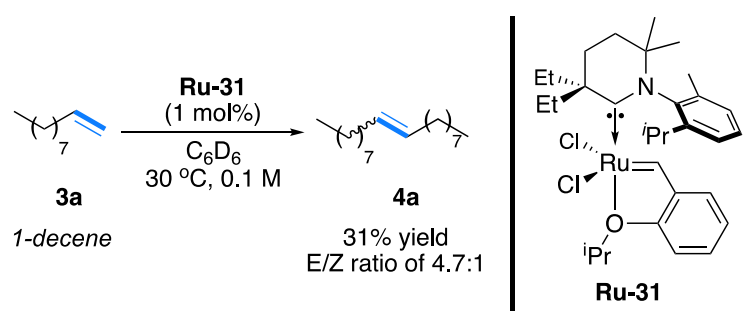

Scheme 22 Activity of CAAC-6 Hoveyda-Grubbs type complexes in self-metathesis

To improve the Z-selectivity of the self-metathesis reaction, Grubbs and coworkers compared the activity of several cyclometalated carbene ruthenium complexes. As illustrated by selected examples in Scheme 23, NHC complexes (such as $\mathbf{G}$ ) were found to outcompete the CAAC ruthenium variant Ru-61 in the self-metathesis of allylbenzene $\mathbf{8}$. While the lack of reactivity was attributed to the instability of Ru-61, the diminished Z-selectivity was proposed to originate from conformational differences with NHCs variants.

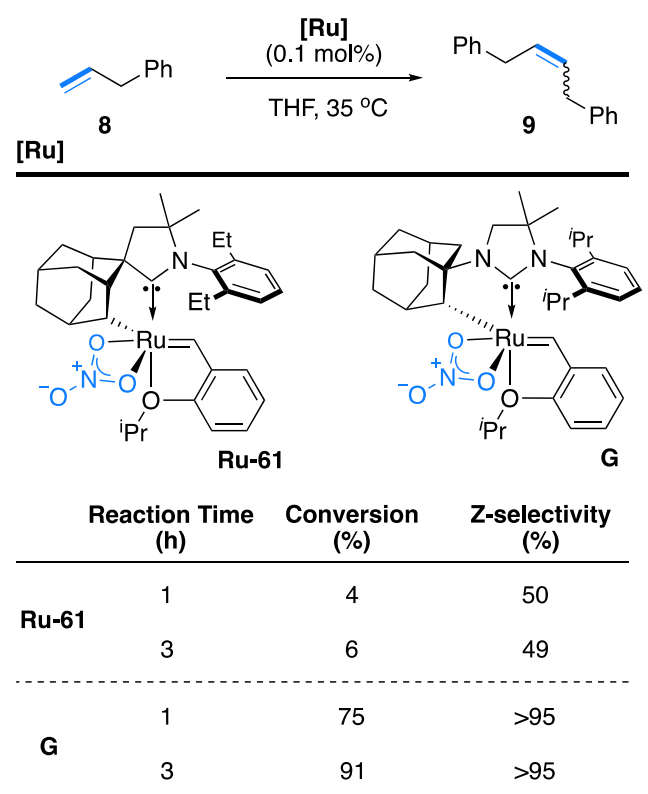

Scheme 23. Activity of cyclometalated CAAC complexes in self-metathesis 


\subsubsection{Cross metathesis}

The development of E/Z-diastereoselective olefin metathesis catalysts is an area of substantial interest in organic chemistry. ${ }^{81,82}$ Typically, the E/Z diastereoselectivity of an olefin metathesis reaction is controlled by the thermodynamic stability of the olefin isomers rather than the selectivity of the catalyst. Looking to further investigate the influence of CAACs on this predicament, Grubbs and coworkers reported that CAAC-substituted catalysts exhibit lower $\mathrm{E} / \mathrm{Z}$ ratio of $\mathbf{1 1}$ (2:1 at 70\% conversion) in the cross metathesis of cis-1,4-diacetoxy-2-butene 10 with allylbenzene 8 (Scheme 24). ${ }^{33}$ As highlighted by the selectivity of $\mathbf{C}^{\text {SIMes }}$, NHCcatalysts are typically more selective towards the most thermodynamically stable E-olefins, whereas CAACs afford higher ratio of Z-olefins. Interestingly, the shorter reaction times observed with the less hindered Ru-9 (at $\sim 60 \%$ conversion after $1 \mathrm{~h}$ at $22{ }^{\circ} \mathrm{C}$; vs. $32 \mathrm{~h}$ for Ru$\mathbf{1}$ and $48 \mathrm{~h}$ for $\mathbf{R u}-2$ at $60{ }^{\circ} \mathrm{C}$ ) indicate that the higher $\mathrm{Z}$ selectivity observed with CAACs is a result of the inherent catalyst selectivity, rather than an artefact of a less active catalyst unable to isomerize olefins.

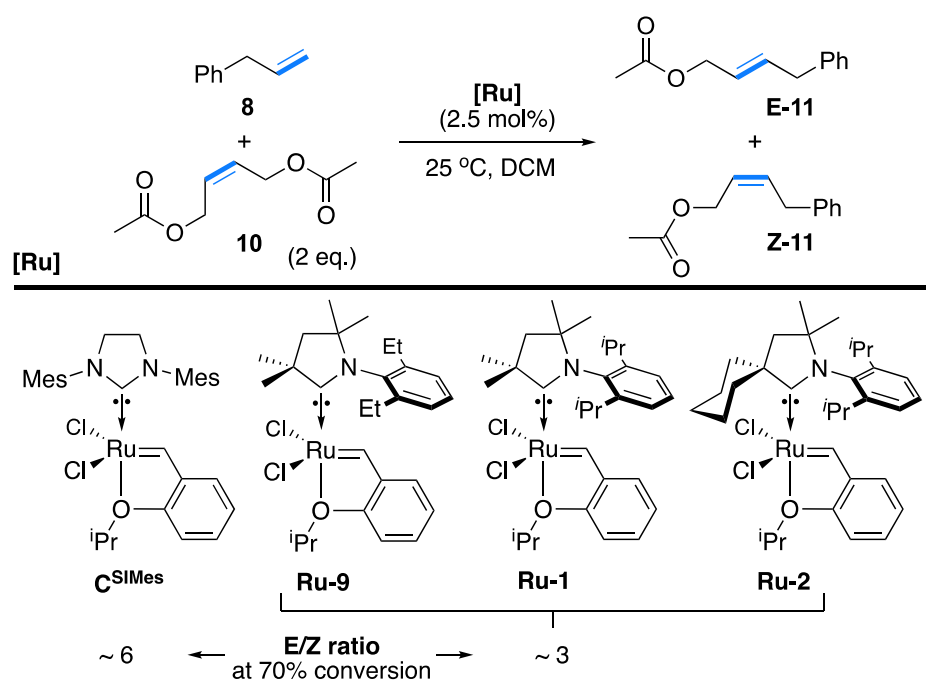

Scheme 24. Cross metathesis with CAAC ruthenium catalysts appears to be more E-selective than with NHC variants

The activity of the CAAC ruthenium catalysts in cross metathesis of methyl oleate $\mathbf{5}$ has also been achieved with 1,4-diacetoxy-2-butene 10. It was found to be quite straightforward, 
achieving up to $99 \%$ yield of the corresponding olefins 12 and $\mathbf{1 3}$ under solvent free conditions with catalyst Ru-44 at $0.05 \mathrm{~mol} \%$ loading and $65^{\circ} \mathrm{C}$ (Scheme 25). Note that the reaction can also be achieved under protic conditions in methanol using the more polar $\mathbf{R u}-\mathbf{4 5}$. $^{36}$

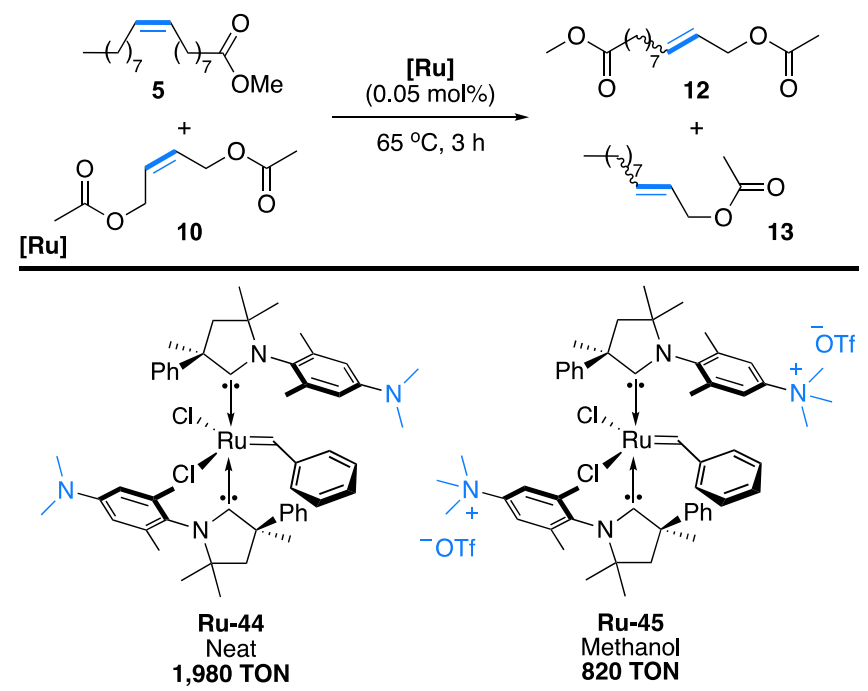

Scheme 25 Cross metathesis of methyl oleate with Bis-CAAC-Ru complexes Ru-44 and Ru-45

In recent years, the production of value-added molecules from microalgae including pigments, vitamins, proteins and lipids has shown significant potential. Specifically, ${ }^{83}$ for polyunsaturated fatty acids, a class of lipids which are of particular interest given their range of applications in cosmeceuticals, nutraceuticals, fine chemicals, pharmaceuticals, and biodiesel. ${ }^{84}$ Despite the difficulty of transforming such complex molecules, Tuba, Tóth and coworkers have shown that Hoveyda-Grubbs Ru-23 and indenylidene Bis(CAAC)Ruthenium Ru-45 were active in the cross metathesis of 1,4-diacetoxy-2-butene $\mathbf{1 0}$ with 1,2-dioleoyl-snglycero-3-phosphocholine 14 (DOPC) (Scheme 26), ${ }^{36}$ a glycerophospholipid obtained from low value algae. 


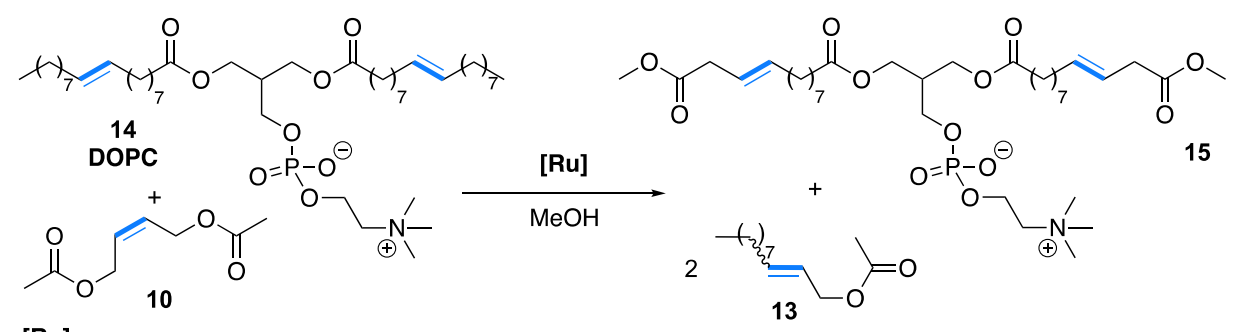

[Ru]
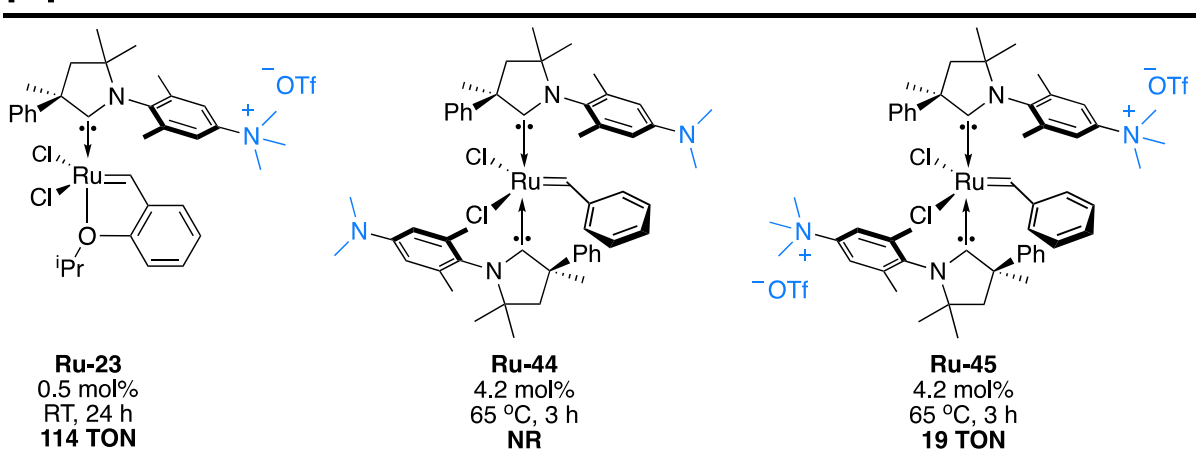

\section{Scheme 26 Cross metathesis of polyunsaturated fatty acids}

The use of nitriles in olefin metathesis is quite attractive as it offers a convenient access to value-added chemicals such as the Rilsan ${ }^{\circledR}$ Nylon 11 precursor “10-cyanodec-9-enoate” 16, which is obtained by reaction of methyl 9-decenoate $\mathbf{1}$ with acrylonitrile. Yet, as noted by Fogg and others, ${ }^{85,86}$ traditional NHC ruthenium metathesis catalysts $(\mathbf{B}, \mathbf{C})$ are susceptible to decomposition in the presence of nitriles (e.g. acrylonitrile). Looking to improve upon the best NHC catalytic systems in the field, ${ }^{87,88}$ Skowerski and coworkers envisaged capitalizing on the enhanced activity and stability of Grela-type catalysts bearing CAAC ligands. ${ }^{57}$ As highlighted in Scheme 27, despite the proficiency of the NHC Grela-type $\mathbf{D}^{\text {SIPr }}$, CAAC derived Ru-50 was found to be much more reactive leading up to 24,800 TON. Performing the same reaction with 20 ppm of Ru-50 and at $85{ }^{\circ} \mathrm{C}$ led to 30,000 TON and 82\% selectivity. In line with previous comments, ${ }^{31}$ the authors proposed that this improved performance originates from higher stability of the active species rather than from better kinetics. This postulate was later supported by a DFT study by Trzaskowski and coworkers, who demonstrated that in marked contrast with NHCs, CAAC-derived ruthenium catalysts were less susceptible to undergo acrylonitrileassisted degradation. ${ }^{89}$ The superior activity of CAAC catalysts in cross metathesis processes 
with acrylonitrile was successfully extended to methyl oleate 5 and 1-decene 3a affording the corresponding olefins 17 and 18 (Scheme 28). ${ }^{90}$
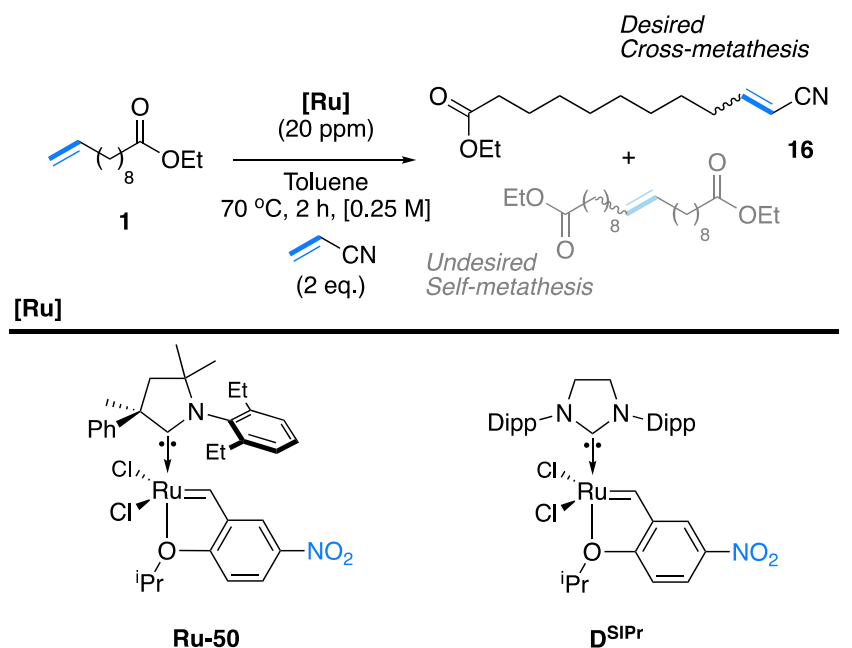

$73 \%$ conv., $84 \%$ select. 24,800 TON

$40 \%$ conv., $75 \%$ select. 12,000 TON

Scheme 27 CAAC ruthenium catalysts remain very efficient in Cross metathesis in the presence of nitriles

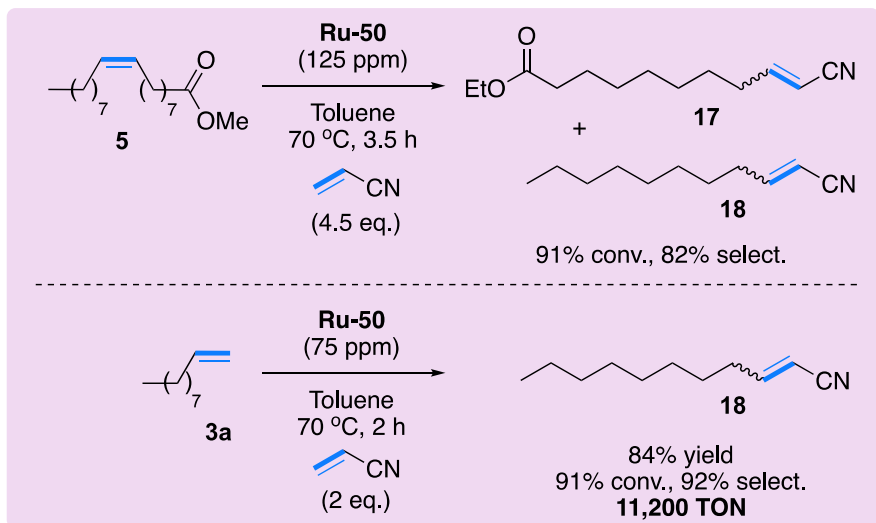

Scheme 28 Cross metathesis of methyl oleate or 1-decene with acrylonitrile using Grela CAAC-Ru catalyst Ru-50.

Acrylates (type II olefins ${ }^{78}$ ) have a significant number of applications, ${ }^{91}$ but have poor reactivity in metathesis transformations as shown with Grubbs $2^{\text {nd }}$ generation catalysts which require activation by a copper additive. ${ }^{92,93}$ Having found that CAAC catalysts allowed for improved catalytic activities in the cross metathesis of ethyl 10-undecenoate $\mathbf{1}$ with acrylonitrile, ${ }^{57}$ Skowerski and coworkers naturally extended their study to acrylates. ${ }^{94,90}$ Using ethyl 10-undecenoate $\mathbf{1}$ in the presence of methyl acrylate, these authors compared the activity 
of CAACs Ru-46,50 to NHCs $\mathbf{D}^{\text {SIMes }}$ and $\mathbf{D}^{\text {SIPr }}$ (Scheme 29). However, with turnovers as high as 34,110, NHC-based catalysts were found to be more selective than CAAC catalysts, which are more prone to undergo self-metathesis. The authors could confirm these results across a larger range of CAAC complexes Ru47-49,51,52,69.90
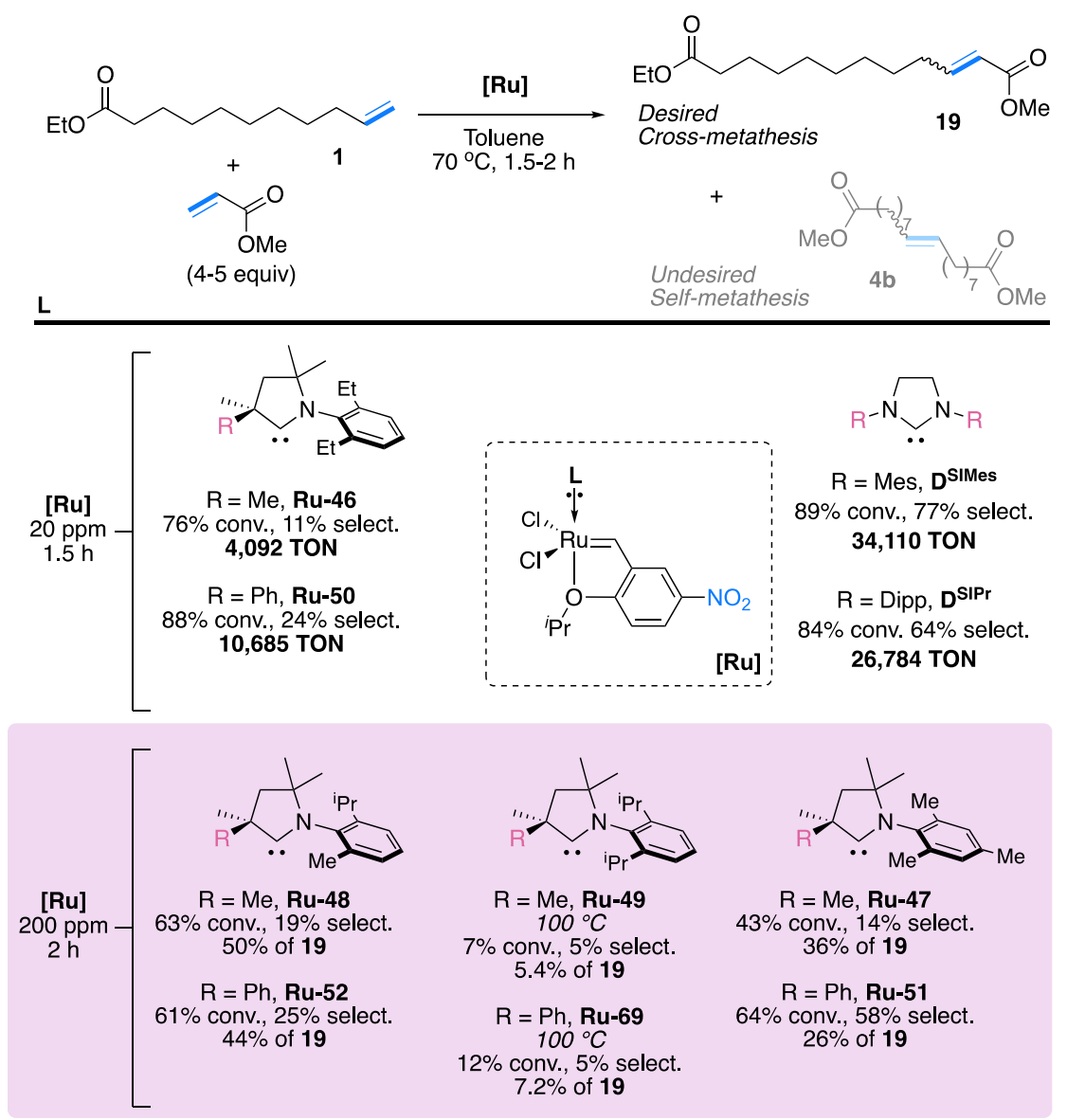

Scheme 29 Cross metathesis with methyl acrylate and CAAC-Ru Grela type complexes

As shown in Scheme 30, these challenging cross metathesis reactions between electrondeficient methyl acrylate and acrylonitrile with methyl 9-undecenoate $\mathbf{3 b}$ was readily extended to bis(CAAC)Ru-indenylidene pre-catalysts. ${ }^{52}$ Note that in this case the use of the more reactive $\mathbf{R u}-\mathbf{4 3}$ without the necessity of adding $\mathrm{CuCl}$ to activate the catalyst. 


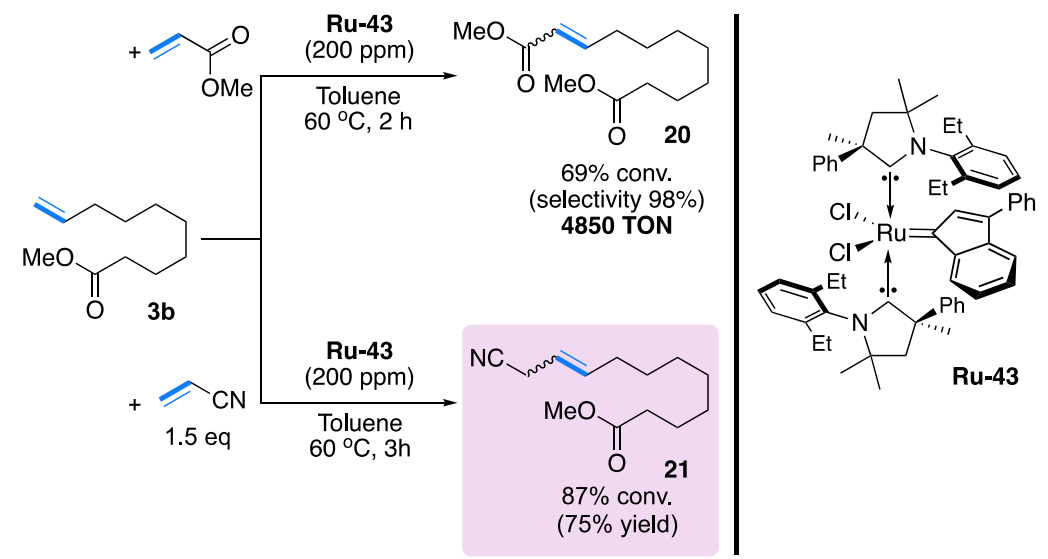

Scheme 30 Activity of Bis(CAAC)Ru-indenylidene Ru-43 in the Cross metathesis with methyl acrylate and acrylonitrile

Extending the field to asymmetric transformations, we recently examined the activity of optically pure CAACs in challenging asymmetric cross metathesis (ACM). ${ }^{95}$ As shown in Scheme 31, we found that Grela type enantiopure (CAAC)Ru-(S) Ru-71 afforded 24 with up to $50 \%$ ee in the cross metathesis of diene 22 with allyl acetate $23 .{ }^{75}$ Note that these preliminary results surpass state of the art chiral NHC ligands, which suggest that further investigations should be performed to delineate the impact of CAACs in ACM. ${ }^{96}$

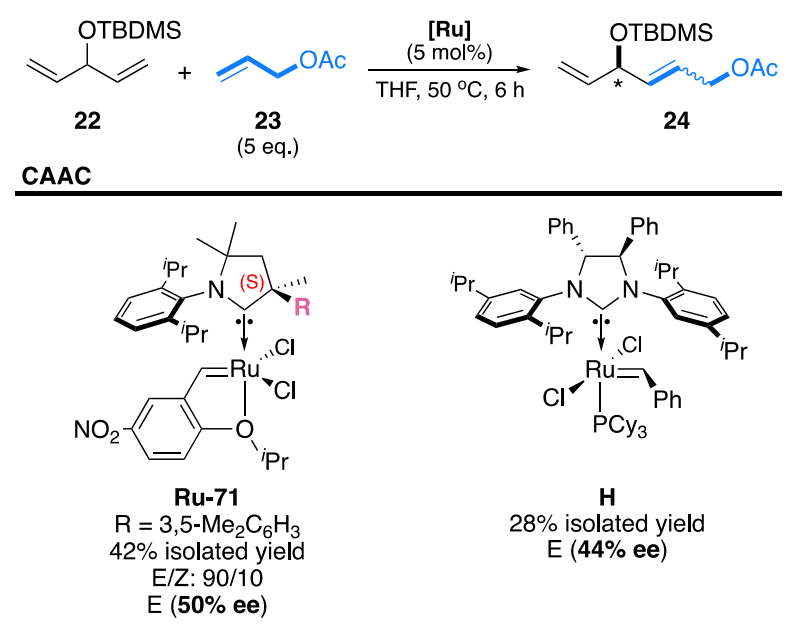

Scheme 31 First application of an optically pure CAAC in asymmetric cross metathesis

\subsection{Application to Ring-Closing Metathesis}

\subsubsection{Small molecules}

The catalytic performance of CAAC-based ruthenium catalysts in ring-closing metathesis (RCM) was first established by Grubbs and coworkers in the RCM of diallylmalonate $25 .{ }^{32}$ As 
shown in Scheme 32, pyridine-based CAAC-complexes Ru-32,33 showed moderate reactivities (50\% conv. over $24 \mathrm{~h}$ ), which was attributed to premature catalyst decomposition occurring even at room temperature. As expected, improved efficiencies were observed with the more stable Hoveyda-type derivatives Ru-1,2, reaching almost full conversions with trisubstituted olefin 27, even at 1 mol\% catalyst loading, albeit with longer reaction times. (Scheme 33). As observed between Ru-1,2 and Ru-9 the catalytic activity of CAAC catalysts is largely influenced by sterics. Improving upon these results, Skowerski and coworkers obtained higher activities with the least sterically hindered Ru-9 and Ru-5. ${ }^{90}$ However, CAAC catalysts could not efficiently perform the RCM of dimethyl diallylmalonate to yield the cyclic tetra-substituted olefin (not shown). Examining the influence of the substitution of the backbone, Zhang, Shi and coworkers obtained higher reactivity with Ru-19-21 featuring an isopropyl instead of their gem-dimethyl analogues (Scheme 33). ${ }^{35}$ While these results clearly highlight the importance of sterics in this process, they also indicate that steric decongestion at the $N$-aryl ortho-substituent is more critical than on the backbone of the CAAC ligand.

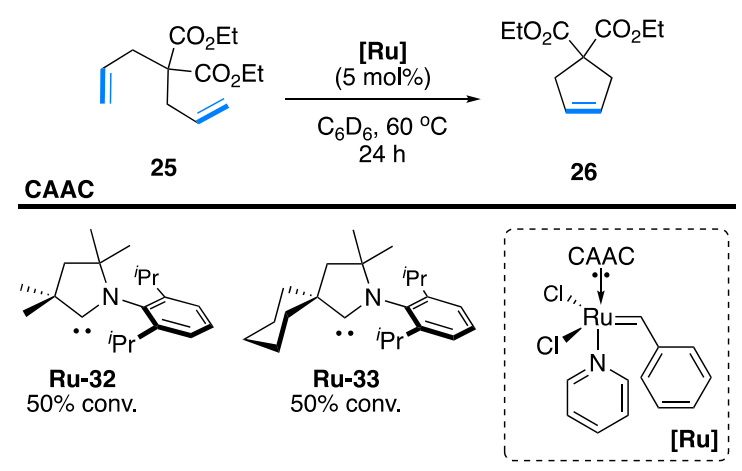

Scheme 32 Ring Closing-Metathesis using pyridine-based CAAC-complexes Ru-32 


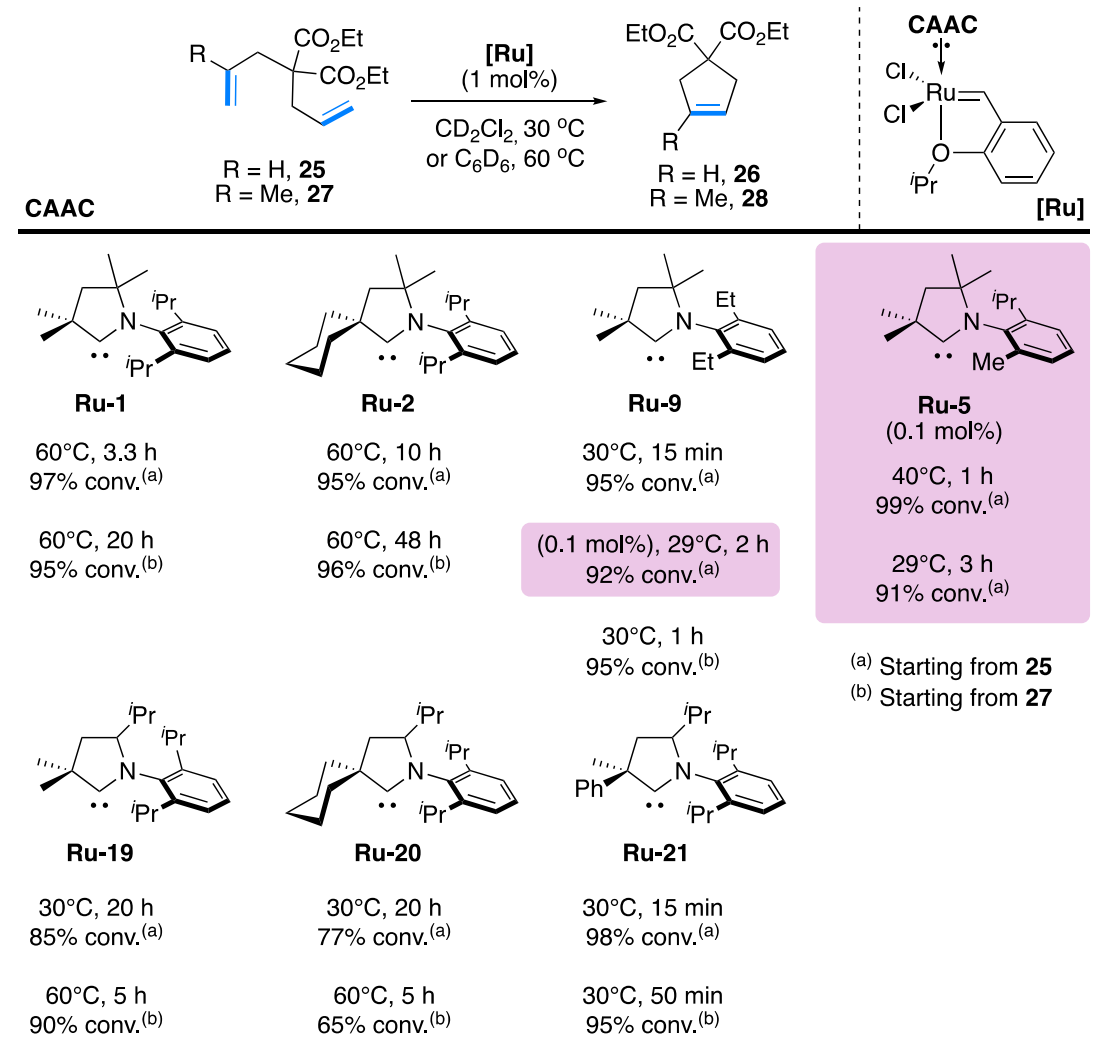

Scheme 33 Activity of Hoveyda-Grubbs CAAC catalysts in Ring Closing-Metathesis of diallyl malonate

Investigating the structure/activity relationship of Grela-type catalysts, Skowerski and coworkers further highlighted the importance of sterics as shown by the very efficient Ru-47 (scheme 34). ${ }^{59}$ Note that replacing a methyl by a phenyl on the quaternary carbon next to the carbene center also led to a faster RCM (Ru-50,52). Going further, these authors considered the nature of the styrenyl motif (Scheme 35). ${ }^{59,90}$ Notably, introduction of a modified styrenyl ether ligand, containing the Weinreb-amide functionality, drastically improved the initiation rate of Ru-54-56. Per comparison, $N$-chelating morpholine moiety (Ru-74) was less efficient, requiring a thermal activation to initiate the RCM. Note that the replacement of chloride by iodide in Ru-55 appeared to be detrimental, while addition of an electron donating methoxy group in Ru-75 led to a severe drop of reactivity in marked contrast with Ru-50 bearing an electron withdrawing group. Such behavior has also been observed with NHC-based 
catalysts. ${ }^{97}$ A remarkable initiation rate was also observed with iodine-chelated catalyst $\mathbf{R u}-\mathbf{7 6}$ reaching full conversion within $10 \mathrm{~min}$.

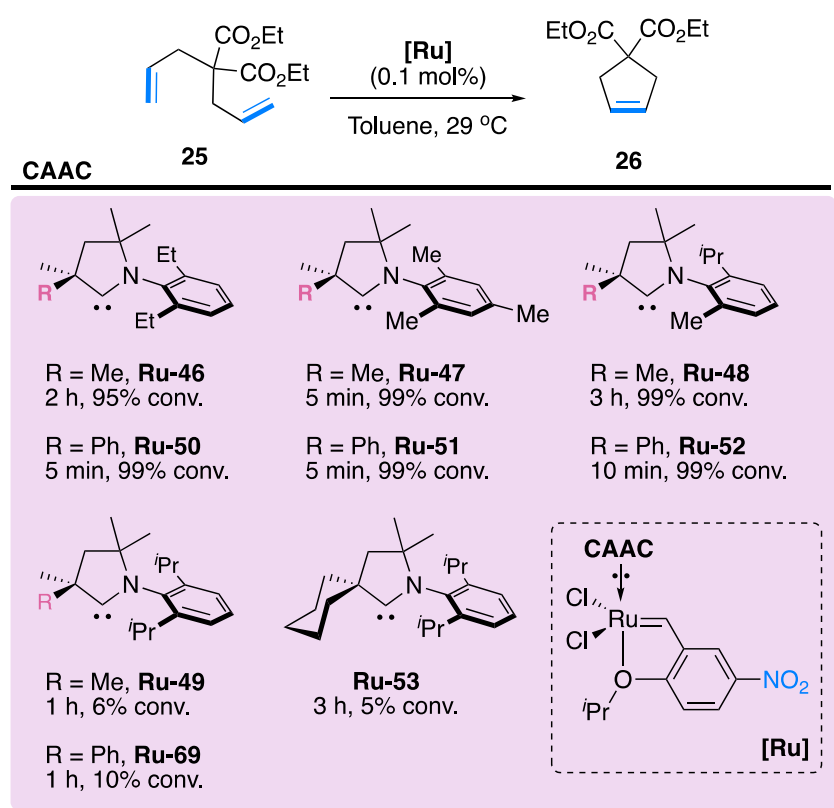

Scheme 34 Activity of nitro-Grela CAAC catalysts in Ring Closing-Metathesis of diallyl malonate

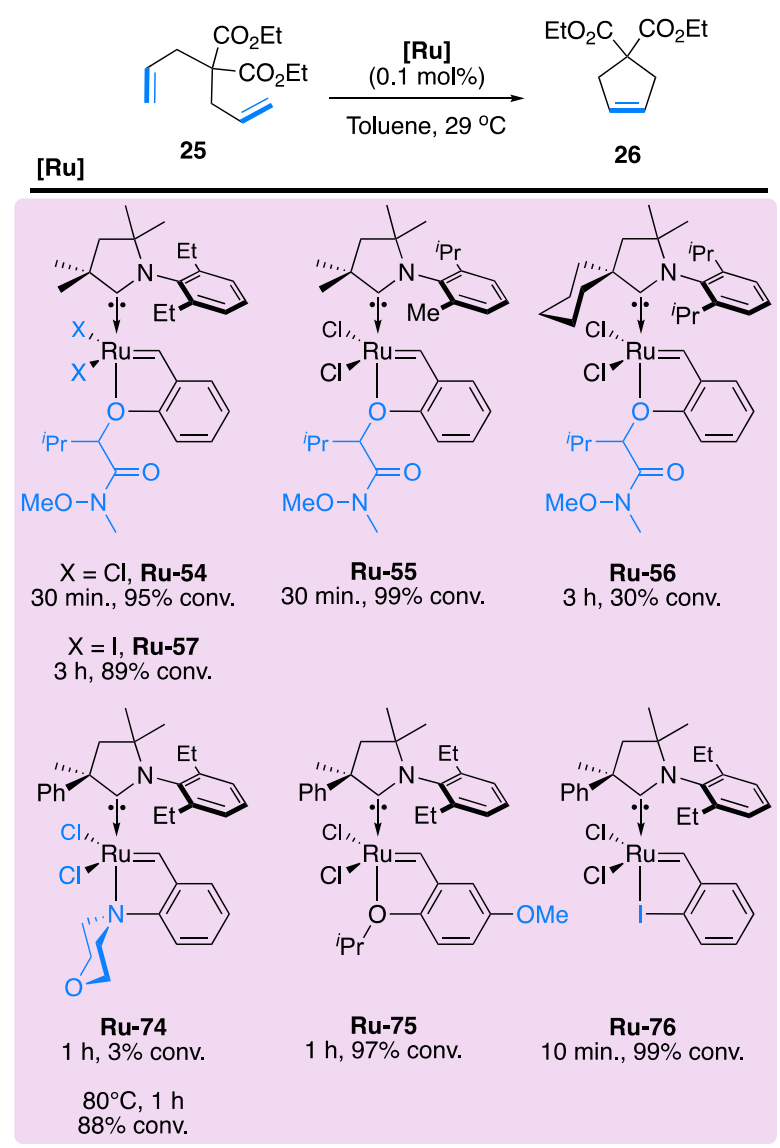

Scheme 35 Impact of the styrenyl ether ligand on the Ring Closing-Metathesis of diallyl malonate 
As already mentioned, nitriles are known to poison many Ru-based olefin metathesis catalysts. ${ }^{85,86}$ However, Skowerski and coworkers examined the RCM of diallyl malonate 25 in the presence of nitrile additives. They reported that CAAC-Ru-50 was only slightly impacted, maintaining high reactivity at low catalyst loading (0.02 mol\%), in marked contrast with Ru-46 NHC-based catalyst C $^{\text {SIPr }}$ (Scheme 36). ${ }^{57}$ Additional experiments and DFT calculations highlighted that some CAAC-Ru catalysts impede the formation of transient ruthenium cyanomethylidenes that are more prone to undergo acrylonitrile-assisted decomposition. ${ }^{89}$ In another report, it was also shown that CAAC-catalysts are tolerant to methyl acrylates (as in 30) another well-known poison for metathesis catalysts. ${ }^{94}$

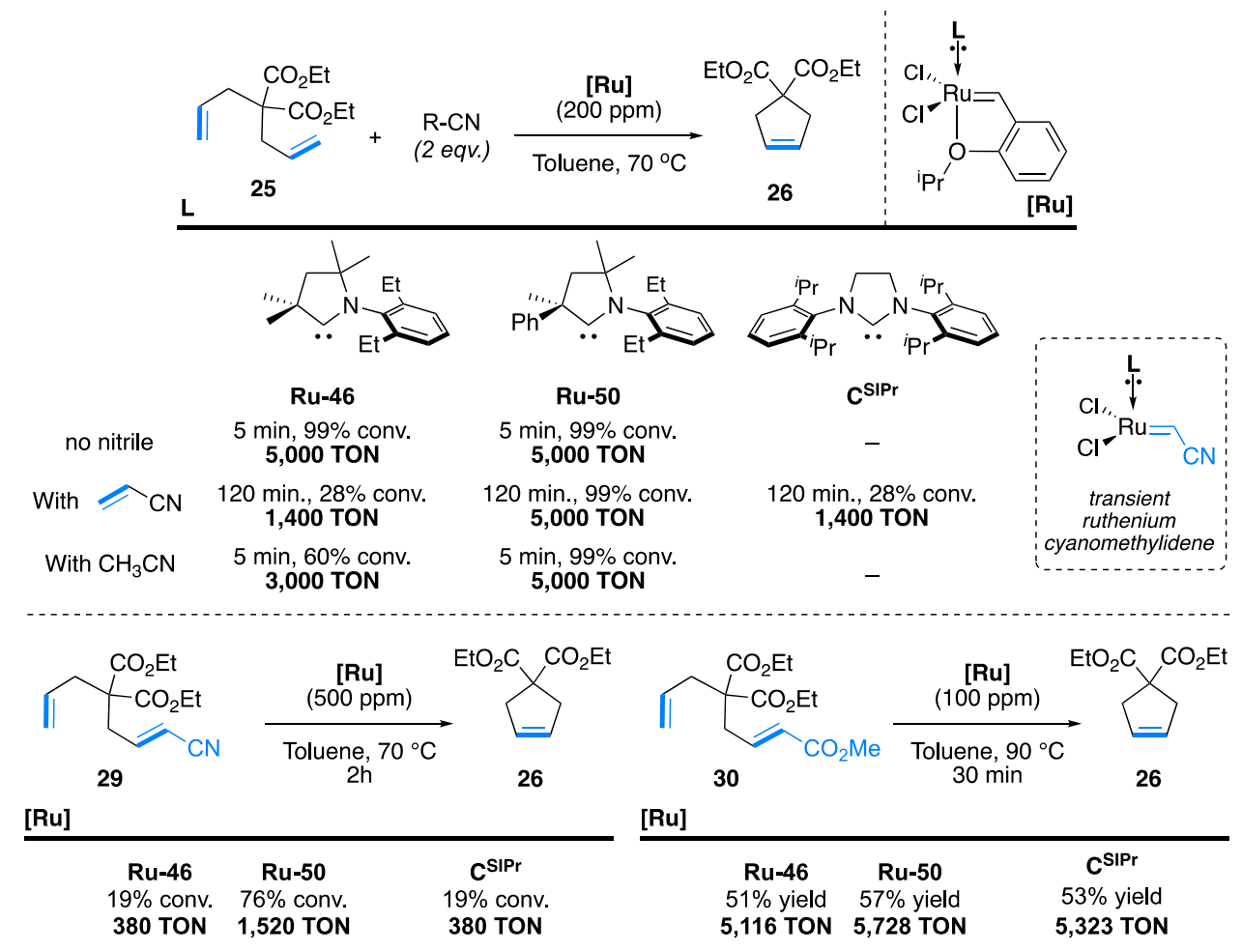

Scheme 36 CAAC ruthenium catalysts remain very efficient in Ring Closing Metathesis in the presence of nitriles or acrylates

Recently, Grubbs and coworkers extended these studies to six-membered CAAC-Hoveyda catalysts Ru-28-31 (Scheme 37). ${ }^{40}$ As with their 5-membered counterparts, some important structure/activity insights were identified through an initiation study involving butyl vinyl ether (not shown), combined with reactive profiles of the benchmark RCM of diallylmalonate 25. 
As expected from more donating ligands, faster catalyst initiation was observed with CAAC-6 complexes (vs. CAAC-5), likely due to a weaker Ru-O bond. For now, CAAC-6 catalysts do not meet the catalytic activities of CAAC-5 motifs. However, given the small range of CAAC6 studied and the critical influence of subtle steric modifications of the ligand structure in these systems, it seems premature to critically assess the impact of CAAC-6 in olefin metathesis.
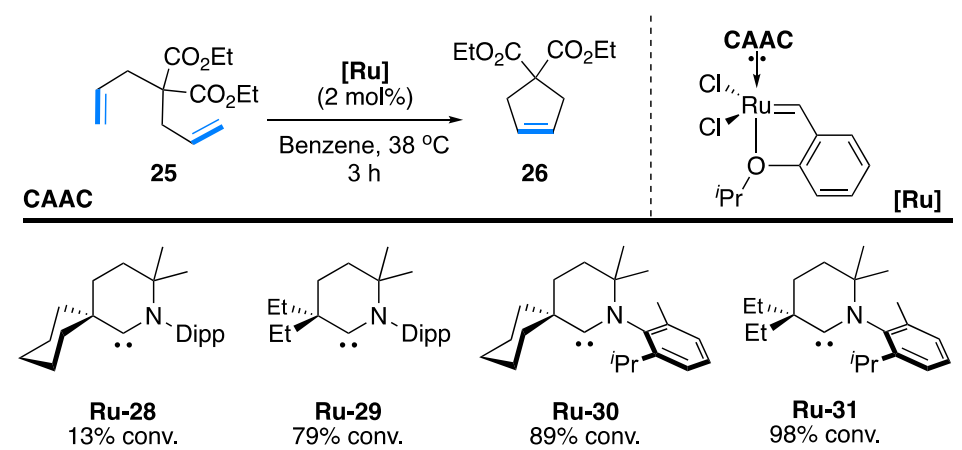

\section{Scheme 37 Activity of CAAC-6 Hoveyda-Grubbs catalysts in Ring Closing Metathesis}

Lemcoff and coworkers have investigated the reactivity of latent sulfur-chelated $\mathrm{Ru}$ benzylidenes containing CAACs in the RCM of tosylsulfonamide 31 (scheme 38). ${ }^{47}$ Under drastic thermal conditions $\left(150^{\circ} \mathrm{C}\right)$, cis and trans $\mathbf{R u}-\mathbf{5 8 , 5 9}$ afforded excellent conversions to 7-membered 32, with extremely low isomerization of the double bond ( $97 \%$ selectivity). This is in marked contrast with the CAAC Hoveyda-type Ru-5 and NHC SIMes cis-variant I, which give significant amounts of isomerized by-products. ${ }^{79}$

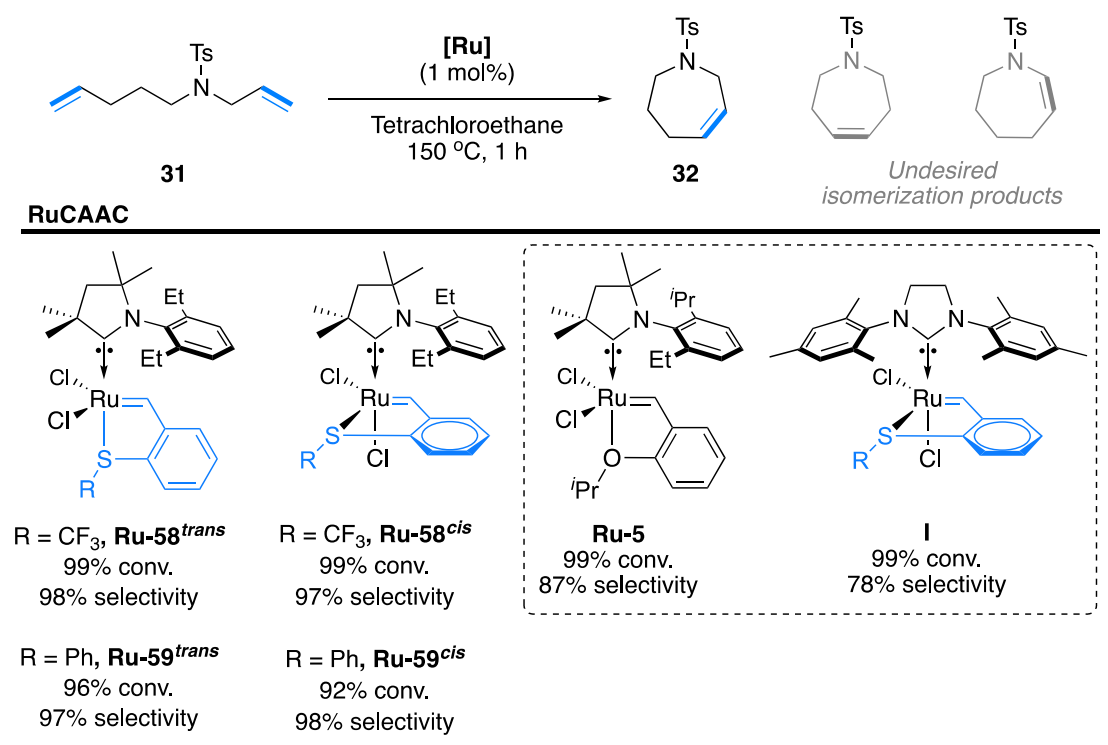


Scheme 38 Activity of sulfur-chelated (CAAC)Ru-benzylidenes in the RCM of tosylsulfonamide

Looking for even more efficient catalysts, Skowerski and coworkers disclosed the remarkable activity of bis(CAAC)Ru indenylidene complexes Ru-36-43 (Scheme 39). ${ }^{52,59}$ Compared to traditional Hoveyda-Grubbs CAAC ruthenium complexes, bis(CAAC)Ru indenylidene complexes were shown to be more difficult to activate (Ru-36: 1\% in 1 h versus Ru-9: 95\% in 15 min). However, this could be overcome by promoting ligand to ligand steric repulsion through the CAAC motifs (Ru-36 vs. Ru-39 or Ru43), or by simple addition of a $\mathrm{CuCl}$ additive.

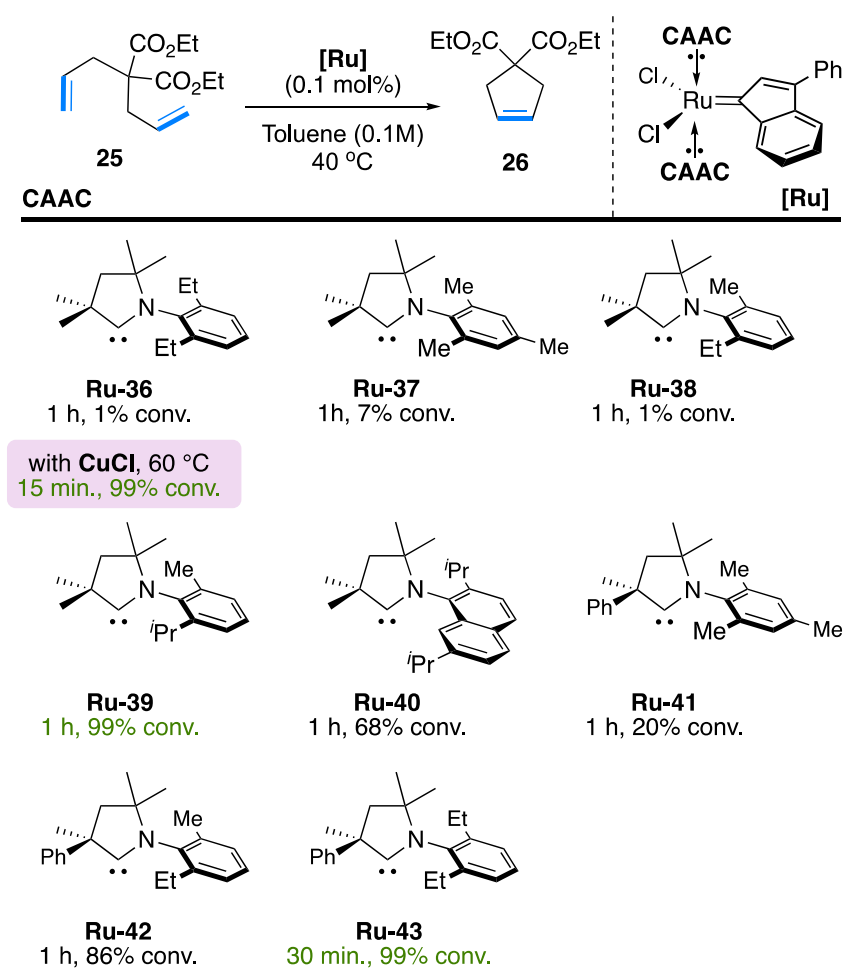

Scheme 39 Activity of Bis(CAAC)Ru-indenylidene complexes in Ring Closing Metathesis

The most performant catalyst $\mathbf{R u - 4 3}$ was found to outperform the traditional Grubbs II catalyst (50\% yield and 8,300 TON, not shown) in the RCM leading to proline derivative 33 (TON 15,300) (Scheme 40). Seven-membered ring azepine derivative 34 and challenging (sterically hindered) tetra-substituted olefin 35 were also efficiently transformed, as well as diallyltosylamine $36 .{ }^{90}$ 

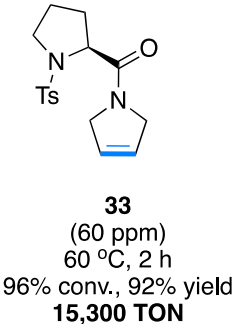
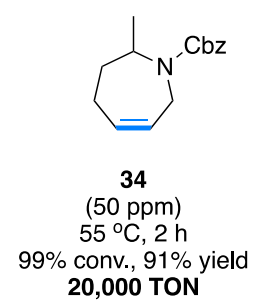

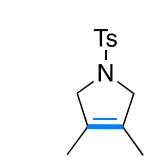

35
$(0.1 \mathrm{~mol} \%)$
$70^{\circ} \mathrm{C}, 2 \mathrm{~h}$ conv., $79 \%$ yield

790 TON
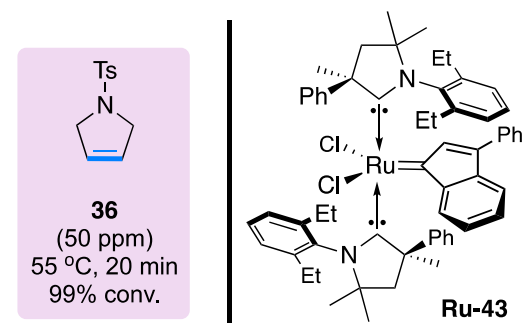

Scheme 40 Bis(CAAC)Ru-indenylidene Ru-43, a powerful catalyst for RCM of azo-dienes

Tuba, Tóth and coworkers examined the catalytic performances of Ru-complexes containing polar tags in protic media such as methanol (Scheme 41$).{ }^{36}$ It is worth mentioning that both complexes were highly robust toward air and moisture.

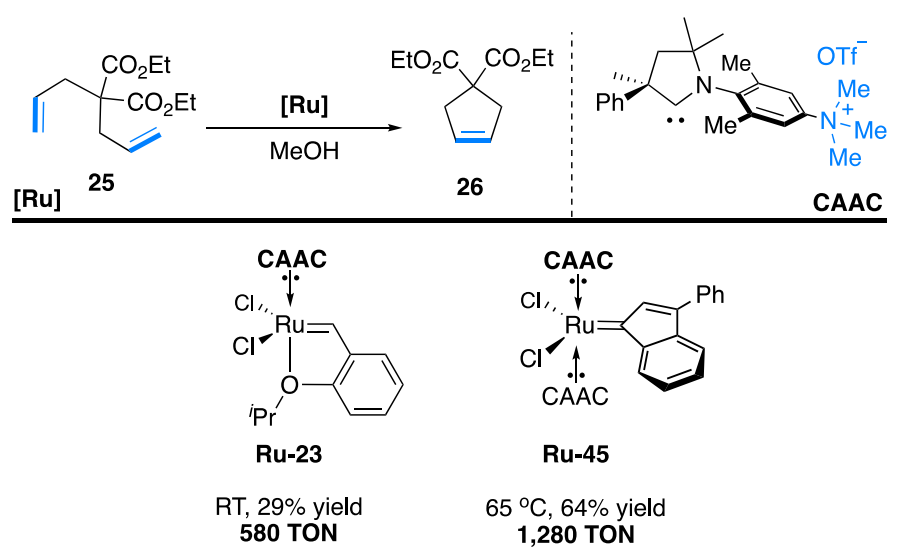

Scheme 41 Ring-Closing-Metathesis catalyzed by ammonium-tagged CAAC Ru-complexes

In the case of the indenylidene chloro-bridge dimer complex Ru-62, the high lability of the bridging anionic ligand considerably increased the initiation rate as well as the productivity in the RCM of diallyl malonate 25 (Scheme 41). ${ }^{66}$ At extremely low catalyst loading $(0.005$ mol\%), it could outperform bis(CAAC)Ru indenylidene complexes Ru-43 and the state of the art NHC-based catalysts (e.g. nitro-Grela, Umicore M2; not shown). Note however that the activity of dimer Ru-62 was comparable (or slightly higher at 9 ppm) than nitro CAAC-catalyst Ru-50. Interestingly, both catalysts remained active in presence of oxygen, even at $1 \mathrm{ppm}$, attesting of their remarkable robustness. ${ }^{98}$ 


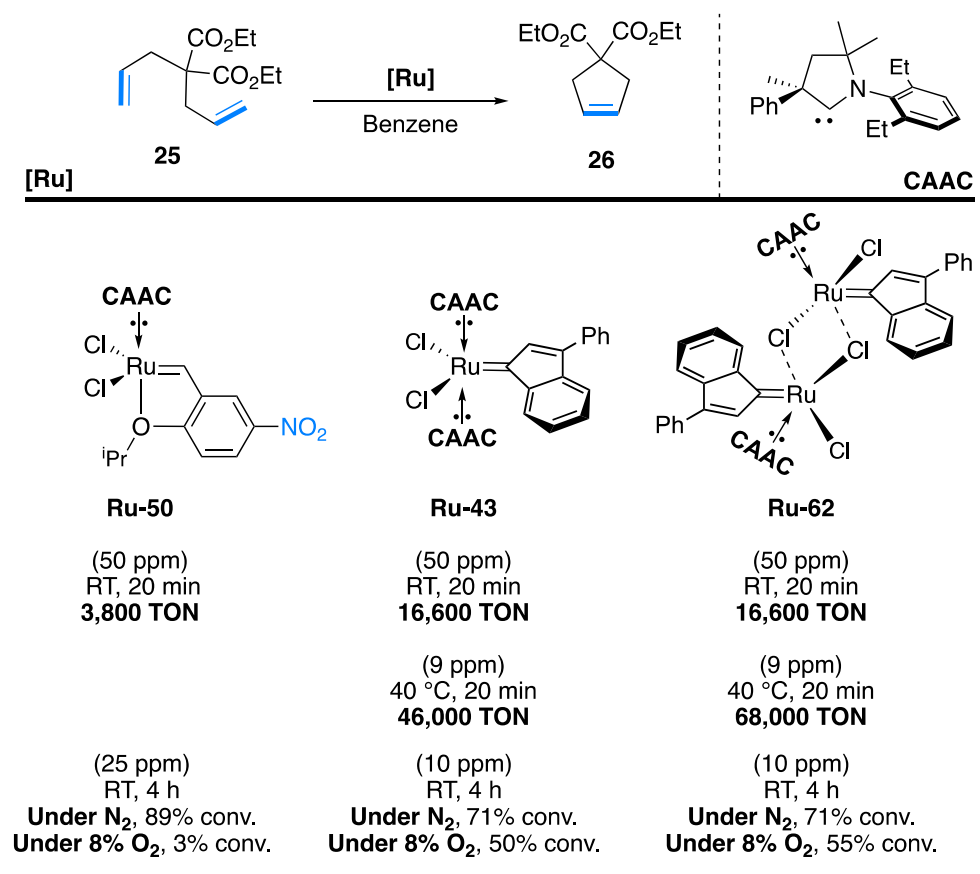

Scheme 42 Fogg's indenylidene chloro-bridge dimer complex Ru-62, a very active RCM catalyst

\subsubsection{Macrocycles}

Macrocycle cores are ubiquitous in numerous natural molecules, notably in pharmaceutical drugs and cosmetics. In this context, olefin metathesis represents a clean and highly competitive synthetic tool to form macrocycle scaffolds (e.g. ketone, lactone, lactam) even those containing various organic functions. Nevertheless, the high dilutions and catalyst loadings required in these processes remains a major drawback. This limits the usefulness of macro-RCM for any practical industrial developments, especially in the area of macrocyclic fragrance molecules. To confront these challenges, Skowerski and coworkers demonstrated that BisCAAC Ru-43 could efficiently convert diene 37 into 16-membered macrocycle 38, a precursor of highly desirable exaltolide, a musk known for its odorant property (Scheme 43). ${ }^{52}$ However, a much more impressive 62,000 TON (TOF 3,000 $\mathrm{min}^{-1}$ ) was achieved with the nitro CAAC-catalyst Ru-50, enabling fast metathetic macrocyclizations at extremely low catalyst loadings (as low as $10 \mathrm{ppm}$ ). ${ }^{57}$ It is worth mentioning that these TONs are the highest reported so far in macro-RCM, outperforming classical NHC-containing catalysts such as Grubbs $\mathbf{B}$, Hoveyda-Grubbs $\mathbf{C}$ or nitro-Grela $\mathbf{D}$, as well as other CAAC-complexes $(\mathbf{R u}-\mathbf{1 1}, \mathbf{4 6})$. At higher 
concentrations, excellent conversions were observed, however at the expense of substantial oligomer formation (up to 31\%).

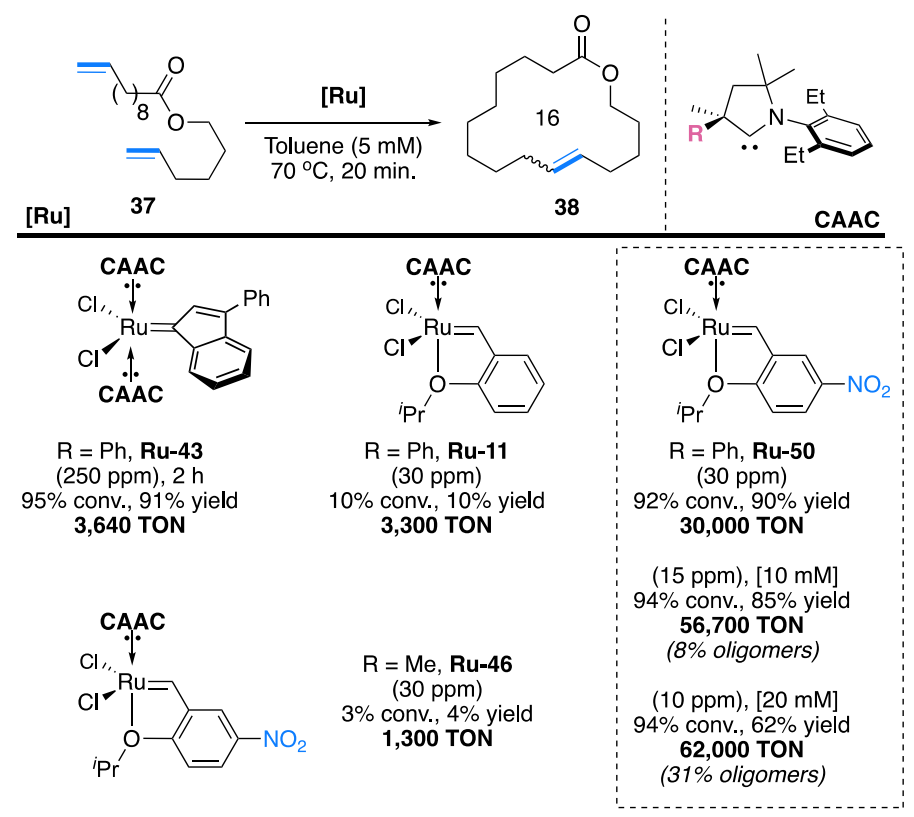

\section{Scheme 43 Activity of nitro-Grela CAAC complexes in Macro-Ring-Closing Metathesis}

Using high substrate concentration (i.e. $200 \mathrm{mM} ; 0.25 \mathrm{~mol} / \mathrm{kg}$ ), reduced pressure and paraffin oil as a solvent, Grela and coworkers investigated the macro-RCM of oleyl derived diene 39 (Scheme 44). Surprisingly compared to NHC J, CAAC-catalysts appeared to be quite inefficient under these specific conditions, both in productivity and selectivity. ${ }^{99,100}$

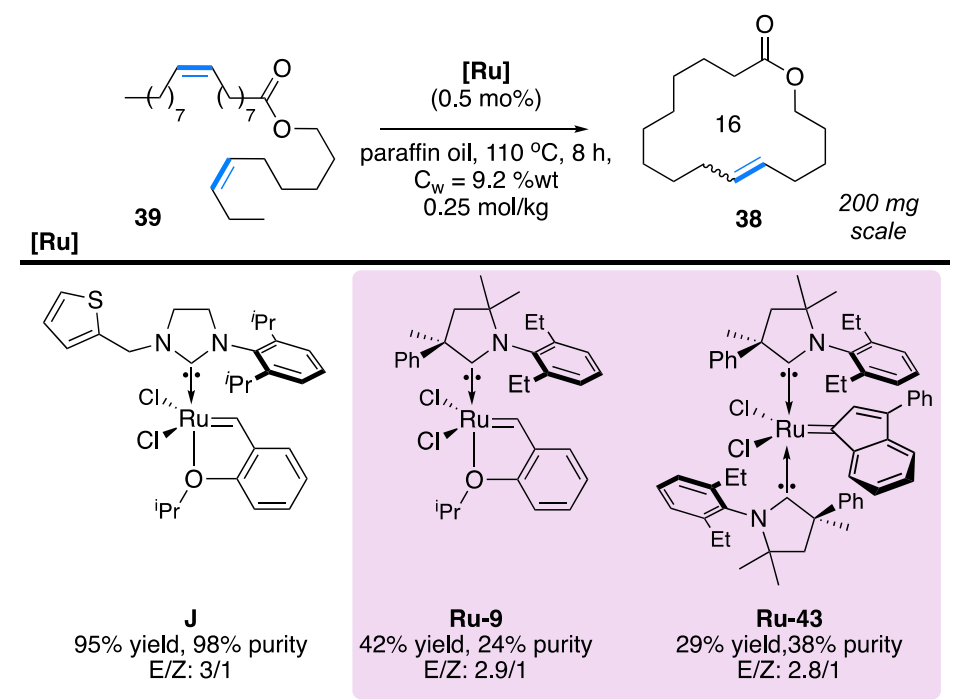

Scheme 44 The activity of CAAC complexes in Macro-Ring-Closing Metathesis 
Recently, Jamison, Bio and coworkers described the macro-RCM of diene $\mathbf{4 0}$ using a continuous flow olefin metathesis process (Scheme 45). ${ }^{101}$ Thanks to a selective membrane allowing a high flux ethylene gas permeation, nitro-CAAC Ru-50 efficiently catalyzed the production of 14-membered macrocyclic lactone $\mathbf{4 1}$, a relevant molecule of the fragrance industry. Despite its excellent performance, significant amounts of oligomers were also formed due to high substrate concentration (i.e. $10 \mathrm{mM}$ ). Note that similar catalytic performances were also obtained using the a bis-iodo-SIMes nitro-Grela catalyst (not shown).

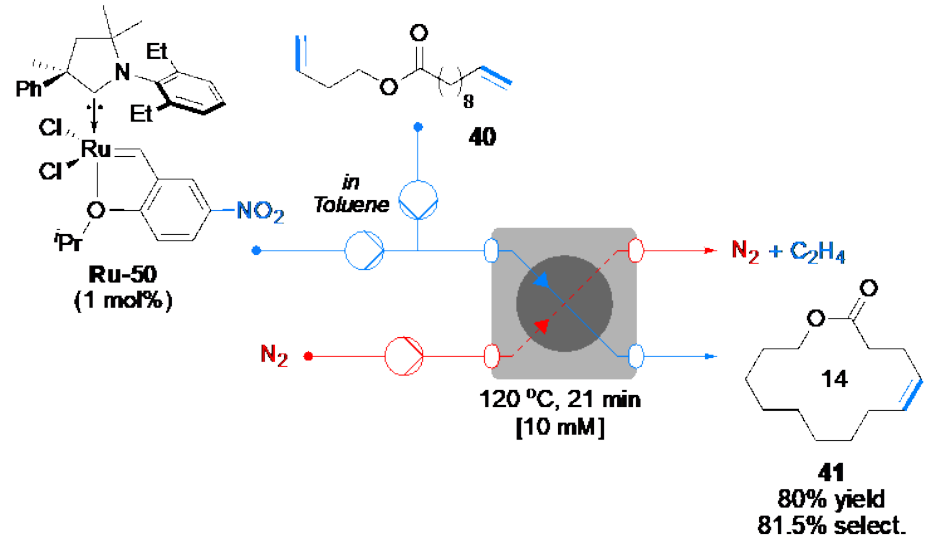

\section{Scheme 45 Macro-RCM of diene 40 in continuous flow using Ru-50}

Fogg's chloro-bridge dimer Ru-62 compared well with nitro CAAC-Ru-50 in the selective formation of exaltolide precursor 37 (i.e. without traces of oligomer) (Scheme 46). ${ }^{66}$ As an added feature, Ru-62 was shown to be more oxygen tolerant than Hoveyda-Grubbs Ru-50. In marked contrast, bis(CAAC)Ru indenylidene $\mathbf{R u - 4 3}$ displayed an acute sensitivity to oxygen, ${ }^{98}$ possibly resulting from $\mathrm{O}_{2}$ binding to its sixth vacant coordination site. Factors favoring this degradation pathway have been proposed to result from several factors such as the inherent $\pi$ acidity of the CAAC ligands, the low ligand lability, and the reduced steric crowding of the indenylidene unit. 


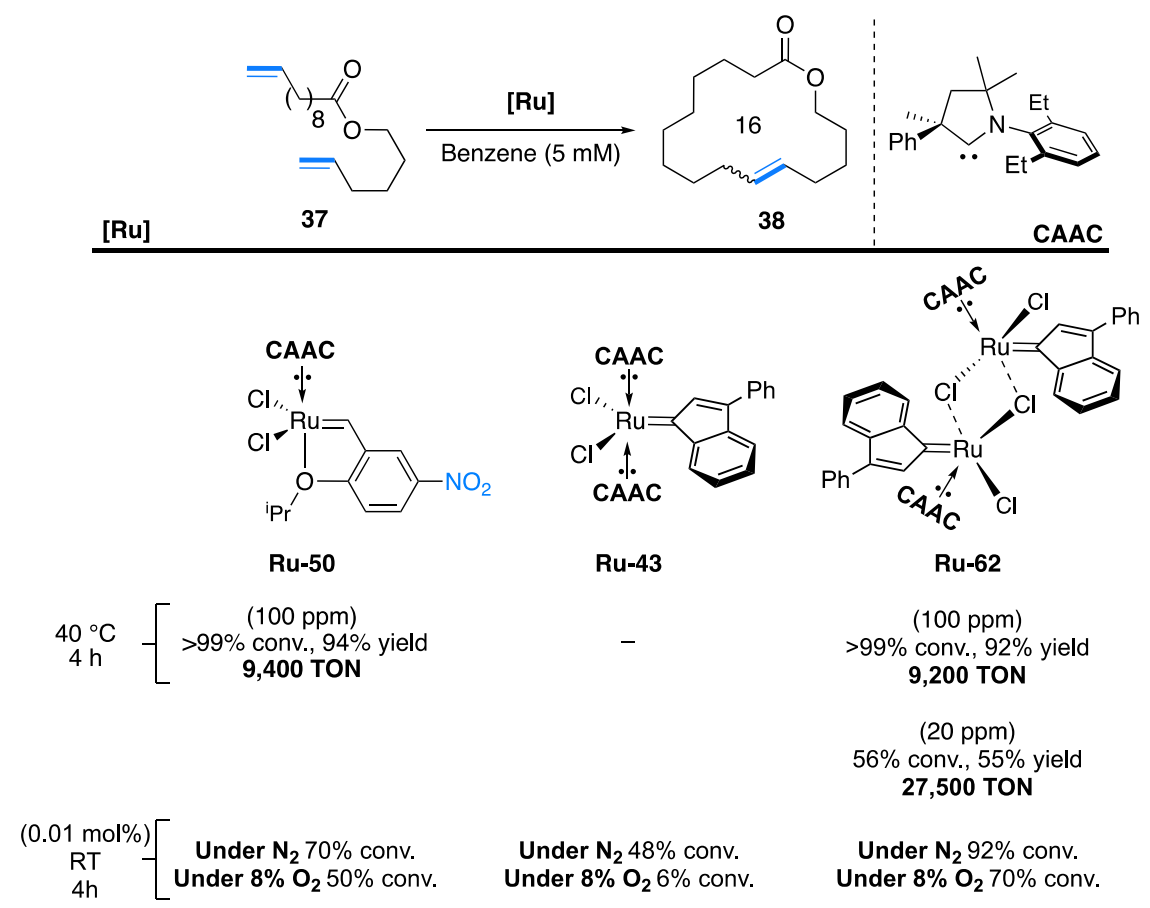

Scheme 46 Fogg's chloro-bridge dimer Ru-62 a competitive catalyst for macro-RCM

\subsection{Applications in Ethenolysis}

\subsubsection{Methyl and ethyl Oleate}

Cross metathesis involving ethylene, the so-called ethenolysis, has received tremendous attention as means to produce alpha-olefins in high demands for many industrial applications (materials, lubricants, surfactants, plasticizers, antimicrobials, etc....). In the context of biomass fuel production (biorefinery), the ethenolysis of unsaturated fatty acids/esters derived from natural vegetable oils (preferentially nonedible ones) provides bio-sourced alpha-olefins. Among the transition-metals able to promote ethenolysis of the biomass, robust and air stable ruthenium alkylidenes complexes rapidly emerged as promising catalyst candidates. However, the instability of propagating methylene species and concurrent inhibition by ethenolysis products only resulted in modest productivity (ca. TON $<14,000$ ). ${ }^{102}$ Complicating the matter further, second generation NHC-based catalysts were shown to favor undesirable selfmetathesis pathways. In that respect, the discovery of CAAC-based catalysts undeniably contributed to overcome these fundamental issues. In 2008, Schrodi and colleagues examined 
for the first time the reactivity of CAAC-Ru Hoveyda-type complexes in the ethenolysis of methyl oleate 5 (Scheme 47). ${ }^{33}$ At low catalyst loading (i.e. 100 ppm) and under 10 bar of ethylene, in solvent-free conditions, Ru-1, Ru-2 and Ru-9 exhibited good conversions and selectivity toward the desired terminal olefins $\mathbf{3 a}$ and $\mathbf{3 b}$. Reduction of the catalyst loading to 10 ppm even allowed up to 35,000 TON with Ru-9, one of the highest reported at that time. Under similar conditions, Piers-type CAAC-Ru-65’ performed as efficiently, whereas the monosubstituted ${ }^{i}$ Pr-CAACs Ru-19-21 gave excellent performances despite a lower purity (96\%) of the methyl oleate and ambient conditions. ${ }^{35,103}$ Comparatively, the Hoveyda catalyst $\mathbf{C}^{\text {SIMes }}$ gave lower yield and selectivity (20 and 33\%, resp.; TON 2,000; not shown). ${ }^{33}$

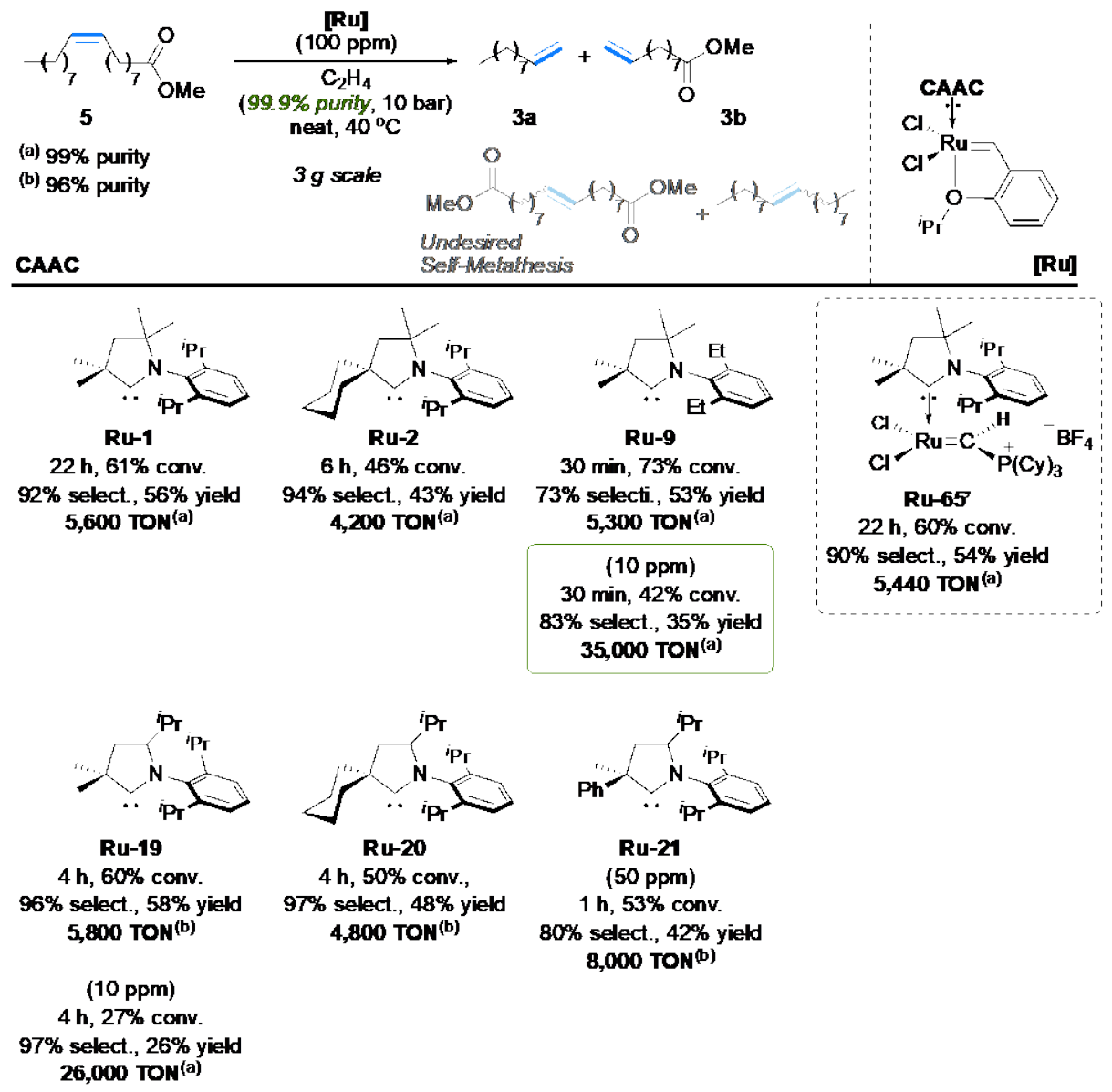

Scheme 47 CAAC Ruthenium catalysts as powerful tools for ethenolysis

Grubbs and coworkers reported an extensive study of the ethenolysis of neat methyl oleate (Scheme 48). ${ }^{31}$ The use of high purity ethylene (99.95\%) considerably improved the performance of catalysts reaching 180,000 TONs with Ru-5 and Ru-7. Pushing the system 
even further, with even higher ethylene purity (up to 99.995\%), allowed reaching 340,000 TON with $\mathbf{R u}-\mathbf{5}$, one of the highest reported to date.

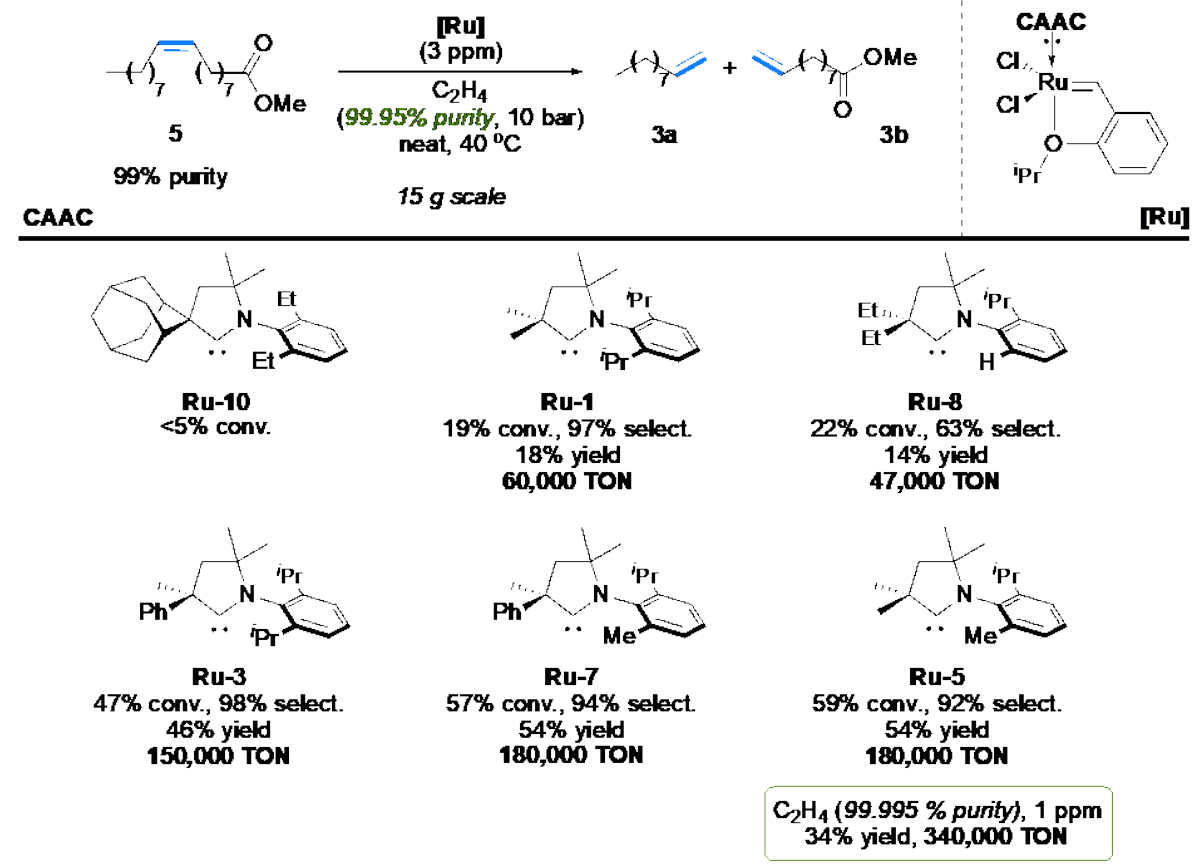

Scheme 48 Importance of the purity of ethylene for improving TON in ethenolysis

This impressive productivity/selectivity was attributed to i) CAAC induced increased electron density at the ruthenium leading to more stable methylidene propagating species and ii) large $\mathrm{N}$-aryl substituents limiting the formation of ruthenium hydrides thereby limiting secondary reaction pathways. Comparison of initiation rates and TONs support this hypothesis, suggesting that an optimal balance must be found to achieve stability and reactivity. Grubbs and coworkers later achieved the low pressure ethenolysis of methyl oleate $\mathbf{5}$, using continuous flow condition with Ru-9 (Scheme 49). ${ }^{104}$ At 50 ppm catalyst loading, Ru-9 surpassed its NHC-counterparts (i.e. Grubbs and Hoveyda-Grubbs) by affording the highest yield (ca. 70\%) and a TON of 27,200. Note that this high catalytic performance was achieved using lower purity material (97\%). 


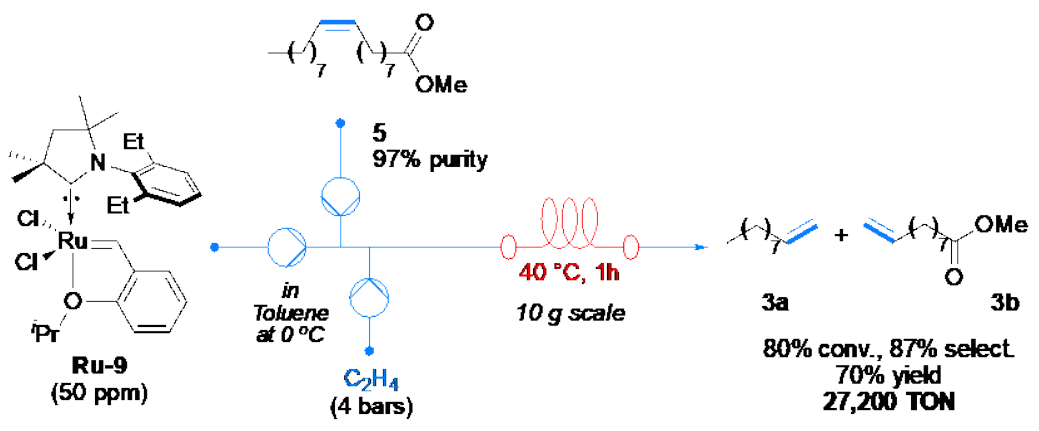

Scheme 49 Low pressure ethenolysis of methyl oleate 5 in continuous flow using Ru-9

Modulating the nature of the styrenyl ether ligand, Mignagni, Vallée and coworkers investigated the reactivity of CAAC-catalysts Ru-24,25 (Scheme 49). ${ }^{37,105}$ Addition of electron donating amino groups was shown to be detrimental to the catalytic activities, even at 1000 ppm catalytic loading. Attempts to activate the catalysts under acidic conditions only resulted in a marginal improvement. More interestingly, activation of Ru-77 with a dimethyl sulfonamide EWG (Zhan type catalyst ${ }^{106}$ ) afforded a very efficient catalyst reaching 59,400 TON. ${ }^{107}$

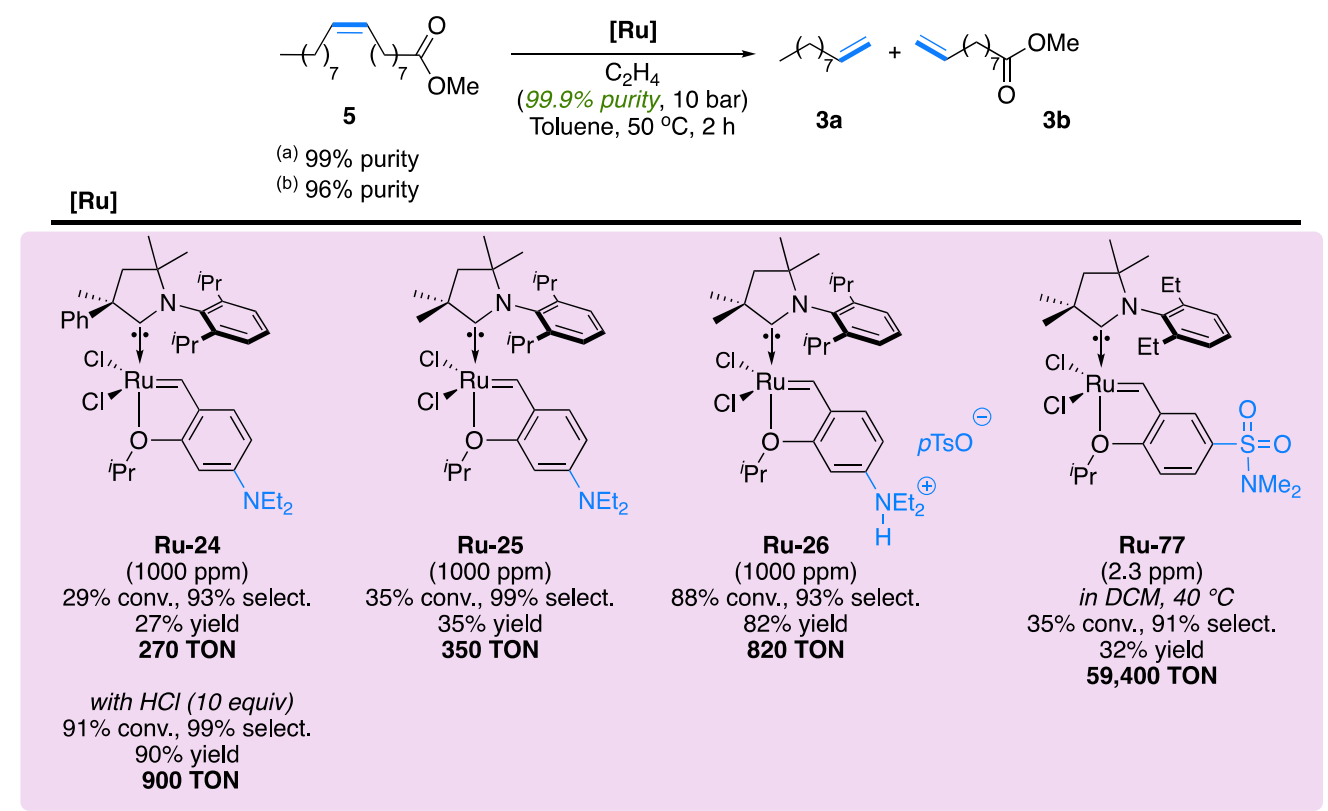

Scheme 50 Impact of the nature of the styrenyl ether ligand in ethenolysis

Similarly, Verpoort and coworkers examined the influence of labile benzylether, benzylthioether and benzylamine chelating groups. ${ }^{39}$ As shown in Scheme 51, all Ru-27 catalysts converted methyl oleate 5 (neat) with excellent selectivity (98\%) and impressive 
TONs (from 180,000 to 210,000), outperforming the Hoveyda complex Ru-3 (150,000, see Scheme 48). The reaction carried out with high purity ethylene gas (99.995\%), in the presence of benzylamine-chelated $\mathbf{R u - 2 7 e}$ and a Brønsted acid activator $\left(\mathrm{HSiCl}_{3}\right)$, afforded the highest TON value reported so far (390,000), slightly surpassing the state of art Ru-5 (340,000).

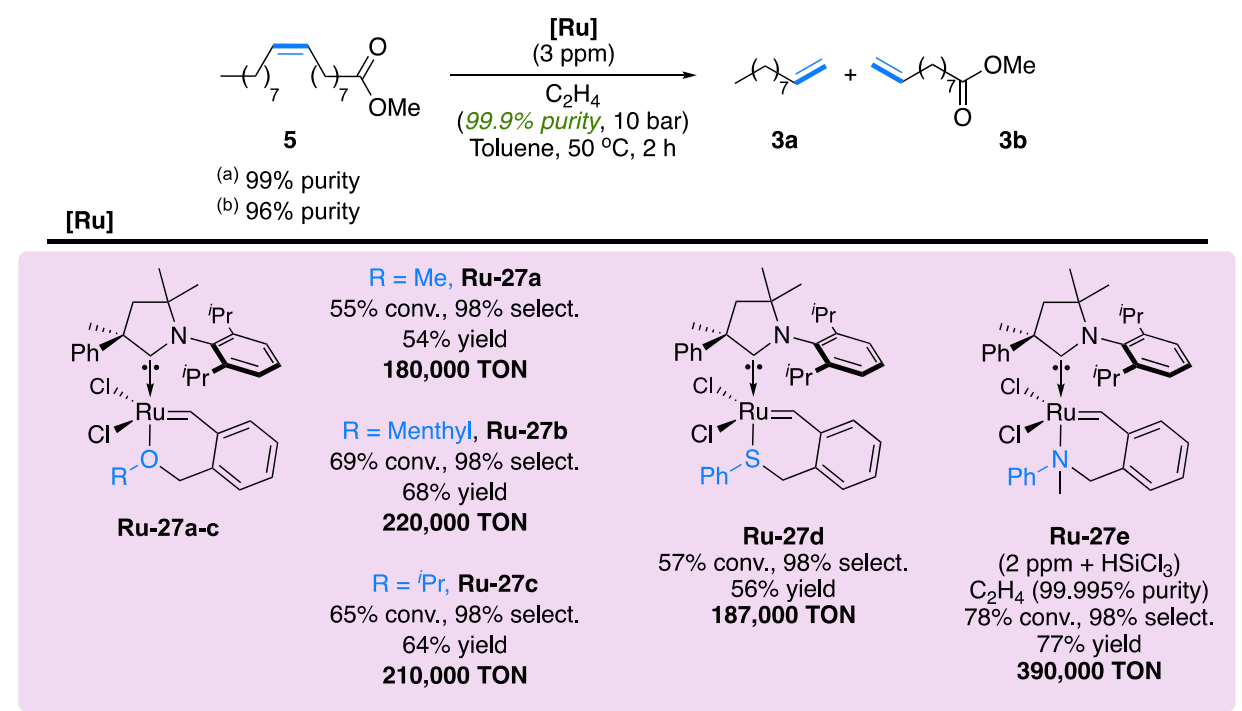

Scheme 51 Benzylether, benzylthioether and benzylamine substited CAAC-Ru catalysts display very reactivities

As depicted in Scheme 52, six-membered CAAC-ligated Ru-catalysts Ru-28-31 displayed much poorer reactivities than their five-membered counterparts in the ethenolysis of neat methyl oleate $5 .{ }^{40}$ Given a significant drop of activity at elevated temperature, it is likely that the poor catalytic behavior of these complexes could be imparted to their lower stability. Nevertheless, the authors also noted that CAAC-6 catalysts outperformed CAAC-5 in term of selectivity. 


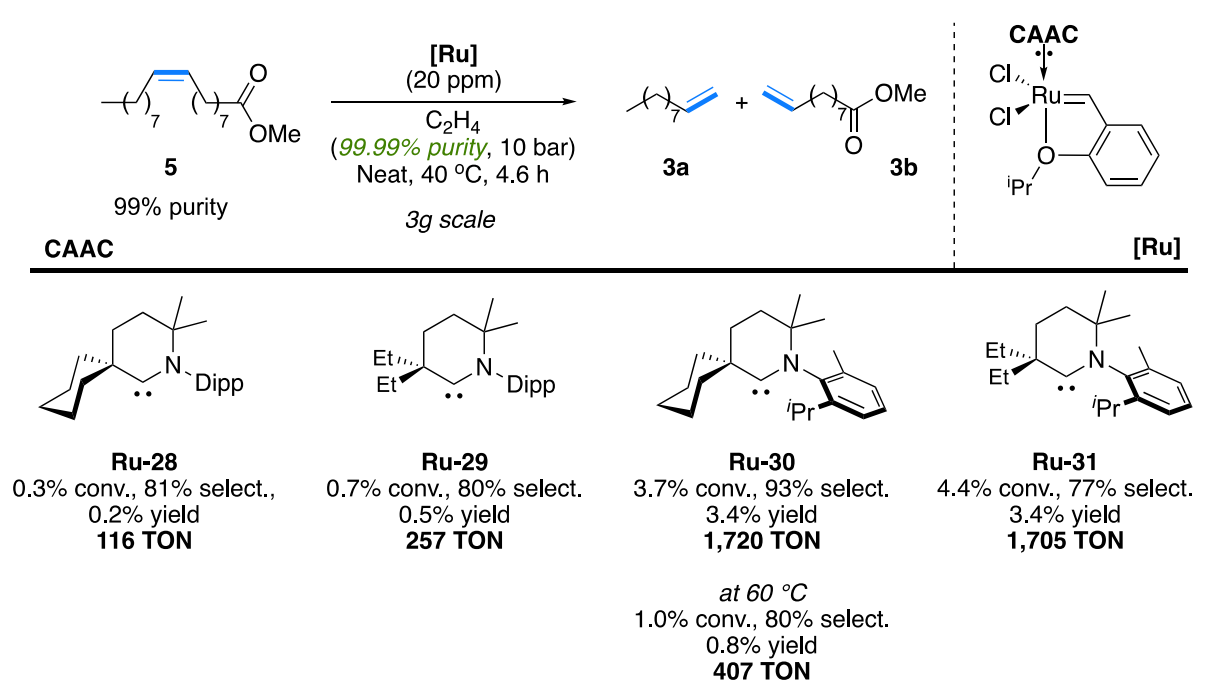

\section{Scheme 52 Activity of CAAC-6 Hoveyda-Grubbs catalysts in Ethenolysis}

Capitalizing on these results, Chen and coworker envisaged combining the Ru-ethenolysis and Pd-copolymerization of internal olefins to generate highly desirable polar functionalized linear low density polyethylene materials. ${ }^{108}$ Using neat methyl oleate, and thanks to the high selectivity of CAAC-catalyst in ethenolysis, this tandem catalytic process involving CAAC Ru-11/Pd-1 was able to produce valuable copolymers with high molecular weight and a tunable incorporation of 1-decenoate/1-decene (Scheme 53). It is worth noting that the direct copolymerization route failed due to the steric mismatch between the 1,2-disubstitued olefin and the palladium catalyst.

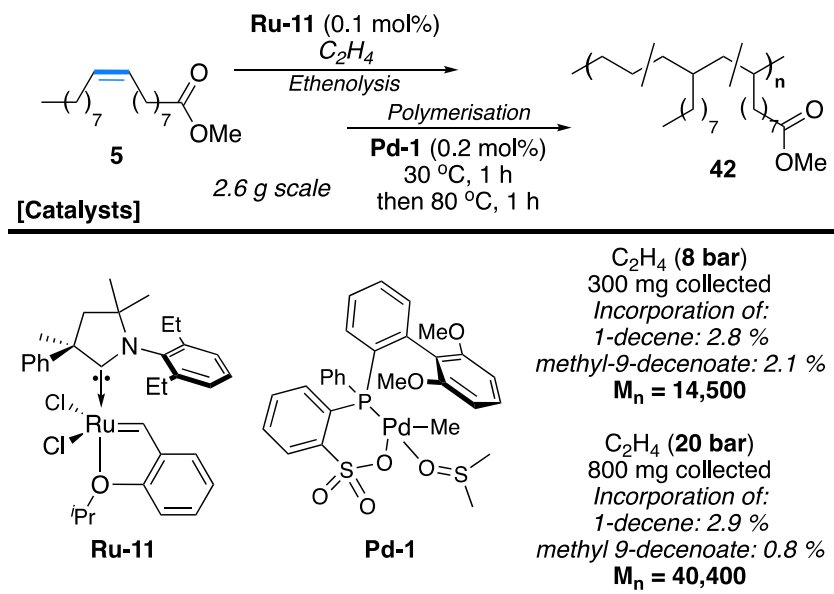

Scheme 53 Tandem Ru-ethenolysis and Pd-copolymerization of internal olefins towards polyethylene materials 
CAAC-catalysts were also investigated in the ethenolysis of ethyl oleate 5'. The later takes the advantage of a higher boiling point allowing for an easier separation of the corresponding products. ${ }^{109}$ In an extensive study, Grela and coworkers reported on the catalytic activity of sixty-five NHC and CAAC Ru-complexes in the ethenolysis of 5’ (95\% purity; 15 mmol scale) under ambient conditions (Scheme 54). ${ }^{109}$ Amongst all the catalysts screened, CAAC Ru-9 and NHC $\mathbf{J}$ were shown to be the most efficient (i.e. combining high reactivity and high selectivity). Note that a lower activity was observed with iodine derived CAAC Ru-78 albeit a higher selectivity (99\%). Expanding upon their work, these authors could perform large scale production using Ru-9 as a catalyst (Scheme 55). ${ }^{110}$ Note that in this case they relied on SnatchCat as a metal scavenger to facilitate the purification.

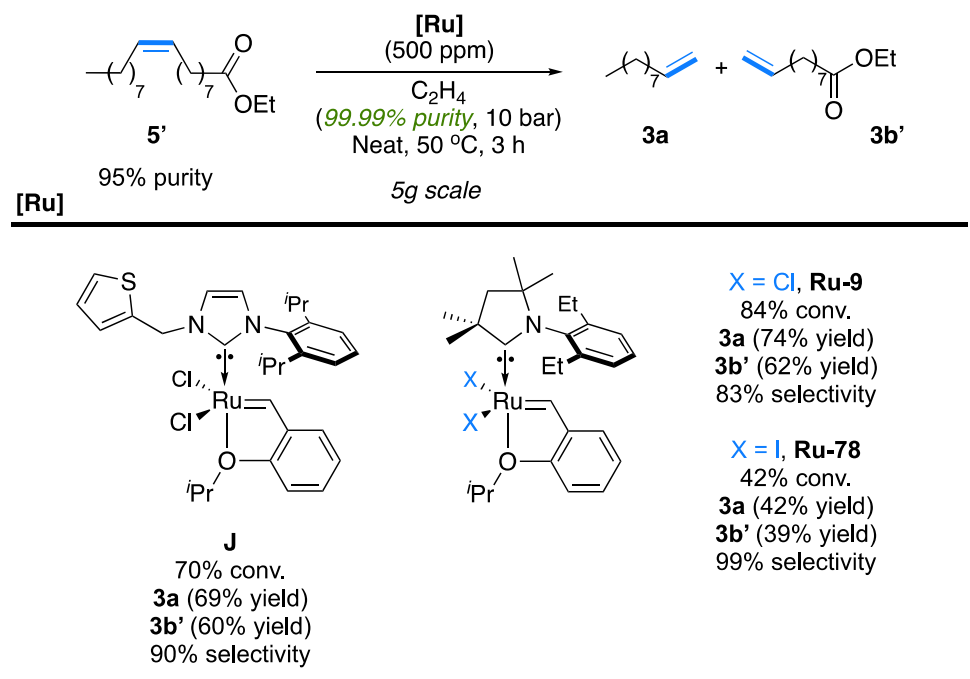

Scheme 54 CAAC-Ru catalysts in the ethenolysis of ethyl oleate

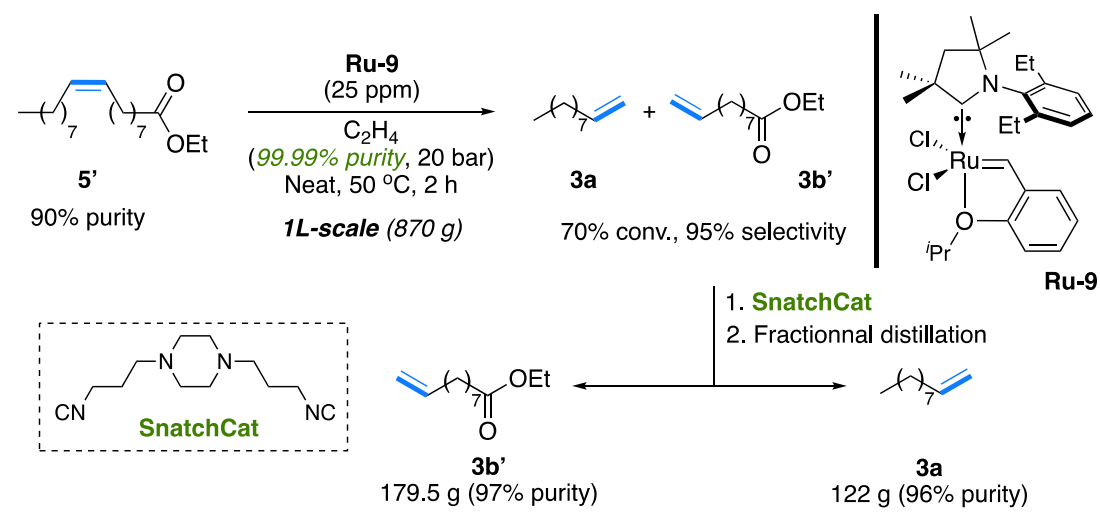

Scheme 55 Large scale ethenolysis of ethyl oleate under ambient conditions using Ru-9 
Bis(CAAC)Ru indenylidene complexes developed by Skowerski and workers also proved to be efficient in the ethenolysis of neat methyl oleate 5 affording up to 86,000 TONs (Scheme 56). ${ }^{52}$ As expected, higher activities were obtained with the more sterically demanding phenyl substituted CAAC catalysts Ru-41-43 and sterically unbalanced $N$-aryl Ru-39 and Ru40 reaching 86,000 TONs. Despite such exceptional reactivities, these catalysts remained slightly less reactive than nitro-Grela Ru-48 (TON 94,000).

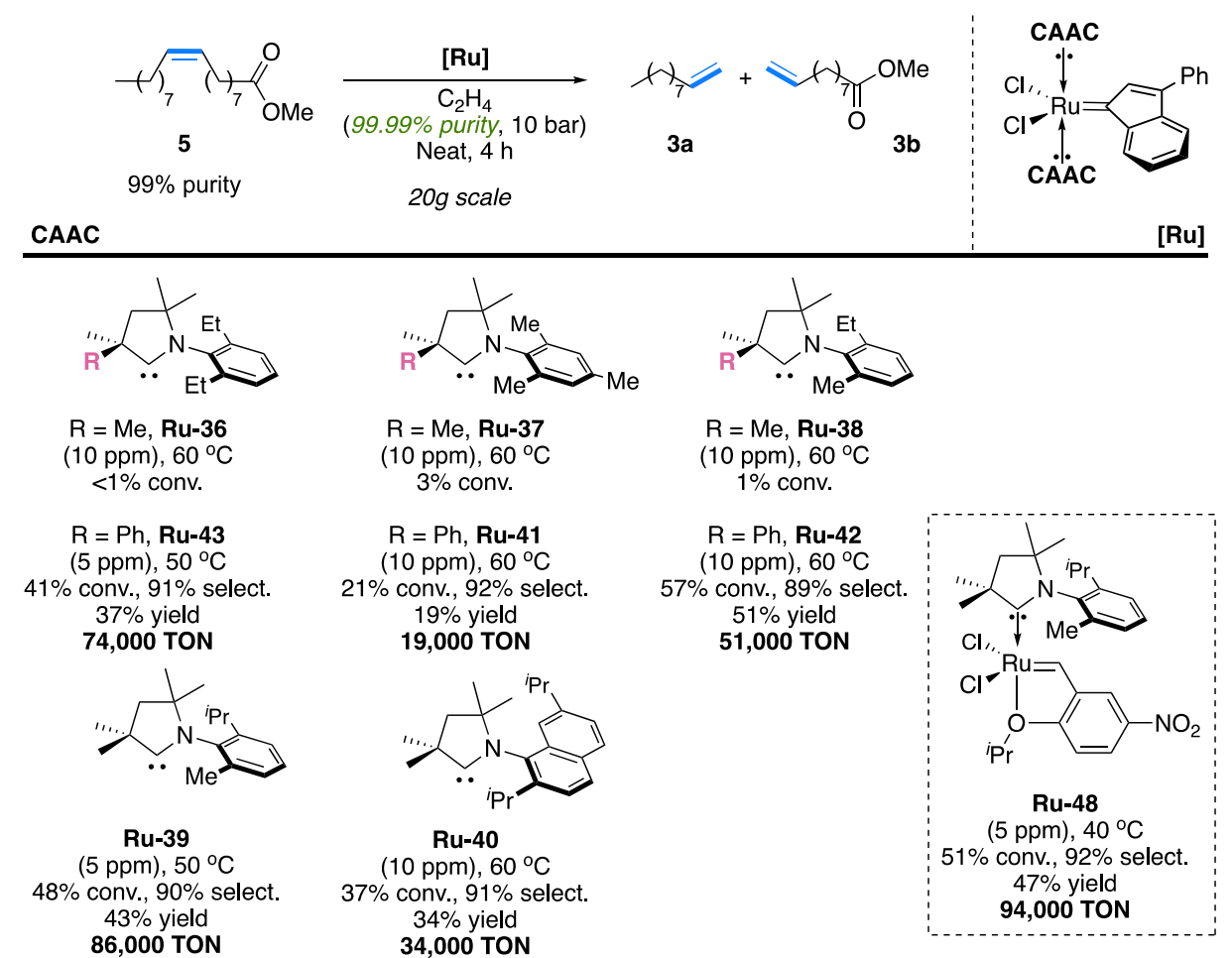

Scheme 56 Catalytic performances of bis(CAAC)Ru-indenylidene complexes in ethenolysis

With up to 50,000 TON, Fogg's chloro-bridge dimer Ru-62 was also shown to be a very potent catalyst for this transformation, even outperforming the Grela type catalyst Ru-50 (Scheme 57). ${ }^{66}$ Note however, that with this dimer, the catalytic activity was shown to be largely impacted by ethylene pressures. 


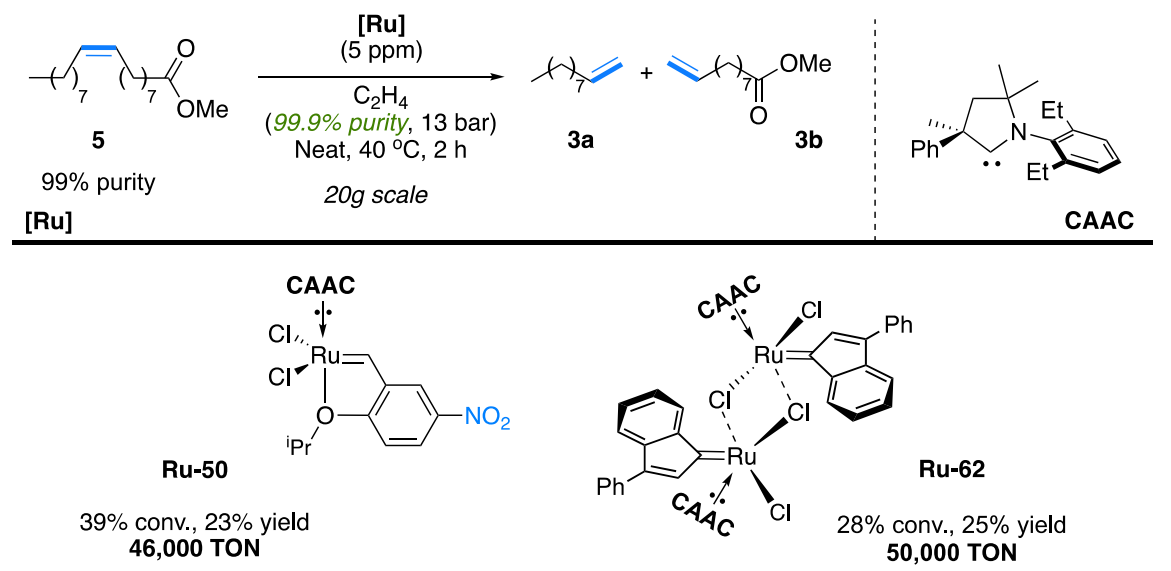

Scheme 57 Fogg's chloro-bridge dimer Ru-62 a competitive catalyst for ethenolysis

\subsubsection{Fatty acid methyl esters (FAME) mixture}

Given the excellent catalytic performance of CAAC-catalysts in the ethenolysis of oleic esters, the methodology was applied to more valuable raw materials, such as FAME mixtures derived from transesterification of seed oils. The ethenolysis of soy FAME was first studied by Grubbs and coworkers using CAAC-Ru catalysts $\mathbf{R u - 5 , 7}$ and $\mathbf{R u - 1 7}$ (Scheme 58). ${ }^{111}$ At 3 ppm catalyst loading and 10 bar of extremely pure ethylene (99.995\%), the corresponding terminal olefins were produced with high TONs, up to 92,000 with Ru-5. Note that these complexes were also shown to efficiently catalyze the butenolysis of soy FAME 43, delivering terminal and internal olefins in high conversions within 30 min (Scheme 59 ).

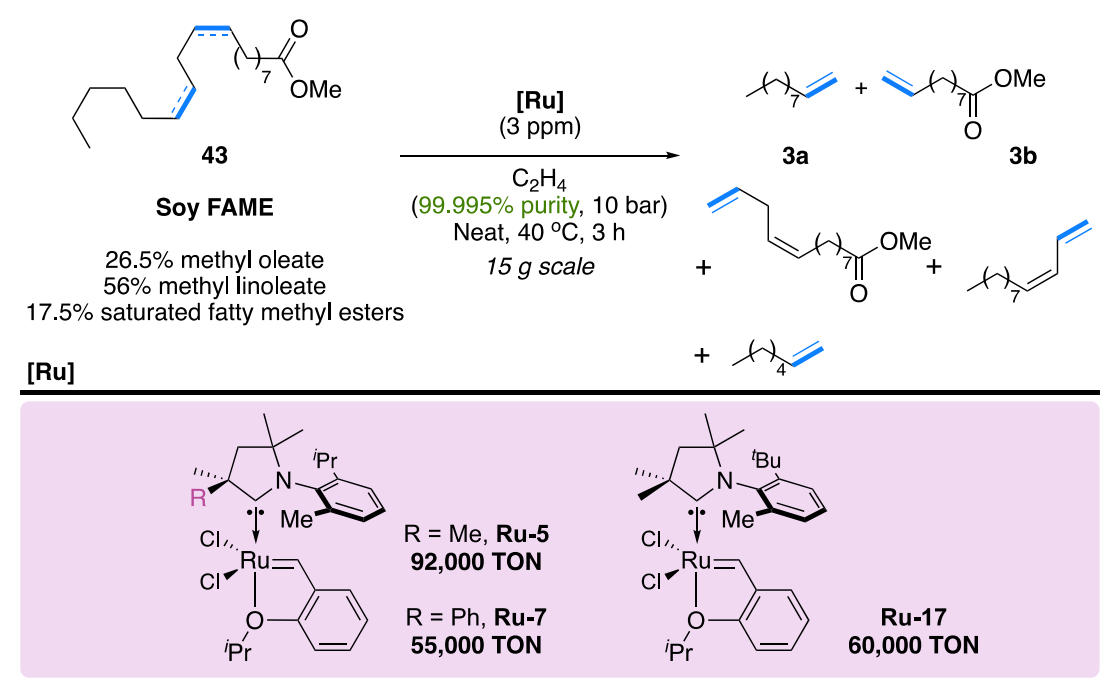

Scheme 58 CAAC-Ru complexes in the ethenolysis of soy FAME 


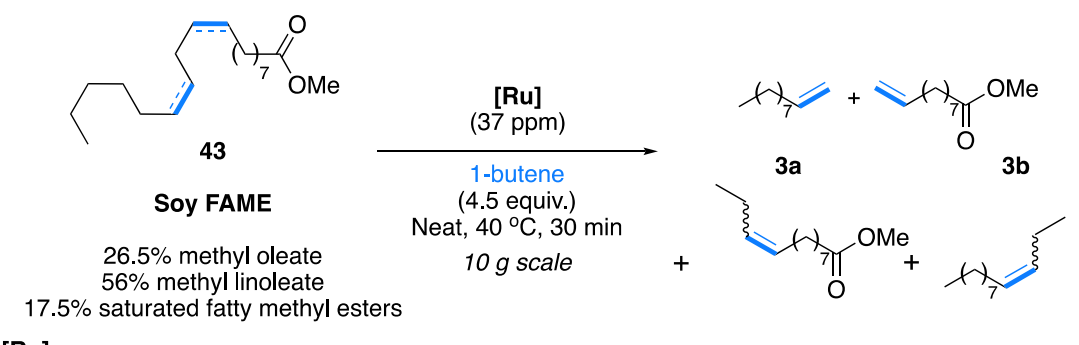

[Ru]

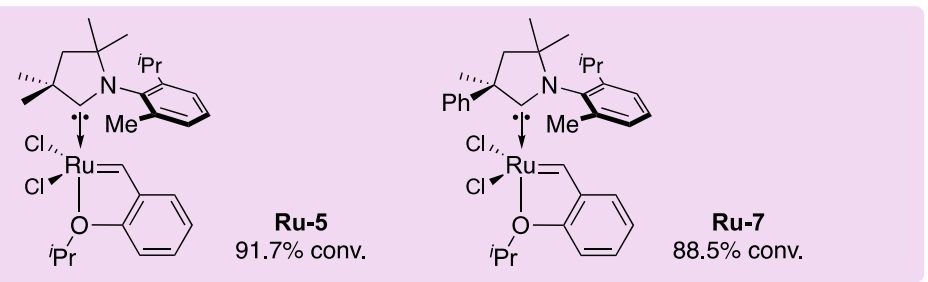

\section{Scheme 59 CAAC-Ru complexes in the butenolysis of soy FAME}

More recently, Grela and coworkers reported the catalytic activity of CAAC Ru-9 in the ethenolysis of rapeseed FAME, performed at a 1 liter-scale, under industrially relevant conditions (i.e. ambient conditions, technical grade of oleic raw materials and ethylene). ${ }^{110}$ Despite these unfavorable settings, Ru-9 remained very active at 25 ppm loading, affording terminal olefins with high conversion and excellent selectivity (Scheme 60). Weinreb-amide containing CAAC-catalysts Ru-54-56 were used by Skowerski for large-scale transformation of rapeseed FAME but in this case lower productivities were obtained..$^{59}$

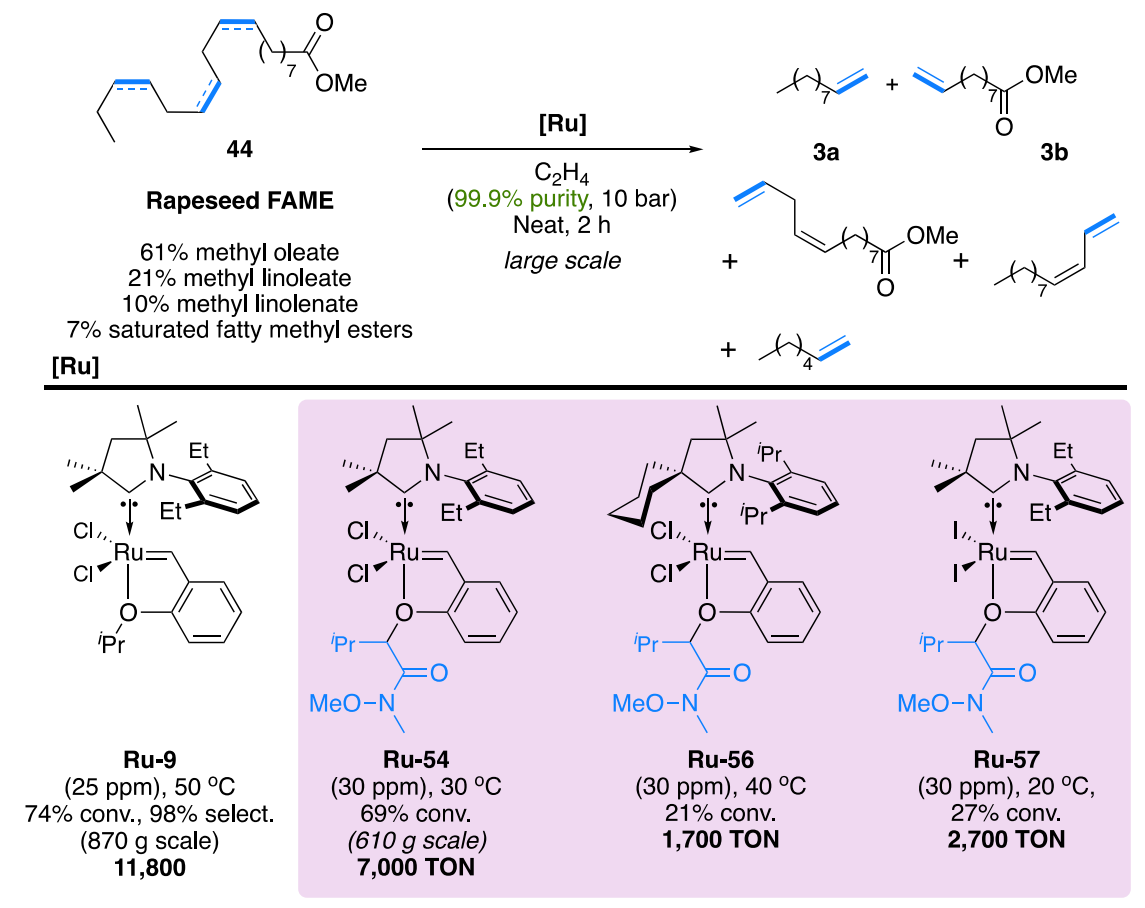




\section{Scheme 60 CAAC-Ru complexes in the ethenolysis of rapeseed FAME}

In 2017, Goossen and coworkers described the effective conversion of rapeseed FAME into biofuel via a catalytic process taking advantage of three specific catalysts: CAAC-Ru-1 (for ethenolysis), $\left[\mathrm{Pd}(\mathrm{I})(\mu-\mathrm{Br})\left({ }^{t} \mathrm{Bu}_{3} \mathrm{P}\right)\right]_{2} \mathbf{P d}-2$ (for isomerization) and state of the art SIPr-M73 ruthenium catalyst $\mathbf{K}^{112}$ (for cross- and self-metathesis) (Scheme 61). ${ }^{113}$ Used in a 1:4:1 ratio, these three mutually compatible catalysts performed the large scale transformation of rapeseed FAME to produce a mixture of $\mathrm{C}_{12}-\mathrm{C}_{14}$ linear internal olefins (monoesters, diesters and hydrocarbons), thus affording an end-product with boiling specifications expected for biodiesel fuels. Advantageously, this eco-friendly and practical process produces no wastes, involves soft conditions $\left(60^{\circ} \mathrm{C}\right)$, and requires no solvent. Note that the use of the highly active ethenolysis catalyst CAAC-Ru-1 was shown to be critical in promoting high ethylene incorporation into the product mixture.

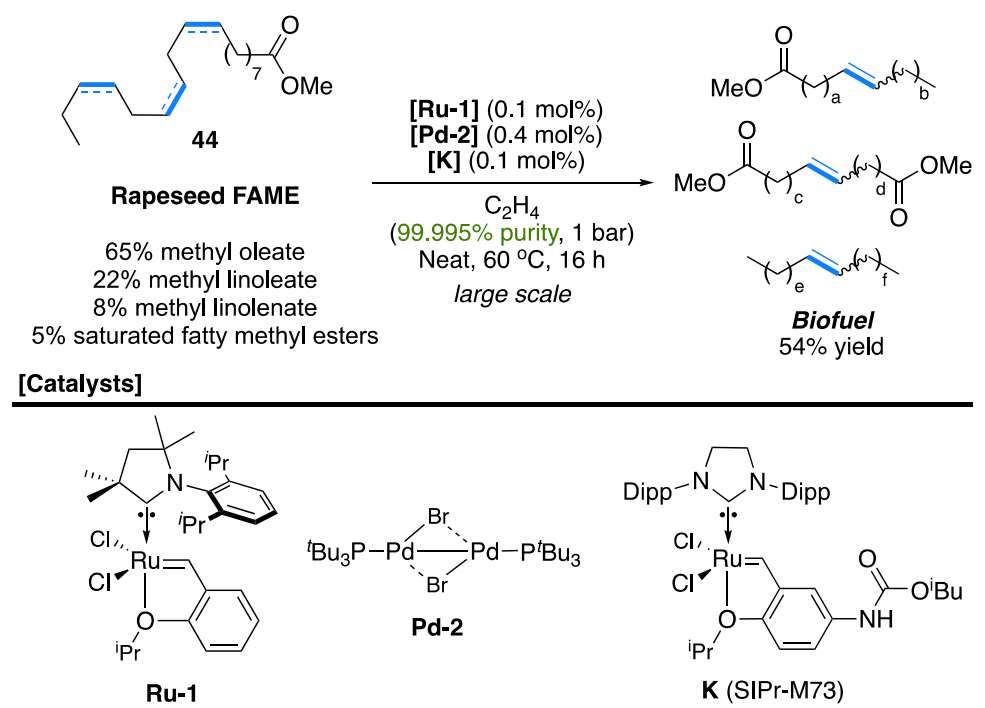

Scheme 61 One-pot, three-catalysts transformation of rapeseed FAME into biofuel

\subsubsection{Other substrates}

Aside from the transformation of bio-sourced unsaturated fatty esters, the ethenolysis reaction remains widely underexplored. In 2020, Fedorov, Togni and coworkers examined the catalytic activity of a number of ruthenium catalysts in the ethenolysis of inexpensive maleate esters, 
competitive alternatives to industrially relevant acrylates. ${ }^{114,115}$ In contrast with the promising productivity (up to 5,200 TON) and good selectivity (up to 99\%) obtained with HoveydaGrubbs catalyst $\mathbf{C}^{\text {SIMes }}$ in ethenolysis of dimethyl maleate 45, CAAC complexes $\mathbf{R u - 2 , 5}$ proved to be much less efficient (Scheme 62). Although not discussed by the authors, this unexpected inefficiency, which severely contrasts with high TONs exhibited with fatty esters, could be the result of the rapid deactivation of the transient $\mathrm{CAAC}-\mathrm{Ru}=\mathrm{CHCO}{ }_{2} \mathrm{Me} .{ }^{116}$

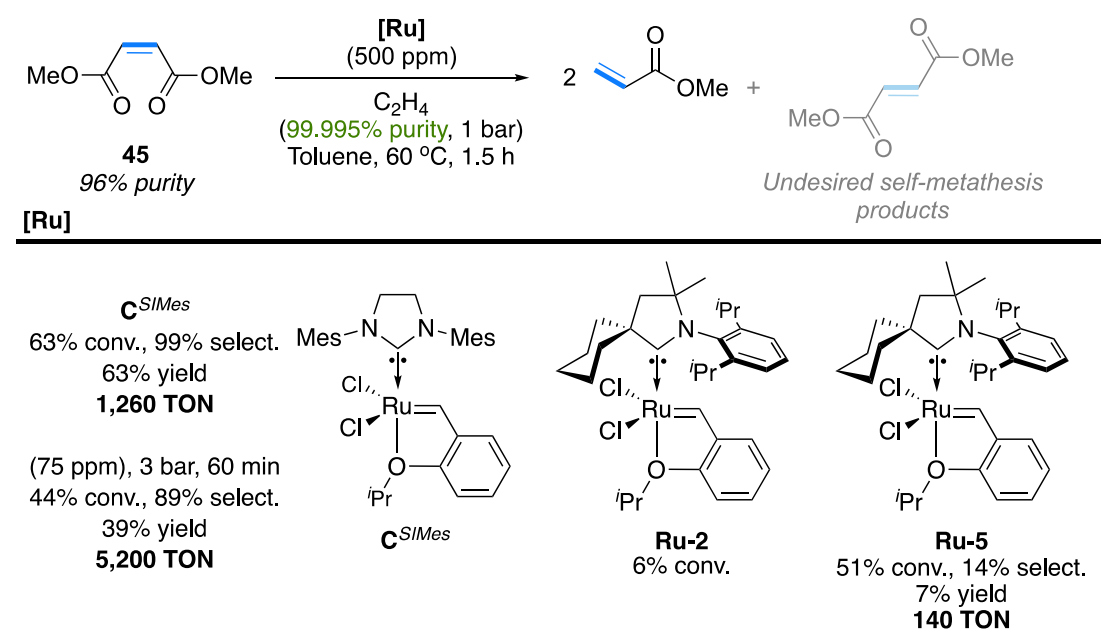

\section{Scheme 62 Carbene-Ru complexes in the ethenolysis of acrylates}

Recently, Grela and coworkers reported the ethenolysis of $\beta$-caryophyllene $\mathrm{E}$, a bicyclic sesquiterpene, ubiquitous in various essential oils, that is largely used as an additive in food industry and as a fragrance ingredient (Scheme 63). ${ }^{117}$ CAAC-Ru-9 showed promising catalytic performance, leading to the expected triene 46 with a TON of 404 (ca. 20\% conversion at $0.05 \mathrm{~mol} \%$ ). Note that a lower $4 \%$ conversion (TON of 81 ) was observed with standard Hoveyda $\mathbf{C}^{\text {SIMes, }}$, while higher TONs (up to 2,876) were reached with a newly designed Ru-catalyst L, containing an unsymmetrical phenanthrene-based NHC. 


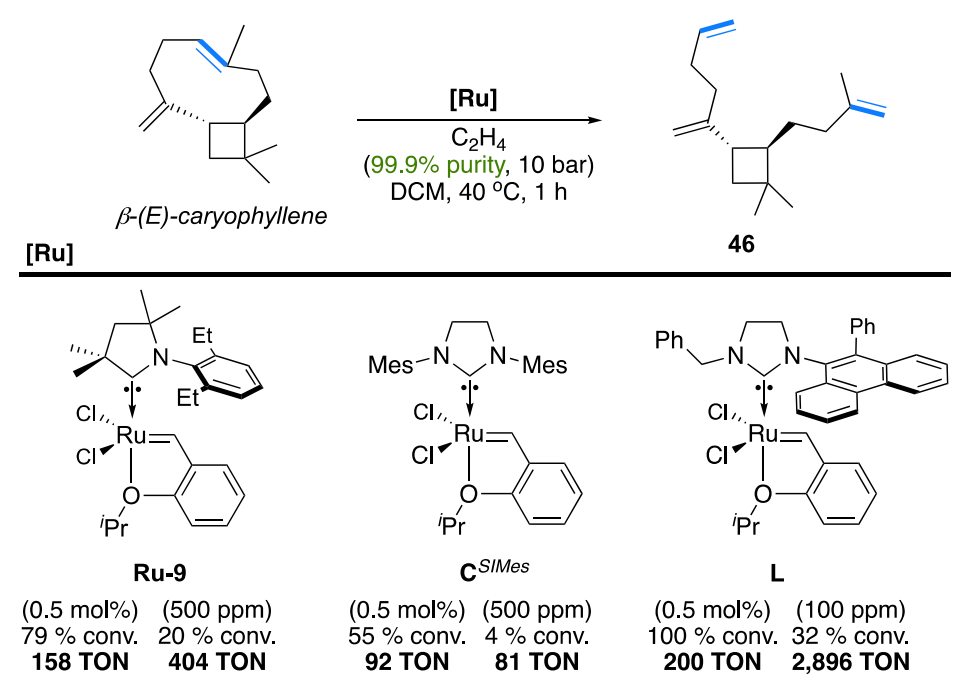

Scheme 63 Comparing the activities of Carbene-Ru complexes in the ethenolysis of $\beta$-caryophyllene $\mathbf{E}$

\subsection{Application to ROCM}

The two-directional desymmetrisation of chains is a popular strategy for the synthesis of complex molecules. Using ring-opening metathesis polymerisation (ROMP) or asymmetric ring-opening cross metathesis (AROCM), cyclic alkenes have been exploited as potential chain precursors. Interestingly, there are much fewer examples involving ring-opening metathesis and double cross metathesis (ROCM). Capitalizing on this approach, Lee and coworkers described a large scale two-directional desymmetrisation of cyclooctene using Soybean oil (Scheme 64). ${ }^{118}$ Comparing the catalytic activities of CAAC Ru-63' to the NHC catalyst $\mathbf{C}^{\text {SIMes }}$, these authors demonstrated that NHCs perform much more efficiently. However, given the lack of more comprehensive studies, it seems premature to draw some conclusion.

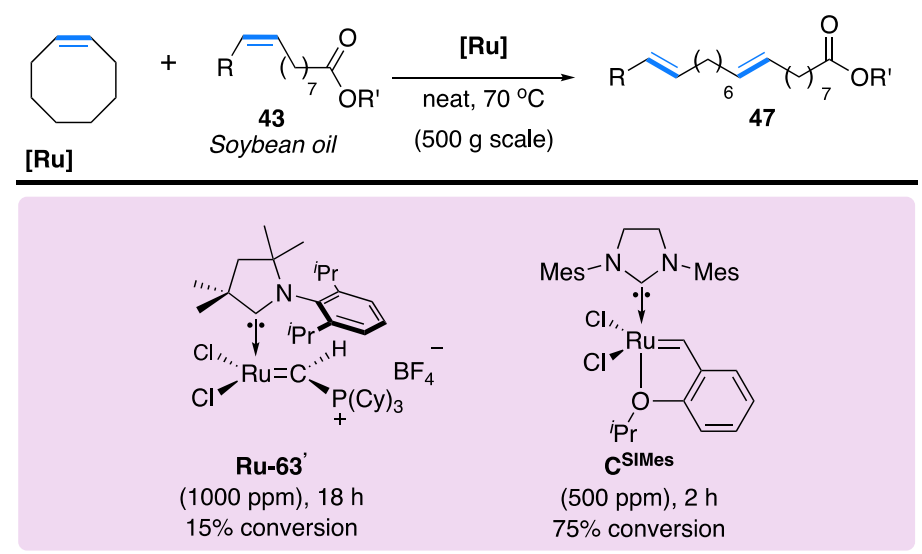

Scheme 64 Tandem ring-openning cross metathesis with CAAC-Ru Piers type catalyst 
Owing to their unique and highly modular steric environment, chiral NHCs have attracted considerable interests for the development of AROCM transformations. ${ }^{119,120}$ Having developed an efficient access to optically pure CAAC ruthenium metathesis catalysts, we evaluated their activity in AROCM. ${ }^{75}$ So far, chiral CAACs catalysts are less reactive and E/Z selective than Hoveyda-Grubbs type chiral catalysts, such as the one developed by Blechert and coworkers $\mathbf{C}^{\text {Blechert }}$ (Scheme 65). ${ }^{121}$ However, they have been shown to trigger asymmetric induction in AROCM up to 92\% ee. While the specifics of the chiral induction phenomenon in these C1-symmetric chiral CAAC ligands are still unclear, DFT studies indicate that it likely originates from steric clashing between substituents at the quaternary position to the carbene center and the incoming substrate. Taking advantage of the CAAC framework, the remarkable asymmetric induction is clearly illustrated upon comparing the enantio- and E/Z selectivity obtained with the cyclohexyl derived Ru-73, in comparison to the phenyl derived Ru-69 (Entry e). These catalysts were also evaluated in the challenging AROCM of cyclopropenes for which moderate yields but good Z-selectivity were observed (Scheme 66). It can be expected that further modifications of the CAAC motif will permit more competitive asymmetric inductions. 


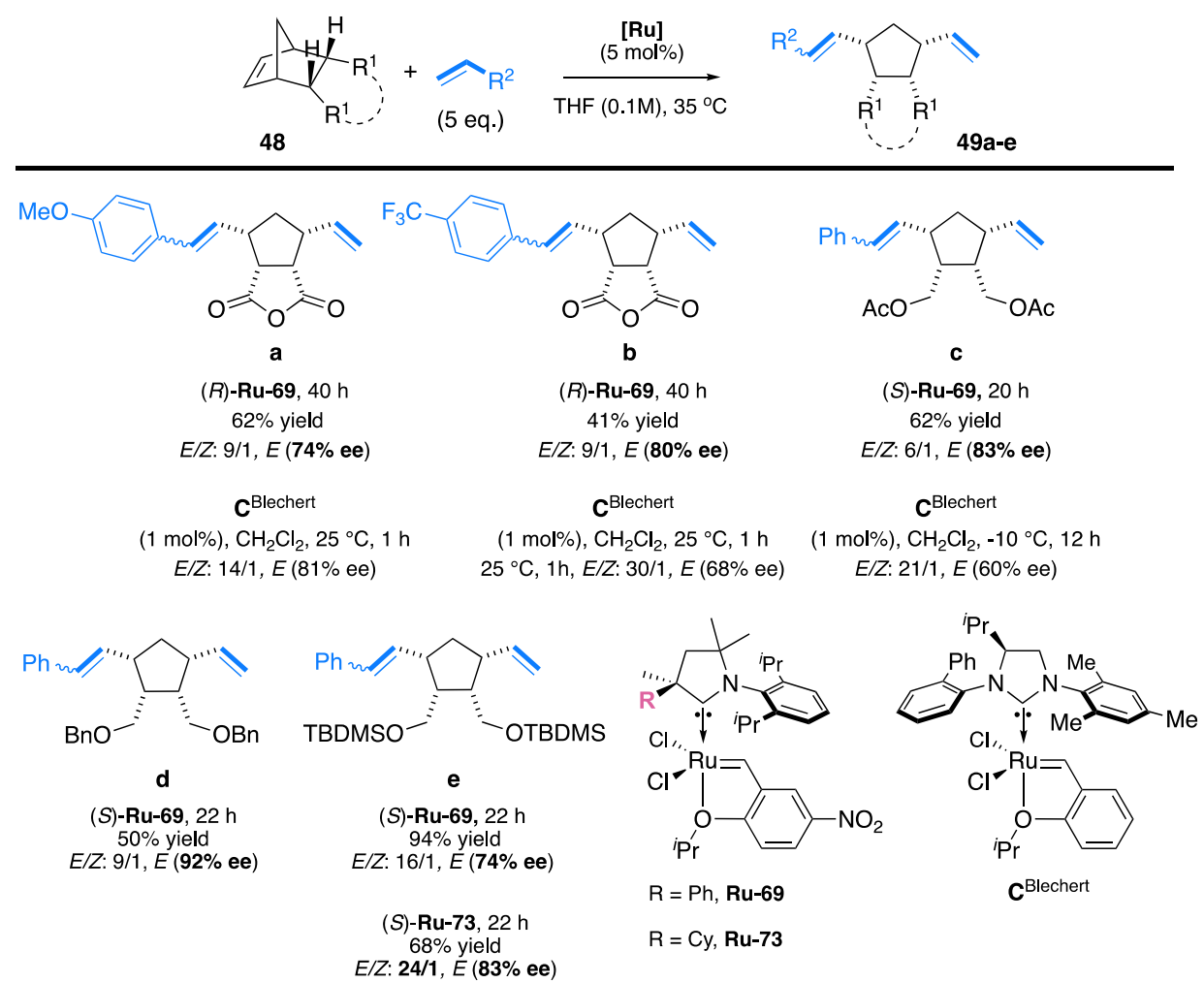

Scheme 65 First example of CAAC ruthenium catalysts in asymmetric ring-opening cross metathesis of norbornenes

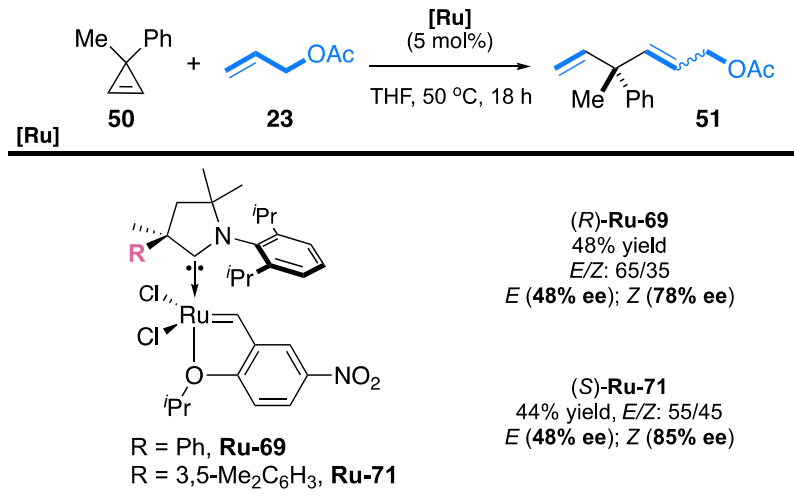

Scheme 66 First example of CAAC ruthenium catalysts in asymmetric ring-opening cross metathesis of cyclopropenes

\subsection{Application to Olefin Polymerization}

NHC ruthenium catalysts have shined in the preparation of polymers via ring-opening metathesis polymerization (ROMP) or acyclic diene metathesis (ADMET) polycondensation. ${ }^{122,123,124,125,126}$ The former, which converts cyclic olefins into linear highly unsaturated polymers via chain polymerization, provides a wide range of unique architectures. 
The latter, involving a step-growth polymerization mechanism is advantageous for the synthesis of polymeric materials containing in-chain functionalities.

\subsubsection{Ring Opening Metathesis Polymerization (ROMP)}

There are surprisingly very few examples of CAAC metathesis ruthenium complexes applied to ring opening metathesis polymerization. Using bis(CAAC)Ru indenylidene $\mathbf{R u}-\mathbf{4 3}$, Skowerski and coworkers investigated the formation of polynorbornene (PNB), an elastomer used in the production of a wide variety of rubber goods which is also known as a super absorbent oil binding polymer (up to 30 times its own weight). ${ }^{52}$ Under mild conditions and using 1000 ppm of catalyst, up to 87\% yield of PNB was obtained (Scheme 67).

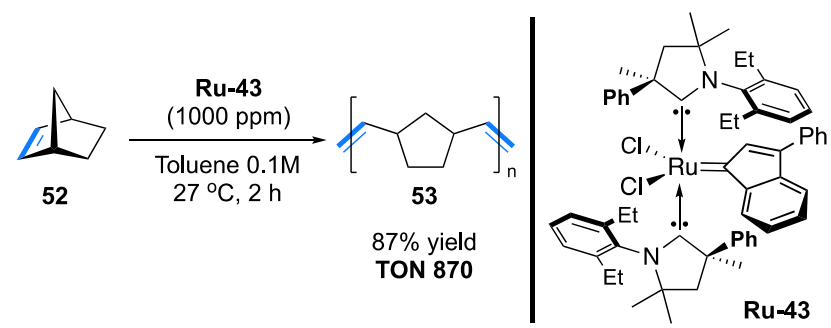

Scheme 67 Activity of Bis(CAAC)Ru-indenylidene in Ring-Opening Metathesis Polymerization of Norbornene.

Compared to norbornene derivatives, there are much fewer examples of ROMP involving lowstrain cyclic olefins such as hydroxyl functionalized cycloalkenes. ${ }^{127}$ Recently, Tuba and coworkers extended the application of CAAC ruthenium catalysts to the polymerization of cyclopent-3-en-1-ol 54, using the more polar $\mathbf{R u - 2 3}$ and $\mathbf{R u - 4 4 , 4 5 .}{ }^{36}$ As shown in Scheme 68, second generation type catalyst Ru-23 performs efficiently in methanol, affording biopolymer 55 in good yields and TONs. Despite the increased solubility of this catalyst, it was shown to be less efficient in a 50/50 mixture of $\mathrm{MeOH} / \mathrm{H}_{2} \mathrm{O}$. As expected, bis(CAAC)Ru indenylidene $\mathbf{R u}-\mathbf{4 4 , 4 5}$ required higher temperature to catalyze this transformation reaching 1,000 TONs with Ru-45. Attempts to obtain the same polymer through acyclic diene metathesis 
polymerization (ADMET) of hepta-1,6-dien-4-ol only led to a mixture of products despite higher catalyst loading (0.5 mol \%).

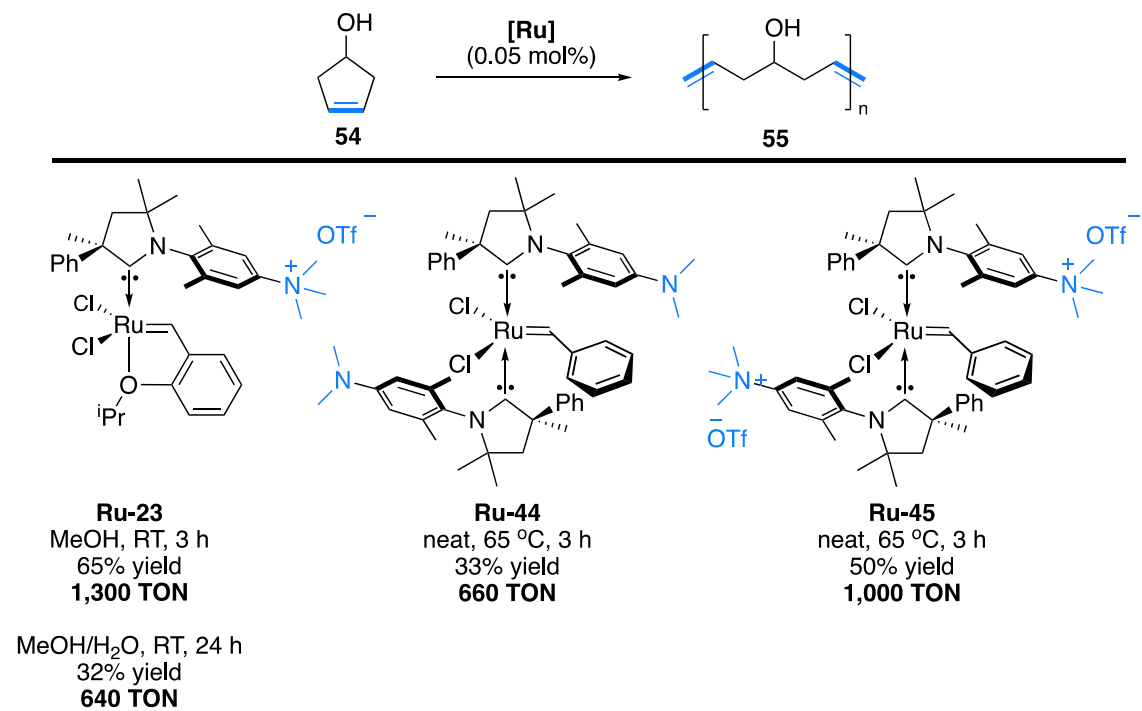

Scheme 68 Activity of polar Bis(CAAC)Ru-benzylidene in Ring-Opening Metathesis Polymerization of cyclopent-3-en-1-ol.

Extending this study to five typical cyclic olefins (52, 56-59) (Scheme 69), Lemcoff and coworkers looked at the reactivity of sulfur-chelated ruthenium benzylidenes Ru-34,35. ${ }^{47}$ Apart from the most reactive ROMP monomer, norbornene 52, both catalysts showed latency at $35^{\circ} \mathrm{C}$. As expected, performing the reaction at higher temperature $\left(75^{\circ} \mathrm{C}\right)$ resulted in full polymerization of 52, meanwhile other monomers remained poorly reactive. Similar results were obtained with sulfur-chelated cis-ruthenium benzylidenes $\mathbf{R u}-\mathbf{5 8} \mathbf{s}^{\text {cis }}$ and $\mathbf{R u - 5 9 ^ { \text { cis } }}$ under thermal conditions. However, taking advantage of the photoactivity of these complexes, the authors could trigger significant catalytic activity under irradiation at $350 \mathrm{~nm}$, as illustrated with Ru-58 ${ }^{\text {cis }}$ and cyclooctene. Screening additional wavelengths with Ru-58 ${ }^{\text {cis }}$ (254 and 419 $\mathrm{nm}$ ), it was found that visible light at $419 \mathrm{~nm}$ resulted in excellent reactivity. The activation of Ru-58 ${ }^{\text {cis }}$ with UV-A and visible light arguably marks a new method for the activation of CAAC containing olefin metathesis catalysts. The polymerization of dicyclopentadiene $\mathbf{5 7}$, a diene of significant industrial importance was also considered, and complete polymerization was observed with $\mathbf{R u}-\mathbf{5 8}^{\text {cis }}$ upon irradiation at $419 \mathrm{~nm}$ or by heating to $80^{\circ} \mathrm{C}$. 


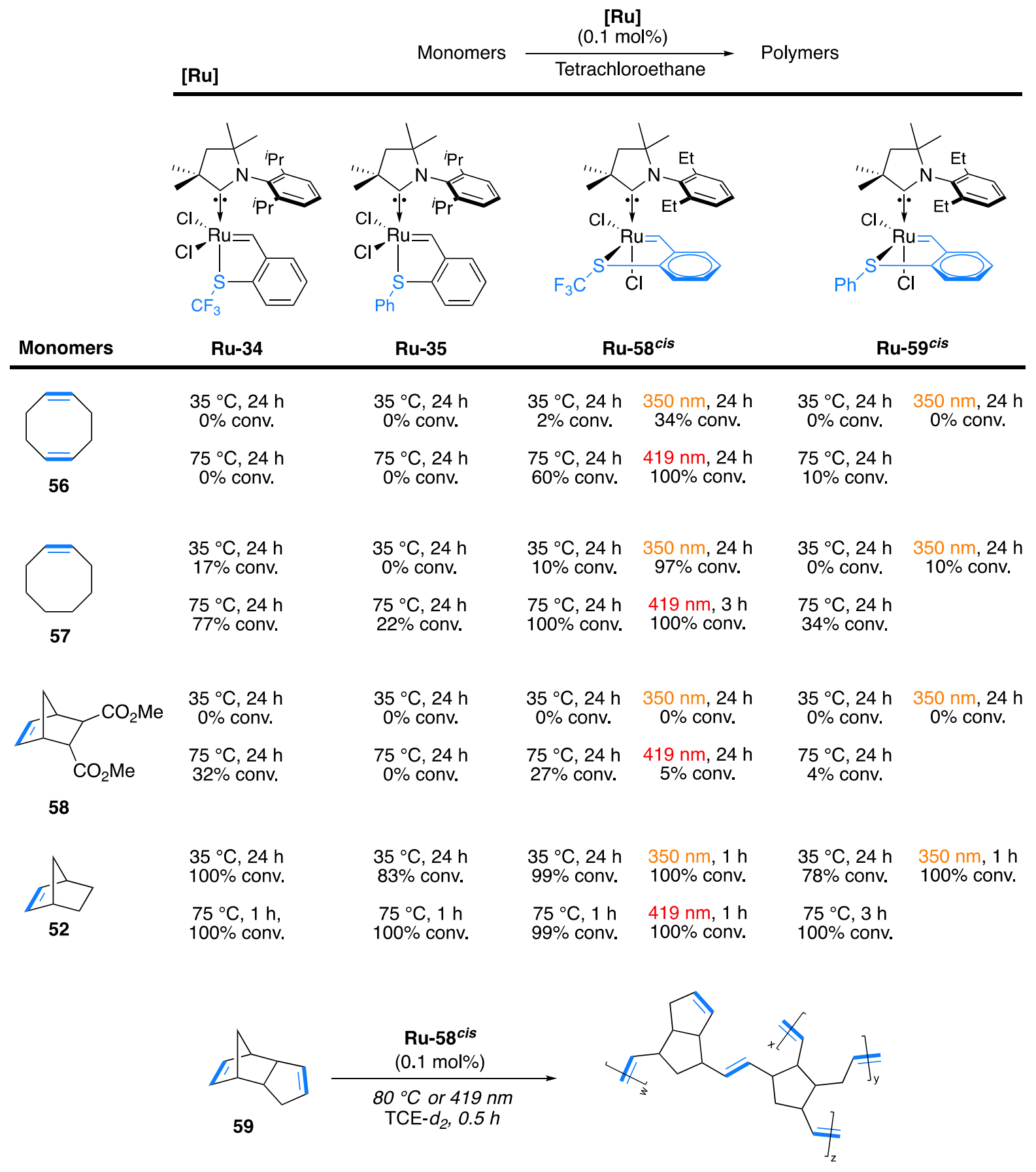

\section{Scheme 69 Polymerization scope for sulfur-chelated CAAC Ru-benzylidenes}

Although the subject of fewer studies, a variation of ROMP is the ring-opening cross metathesis (ROCM). It involves a tandem reaction sequence between a ring-opened cyclicolefin and an acyclic olefin crossed onto the newly formed termini. Probing the activity of CAAC ruthenium catalysts in this process, Holtcamp et al. disclosed that Ru-74 afforded up to $68 \%$ of the desired functionalized hexene-propylene copolymer 62 (Scheme 70 ). ${ }^{128}$ 


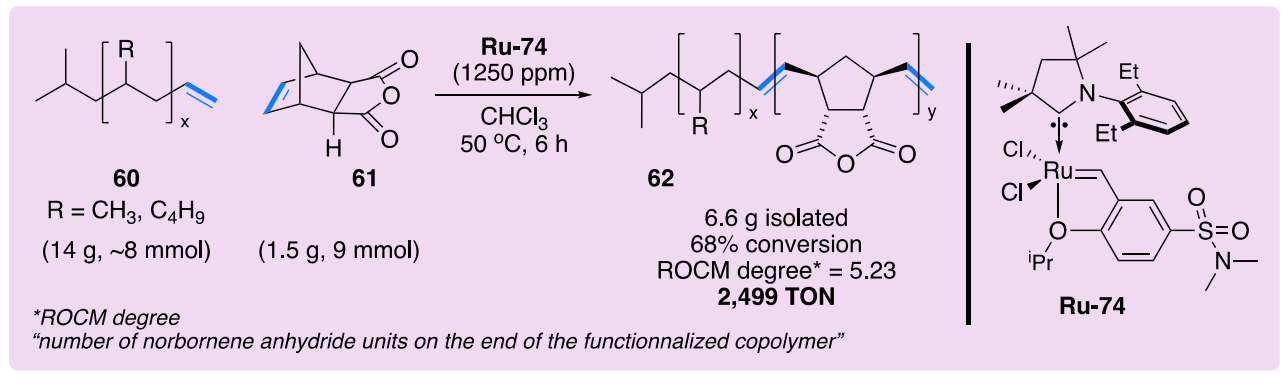

Scheme 70 ROCM with vinyl terminated polymers and Ru-CAAC functionalized Hoveyda type catalyst

\subsubsection{Acyclic Diene Metathesis (ADMET) Polycondensation}

The propensity of CAAC ruthenium catalysts to promote the polymerization of dienes has also been used as a mean to improve the acyclic diene metathesis (ADMET) polymerization of Jojoba oil 65. Traditionally this process requires rather high temperatures (i.e. $200{ }^{\circ} \mathrm{C}$ ) to separate the polyester polymer $\mathbf{6 6}$ from the octadec-9-ene (4a) biofuel side product. However, under these demanding conditions traditional NHC ruthenium catalysts are prone to decompose and thus promote undesirable isomerizations. ${ }^{129}$ This is well illustrated with Hoveyda-Grubbs $\mathbf{C}^{\text {SIMes }}$ which only provides up to $28 \%$ of $4 \mathbf{a}$ (Scheme 71 ). In marked contrast, under the same conditions, CAAC catalysts $\mathbf{R u - 1 , 5 , 9}$ and $\mathbf{R u - 3 6}$ were shown to suppress the isomerization reaching up to $86 \%$ of hydrocarbon $4 a^{79}$ 


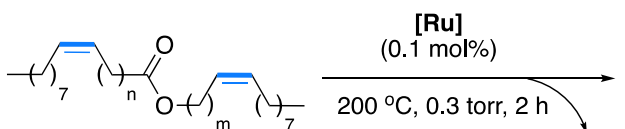

63

Jojoba oil

$n=9,11,13$ or 15

$m=8,10,12$ or 14

2 to $5 \mathrm{~g}$ scale

[Ru]

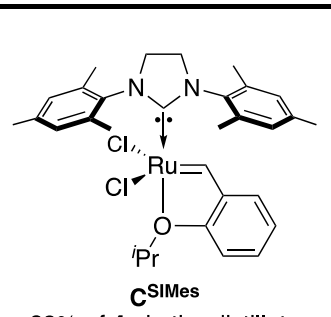

$28 \%$ of $4 a$ in the distillate

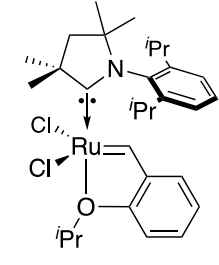

Ru-1

$75 \%$ of $4 \mathbf{a}$ in the distillate

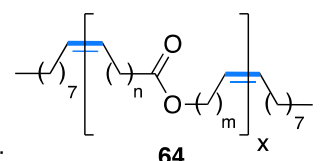

Distillate:

64

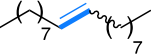

4a + isomerization products

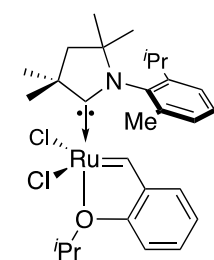

Ru-5
$86 \%$ of $4 \mathbf{a}$ in the distillate

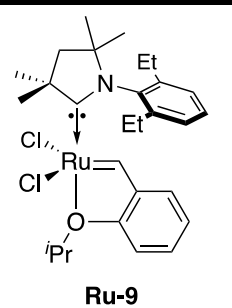

$75 \%$ of $4 a$ in the distillate

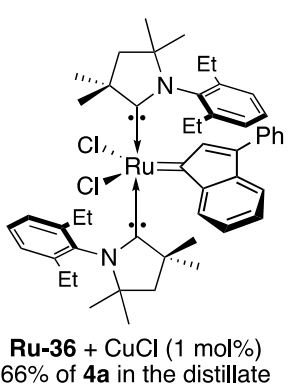

Scheme 71 Highly selective ADMET of Jojoba oil catalyzed by CAAC Ru-complexes

The advantage of using CAAC catalysts in the ADMET was also evidenced with 1,5-hexadiene 65, a precursor to polybutadiene 66. As shown in Scheme 72, a more pronounced isomerization can be seen in the $\mathbf{C}^{\text {SIMes }}$ derived polymer, whereas much fewer defects are observed with $\mathbf{R u}$ 5. ${ }^{79}$ The authors proposed that CAACs afford more stable ruthenium complexes less prone to form the ruthenium-hydride- $\pi$-allyl intermediates necessary to promote the double migration.

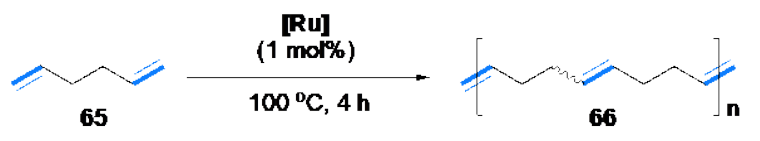

[Ru] + isomerization products
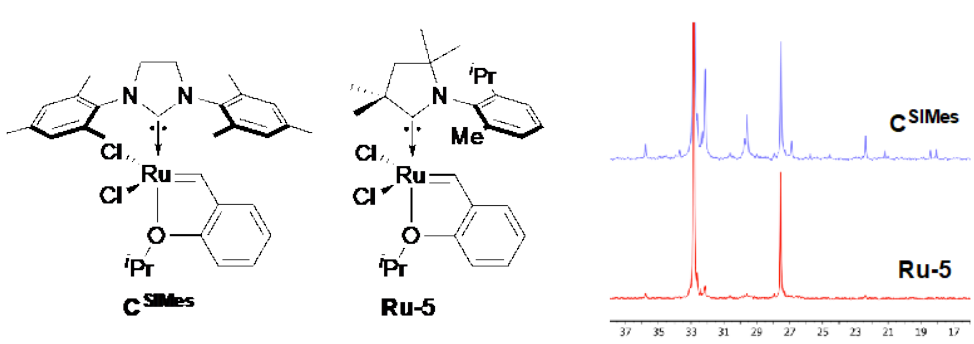

Scheme 72 ADMET of 1,5 -hexadiene illustrating the selectivity of Ru-5 versus $C^{\text {SIMes }}$. 
Capitalizing on these results Wagener and coworkers extended the study to the bulk polymerization of 1-9 decadiene 67 and bis(pent-4-en-1-yl)sulfone 69 (Scheme 73). ${ }^{80}$ While excellent polycondensation results were obtained in both cases, the authors demonstrated the stability of CAAC ruthenium catalyst Ru-3 up to $175^{\circ} \mathrm{C}$, with a slight loss of reactivity at 200 ${ }^{\circ} \mathrm{C}$. While this later result is presumably due to slow catalyst degradation, it clearly shows that CAAC complexes can retain their activities despite the very high working temperatures necessary to maintain liquid state in high crystallinity polymers.

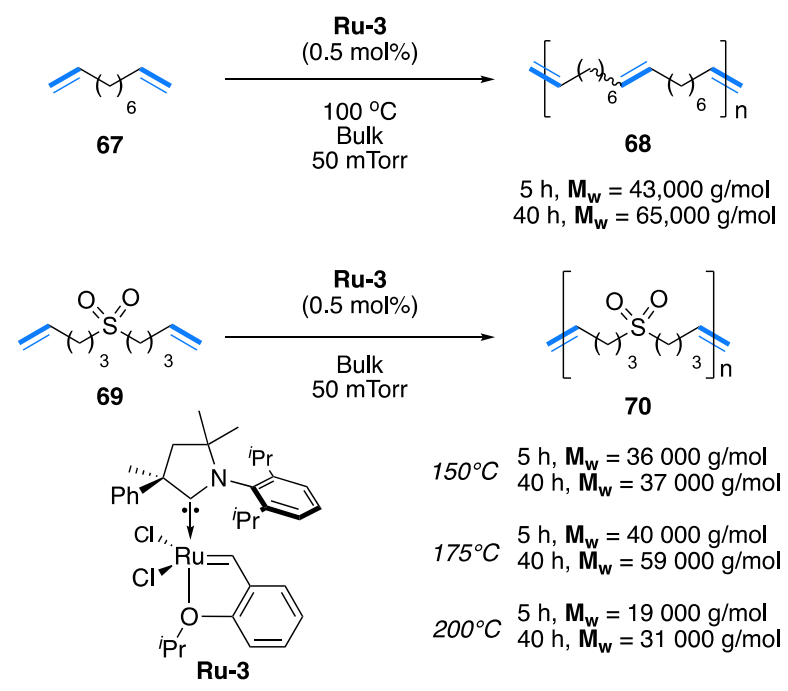

Scheme 73 Ru-3 catalyzed Bulk Acyclic Diene Metathesis Polycondensation

More recently, Tuba and coworkers have shown that ADMET polymerization of heptadiene4-ol 71 could be achieved under protic conditions using the very polar CAAC ruthenium Hoveyda-Grubbs Ru-23 and the bis(CAAC)Ru indenylidene Ru-45 (Scheme 74). ${ }^{36}$ Note that polymer 55 was obtained selectively by ROMP of cyclopent-3-en-1-ol 54 (Scheme 68). 


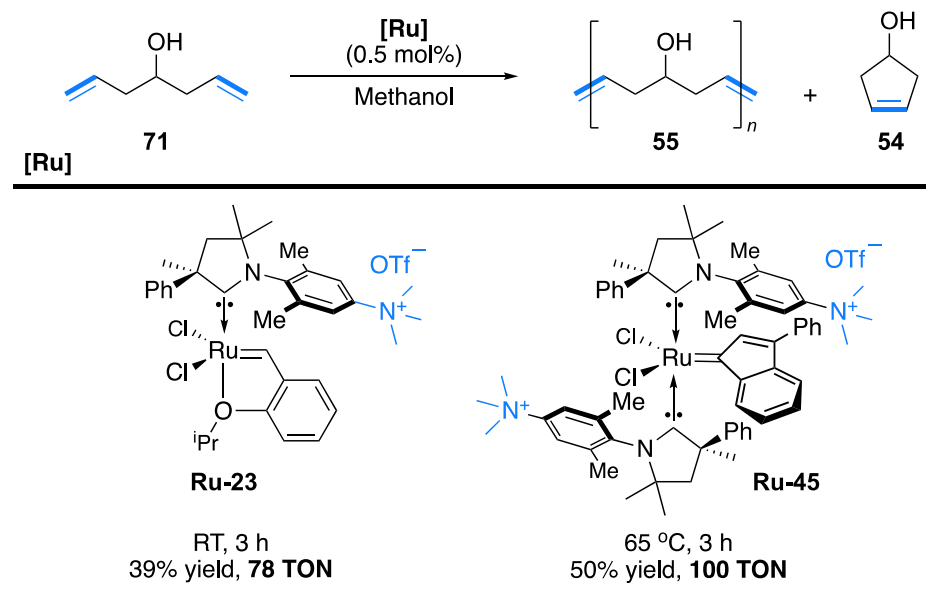

Scheme 74 ADMET of heptadiene-4-ol 71 using polar ammonium tagged CAAC-based catalysts.

\subsection{Application to En-Yne Metathesis}

The en-yne metathesis is a fundamental chemical transformation involving an alkene and an alkyne to generate a diene. ${ }^{130,131}$ Skowerski and coworkers were the first to show that the reactivity of CAACs ruthenium catalysts extends to the intramolecular Ring-Closing En-Yne Metathesis $\left(\mathrm{RCEYM}{ }^{132}\right) .{ }^{52}$ In the presence of $250 \mathrm{ppm}$ of the bis(CAAC)Ru indenylidene complex Ru-43, up to 3160 TONs of 1,3-diene $\mathbf{7 3}$ were obtained starting from en-yne $\mathbf{7 2}$ (Scheme 75). Contrasting with other catalysts, such as Cazin's ruthenium phosphite indenylidene $\mathbf{L}(907 \mathrm{TON})^{133}$ or benzylidene-oxazinone catalysts $\mathbf{M}(1,266 \mathrm{TON}),{ }^{134}$ these results prompt further investigations on the use of (CAAC)Ru catalysts in en-yne metathesis.
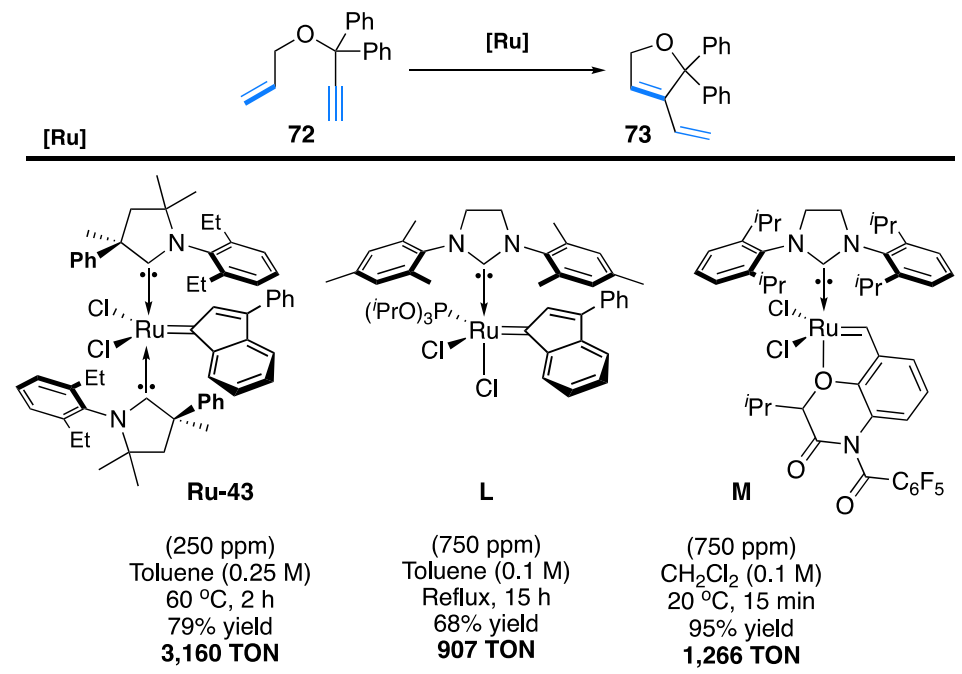

Scheme 75 Comparing the activities of carbene-Ru catalysts in Ring-Closing En-Yne Metathesis 


\subsection{Activity in Degenerate (Nonproductive) Metathesis}

As mentioned previously, CAAC-Ru-complexes have largely outperformed their diaminoNHC counterparts in ethenolysis by remaining highly active at extremely low catalyst loadings (as low as $1 \mathrm{ppm}$ ), thus affording the highest TONs reported so far. To explain these remarkable catalytic performance, Grubbs and coworkers compared several catalysts in non-productive (i.e. degenerative) metathesis events occurring during RCM. ${ }^{135}$ Investigating the RCM of deuterated diethyl diallyl malonate 25-d2 (Scheme 76-A), they showed that Ru-9 and Hoveyda-type NHC ruthenium complexes $\mathbf{C}^{\text {SIPrMe }}$ and $\mathbf{C}^{\text {SIPrEt }}$ displayed almost equal amounts of degenerative vs productive metathesis events (1:1), whereas bulkier $\mathbf{C}^{\text {SIMes }}$ or $\mathbf{C}^{\text {SITol }}$ complexes gave a 1:10 ratio (not shown). These contrasting behaviors were also confirmed during the RCM of deuterated dimethyl allylmethallyl malonate 27-d8 (Scheme 76-B), in which a higher amount of non-productive cross metathesis was observed with $\mathbf{R u - 9 ,} \mathbf{C}^{\text {SIPrMe }}$ and $\mathbf{C}^{\text {SIPrEt}}$. To explain these results, the authors proposed that steric interactions in catalysts bearing unsymmetrical carbene ligands (i.e. $\mathbf{R u - 9}, \mathbf{C}^{\text {SIPrMe }}, \mathbf{C}^{\text {SIPrEt}}$ ) could favor the formation of the less sterically hindered $\beta$-substituted metallacycle (Path b) over the more productive $\alpha$ substituted metallacycle (Path a) (Scheme 76-C). 


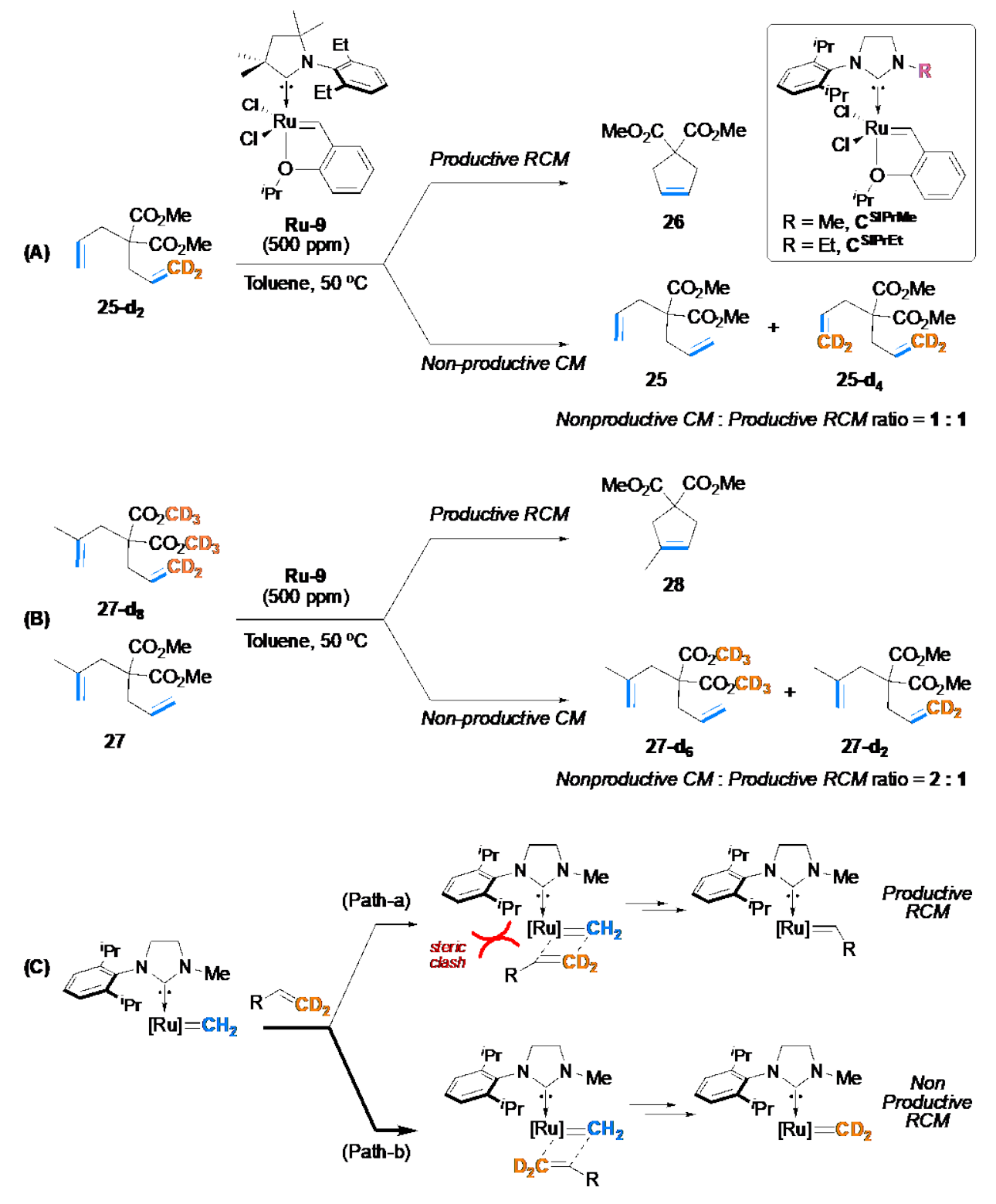

Scheme 76 Nonproductive events in RCM using CAAC catalysts

Later, the same authors reported the clean formation of CAAC-based ruthenacyclobutanes Ru67,68 resulting from the reaction of Piers catalysts Ru-65,66 with an excess of ethylene (Scheme 77). ${ }^{68}$ Unexpectedly, relatively low exchange rate of $\alpha$ and $\beta$ methylene protons in ethylene ruthenacycles was found for Ru-67,68 compared to their NHC variant $\mathbf{O}$. Moreover, substituting DEP at nitrogen with DIPP resulted in a remarkable 2.6-fold increase in the exchange rate, suggesting that subtle changes in ligand architecture is sufficient to alter the reactivity and the selectivity of CAAC catalysts. As pointed by the authors, the relatively low exchange rate observed with Ru-67 suggests that CAAC derived metathesis-relevant 
ruthenacycles may be viable targets for crystallographic characterization. Additionally, the reaction of Piers catalysts Ru-65,66 with cyclopentene $\mathbf{2 6}$ in the presence of one equivalent of ethylene did not lead to the expected substituted ruthenacycle Ru-79,80 (as observed with NHC congeners), ${ }^{68}$ but to the ethylene ruthenacycles Ru-67,68. The authors noted that this peculiarity, although surprising, could be related to the preferential ability of CAAC-catalysts to propagate as methylidene species in metathesis reactions.

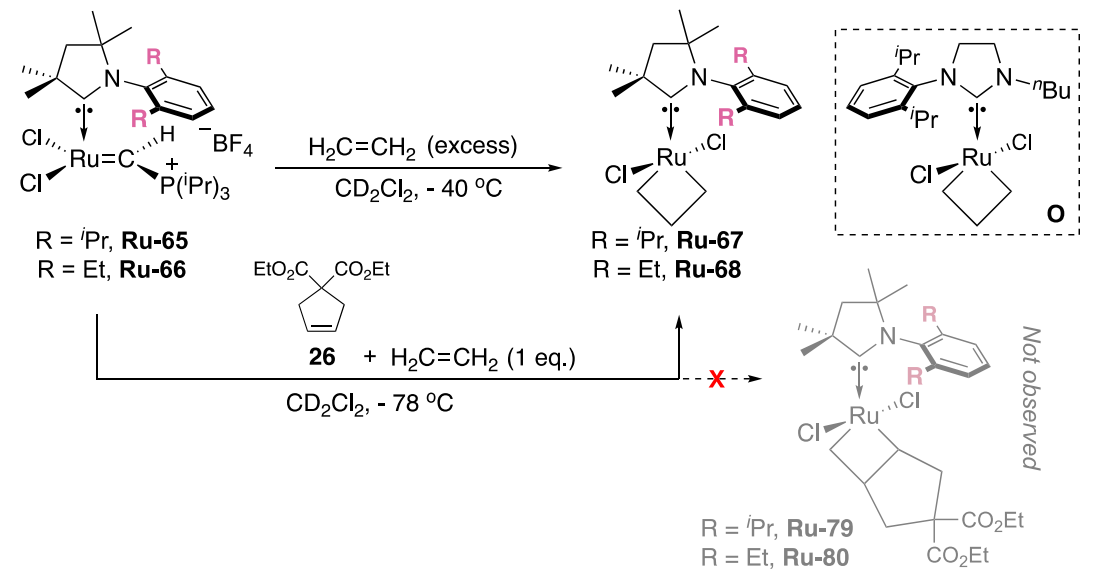

Scheme 77 Probing the origin of degenerate metathesis for CAAC-based Ru complexes via the generation of ethylene ruthenacycles

\section{Conclusions and Future Directions}

Since stable $N$-heterocyclic carbenes were discovered in 1991, whereas CAACs were only isolated in 2005, it is not surprising that NHCs are dominant ligands in many transition metal catalyzed reactions. However, the advent of CAACs in olefin metathesis has resulted in numerous achievements and breakthroughs, including in industry, as illustrated by the number of patents. Compared to NHCs, they reveal enhanced metathesis performances in several reactions, in particular in ethenolysis processes (up to of 390,000 TON). In a recent study, Fogg and Nascimoto noted that such a breakthrough can likely be attributed to the remarkable stability of CAAC-ruthenacycles toward $\beta$-elimination, and CAAC-ruthenium-methylidenes toward bimolecular decomposition at extremely low catalyst loading. ${ }^{136}$ As illustrated by the diversity of complexes obtained so far ( $>70)$, with some of them already prepared industrially, 
the high structural modularity of the CAAC framework is particularly attractive for olefin metathesis applications. Undoubtedly, we expect the number CAAC-ruthenium catalysts and their ensuing applications to increase significantly with other motifs such as the 6-membered CAAC- $6 s^{28}$, the bicylic BiCAACs ${ }^{27}$, the multifunctional FunCAACs ${ }^{22,137}$, and their chiral variant ChiCAACs ${ }^{22,75}$, which have recently been used in asymmetric olefin metathesis. Thanks to the stability of CAAC ruthenium complexes, we are confident that they will prove invaluable for the solid-state characterization of metathesis-relevant ruthenacycles (achiral and chiral) ${ }^{68}$ For the same reason, it can be expected that their enantioselective version might shine as air-stable Z-selective $\mathrm{e}^{138,139}$ and stereoretentive ${ }^{140}$ catalysts. Finally, much remain to be done in their development as new thermo- and photo-switchable latent catalysts for a highlycontrolled polymerization, ${ }^{141142}$ a growing area of research interest.

\section{AUTHOR INFORMATION}

\section{Corresponding Authors}

*Marc Mauduit: marc.mauduit@ensc-rennes.fr;

*Rodolphe Jazzar: rjazzar@ucsd.edu;

*Guy Bertrand: gbertrand@ucsd.edu

\section{ACKNOWLEGMENT}

This work was supported by the Region Bretagne [ARED 2018 “Biometa” N 601, grant 275 (J.M.)], the Agence Nationale de la Recherche [ANR-19- 276 CE07-0017 ChiCAAC (R.J. and M.M.)], and the U.S. Department of Energy, Office of Science, Basic Energy 278 Sciences, Catalysis Science Program, under Award DE- 279 SC0009376 (G.B.). 


\section{References}

1 Igau, A.; Grutzmacher, H.; Baceiredo, A.; and Bertrand, G. Analogous $\square$, $\square$ '-bis-carbenoid, triply bonded species: synthesis of a stable $\square^{3}$-phosphino carbene- $\square \square^{5}$-phosphaacetylene J. Am. Chem. Soc. 1988, 110, $6463-6466$.

2 A.J.; Harlow, R.L.; Kline, M. A stable crystalline carbene. J. Am. Chem. Soc. 1991, 113, 361 - 363.

3 Brown, T. L.; Lee, K. L. Ligand steric properties. Coord. Chem. Rev. 1993, 128, 89 - 116.

4 Scholl, M.; Trnka, T. M.; Morgan, J. P.; Grubbs, R.H. Increased ring closing metathesis activity of ruthenium-based olefin metathesis catalysts coordinated with imidazolin-2-ylidene ligands. Tetrahedron Lett. 1999, 40, 2247 - 2250.

5 Vougioukalakis, G. C.; Grubbs, R. H. Ruthenium-based heterocyclic carbene-coordinated olefin metathesis catalysts, Chem. Rev. 2010, 110, 1746 - 1787.

6 Samojłowicz, C.; Bieniek, M.; Grela, K. Ruthenium-based olefin metathesis catalysts bearing Nheterocyclic carbene ligands, Chem. Rev. 2009, 109, 3708 - 3742.

$7 \quad$ Zhu, D.; Chen, L.; Fan, L.; Yao, Q.; Zhu, S. Recent progress on donor and donor-donor carbenes. Chem. Soc. Rev., 2020, 49, 908 - 950.

8 Gonzalez, S. D.; Marion, N.; Nolan, S. P. N-Heterocyclic Carbenes in Late Transition Metal Catalysis. Chem. Rev. 2009, 109, 3612 - 3676.

9 Nolan, S.P.; Clavier, H. Chemoselective olefin metathesis transformations mediated by ruthe- nium complexes. Chem. Soc. Rev. 2010, 39, 3305 - 3316.

10 Ogba, O. M.; Warner, N. C.; O’Leary, D. J.; Grubbs, R. H. Recent advances in ruthenium-based olefin metathesis. Chem. Soc. Rev. 2018, 47, 4510 - 4544.

11 Scholl, M.; Ding, S.; Lee, C. W.; Grubbs, R. H. Synthesis of Trisubstituted Alkenes via Olefin Cross metathesis. Org. Lett. 1999, 1, 953 - 956.

12 Garber, S. B.; Kingsbury, J. S.; Gray, B. L; Hoveyda, A. H. Efficient and Recyclable Monomeric and Dendritic Ru-Based Metathesis Catalysts. J. Am. Chem. Soc. 2000, 122, 8168-8179.

13 Bidange, J.; Fischmeister, C.; Bruneau, C. Ethenolysis: A Green Catalytic Tool to Cleave CarbonCarbon Double Bonds. Chem. Eur. J. 2016, 22, 12226 - 12244.

14 Weinberger, D. S.; Lavallo, V. Ruthenium olefin metathesis catalysts supported by cyclic alkyl amino carbenes (CAACs) in Handbook of Metathesis Vol. 1, 2nd ed.; Grubbs, R. H.; Wenzel, A. G. Eds.; Wiley-VCH: Weinheim, 2015; pp 87-96.

15 Spekreijse, J.; Sanders, J. P. M.; Bitter, J. H.; Scott, E. L. The future of ethenolysis in biobased chemistry. ChemSusChem 2017, 10, 470 - 482. 
16 Paul, U. S. D.; Radius, U. What Wanzlick did not dare to dream: Cyclic (alkyl)(amino)carbenes (CAACs) as new key players in transition metal chemistry. Eur. J. Inorg. Chem. 2017, 3362 - 3375.

17 Melaimi, M.; Jazzar, R.; Soleilhavoup, M.; Bertrand, G. "Cyclic(Alkyl)(amino)carbenes (CAACs): Recent Developments. Angew. Chem. Int. Ed. 2017, 56, 10056 - 10061.

18 Detailed analyses have already been reported in the following reviews: a) Melaimi, M.; Soleilhavoup, M.; Bertrand, G. Stable Cyclic Carbenes and Related Species beyond Diaminocarbenes. Angew. Chem., Int. Ed. 2010, 49, 8810-8849. b) Soleilhavoup, M.; Bertrand, G. Cyclic (Alkyl)(Amino)Carbenes (CAACs): Stable Carbenes on the Rise. Acc. Chem. Res. 2015, 48, 256266. c) Roy, S.; Mondal, K. C.; Roesky, H. W. Cyclic Alkyl(amino) Carbene Stabilized Complexes with Low Coordinate Metals of Enduring Nature. Acc. Chem. Res. 2016, 49, 357 - 369. d) Kundu, S.; Sinhababu, S.; Chandrasekhar, V.; Roesky, H. W. Stable Cyclic (Alkyl)(Amino)Carbene (CAAC) Radicals with Main Group Substituents. Chem. Sci. 2019, 10, 4727-4741. e) Jazzar, R.; Soleilhavoup, M.; Bertrand, G. Cyclic (alkyl)- and (aryl)-(amino)carbene coinage metal complexes and their applications. Chem. Rev. 2020, 120, $4141-4168$.

19 Lavallo, V.; Canac, Y.; Donnadieu, B.; Schoeller, W. W.; Bertrand, G. CO fixation to stable acyclic and cyclic alkyl amino carbenes: Stable amino ketenes with a small HOMO-LUMO gap. Angew. Chem. Int. Ed. 2006, 45, 3488-3491.

20 Back, O.; Henry-Ellinger, M.; Martin, C. D.; Martin, D.; Bertrand, G., ${ }^{31}$ P NMR Chemical Shifts of Carbene-Phosphinidene Adducts as an Indicator of the $\pi$-Accepting Properties of Carbenes. Angew. Chem. Int. Ed. 2013, 52, 2939-2943.

21 Liske, A.; Verlinden, K.; Buhl, H.; Schaper, K.; Ganter, C., Determining the $\pi$-Acceptor Properties of N-Heterocyclic Carbenes by Measuring the ${ }^{77}$ Se NMR Chemical Shifts of Their Selenium Adducts. Organometallics 2013, 32, 5269-5272.

22 Pichon, D.; Soleilhavoup, M.; Morvan, J.; Junor, G. P.;Vives, T.; Crévisy, C.; Lavallo, V.; Campagne, J.-M.; Mauduit, M.; Jazzar, R.; Bertrand, G. The Debut of Chiral Cyclic (Alkyl)(amino)carbenes (CAACs) in Enantioselective Catalysis. Chem. Sci. 2019, 10, 7807 - 7811.

23 Lavallo, V.; Canac, Y.; Präsang, C.; Donnadieu, B.; Bertrand, G. Stable cyclic (alkyl)(amino)carbenes as rigid or flexible, bulky, electron-rich ligands for transition-metal catalysts: a quaternary carbon atom makes the difference. Angew. Chem. Int. Ed. 2005, 44, 5705 - 5709.

24 Mandal, D.; Dolai, R.; Kumar, R.; Suhr, S.; Chrysochos, N.; Kalita, P.; Narayanan, R. S.; Rajaraman, G.; Schulzke, C.; Sarkar, B.; Chandrasekhar, V.; Jana, A. Influence of N-Substitution on the Formation and Oxidation of NHC-CAAC-Derived Triazaalkenes. J. Org. Chem. 2019, 84, 8899 8909. 
25 Jazzar, R.; Dewhurst, R.D.; Bourg, J.-B.; Donnadieu, B.; Canac, Y.; Bertrand, G. Intramolecular "hydroiminiumation" of alkenes: application to the synthesis of conjugate acids of cyclic alkyl amino carbenes (CAACs). Angew. Chem. Int. Ed. 2007, 46, 2899 - 2902.

26 Jazzar, R.; Bourg, J.-B.; Dewhurst, R.D.; Donnadieu, B.; Bertrand, G. Intramolecular "Hydroiminiumation and -amidiniumation" of Alkenes: A Convenient, Flexible, and Scalable Route to Cyclic Iminium and Imidazolinium Salts. J. Org. Chem. 2007, 72, 3492 - 3499.

27 Tomás-Mendivil, E.; Hansmann, M. M.; Weinstein, C.; Jazzar, R.; Melaimi, M.; Bertrand, G. Bicyclic (alkyl)(amino)carbenes (Bi- CAACs): stable carbenes more ambiphilic than CAACs. J. Am. Chem. Soc. 2017, 139, 7753-7756.

28 Weinstein, C. M.; Junor, G. P.; Tolentino, D.; Jazzar, R.; Melaimi, M.; Bertrand, G. J. Am.Chem. Soc. 2018, 140,9255 - 9260.

29 Bantreil, X.; Nolan, S. P. Synthesis of N-heterocyclic carbene ligands and derived ruthenium olefin metathesis catalysts. Nature Protocols 2011, 6, 69 - 77.

30 Kingsbury, J. S.; Harrity, J. P. A.; Bonitatebus Jr., P. J., Hoveyda, A. H. A Recyclable Ru-Based Metathesis Catalyst. J. Am. Chem. Soc. 1999, 121, $791-799$.

31 Marx, V. M.; Sullivan, A. H.; Melaimi, M.; Virgil, S. C.; Keitz, B. K.; Weinberger, D. S.; Bertrand, G.; Grubbs, R. H. Cyclic Alkyl Amino Carbene (CAAC) Ruthenium Complexes as Remarkably Active Catalysts for Ethenolysis. Angew. Chem., Int. Ed. 2015, 54, 1919 - 1923.

32 Anderson, D. R.; Lavallo, V.; O’Leary, D. J.; Bertrand, G.; Grubbs, R. H. Synthesis and reactivity of olefin metathesis catalysts bearing cyclic (alkyl)(amino)carbenes. Angew. Chem. Int. Ed. 2007, 46, $7262-7265$.

33 Anderson, D. R.; Ung, T.; Mkrtumyan, G.; Bertrand, G.; Grubbs, R. H.; Schrodi, Y. Kinetic Selectivity of Olefin Metathesis Catalysts Bearing Cyclic (Alkyl)(Amino)Carbenes. Organometallics 2008, 27, $563-566$.

34 Turner, Z. R. Chemically Non-Innocent Cyclic (Alkyl)(Amino)Carbenes: Ligand Rearrangement, C-H and C-F Bond Activation. Chem. Eur. J. 2016, 22, $11461-11468$

35 Zhang, J.; Song, S.; Wang, X., Jiaoa, J. Shi, M. Ruthenium-catalyzed olefin metathesis accelerated by the steric effect of the backbone substituent in cyclic (alkyl)(amino) carbenes. Chem. Commun., 2013, 49, $9491-9493$

36 Nagyházi, M.; Turczel, G.; Balla, A.; Szálas, G.;Tóth, I.; Gál, G. T.; Petra, B.; Anastas, P. T.; Tuba, R. Towards Sustainable Catalysis - Highly Efficient Olefin Metathesis in Protic Media Using Phase Labelled Cyclic Alkyl Amino Carbene (CAAC) Ruthenium Catalysts. ChemCatChem 2020, 12, 1953-1957. 
37 Patent: Citadelle, C.; Berthod, M.; Olivier Bourbigou, H.; Vallée, C. Procédé de préparation d’une composition catalytique pour la métathèse de corps gras insaturés. FR 2,947,189 A1, June 29, 2009.

38 Michrowska, A.; Mennecke, K.; Kunz, U.; Kirschning, A. ; Grela, K. A New Concept for the Noncovalent Binding of a Ruthenium-Based Olefin Metathesis Catalyst to Polymeric Phases: Preparation of a Catalyst on Raschig Rings. J. Am. Chem. Soc. 2006, 128, 13261-13267.

39 Patent: Verpoort, F. W. C.; Group 8 tansition metal catalysts and method for making same and process for use of same in olefin disproportionation reactions. WO 2017/185324 A1, November 2, 2017.

40 Samkian, A. E.; Xu, Y.; Virgil, S. C.; Yoon, K.-Y.; Grubbs, R. H. Synthesis and Activity of SixMembered Cyclic Alkyl Amino Carbene-Ruthenium Olefin Metathesis Catalysts. Organometallics. 2020, 39, $495-499$.

41 For an overview of problems associated with in-situ generation of NHC from imidazolinium salts, see: Nascimento, D. L.; Davy, E. C.; Fogg, D. E. Merrifield resin-assisted routes to second-generation catalysts for olefin metathesis. Catal. Sci. Technol. 2018, 8, 1535 - 1544.

42 Sauvage, X.; Demonceau, A.; Delaude, L. Imidazol(in)ium-2-carboxylates as N-Heterocyclic Carbene Precursors for the Synthesis of Second Generation Ruthenium Metathesis Catalysts. Adv. Synth. Catal. 2009, 351, 2031 - 2038.

43 Trnka, T. M.; Morgan, J. P.; Sanford, M. S.; Wilhelm, T. E.; Scholl, M.; Choi, T.-L.; Ding, S.; Day, M. W.; Grubbs, R. H. Synthesis and Activity of Ruthenium Alkylidene Complexes Coordinated with Phosphine and N-Heterocyclic Carbene Ligands. J. Am. Chem. Soc. 2003, 125, 2546 - 2558.

44 Blum, A. P.; Ritter, T.; Grubbs, R. H. Synthesis of N-Heterocylic Carbene-Containing Metal Complexes from 2-(Pentafluorophenyl)imidazolidines. Organometallics 2007, 26, 2122 - 2124.

45 Jolly, P. I.; Marczyk, A.; Małecki, P.; Ablialimov, O.; Trzybiński, D.; Woźniak, K.; Osella, S.; Trzaskowski, B.; Grela, K. Azoliniums, Adducts, NHCs and Azomethine Ylides: Divergence in Wanzlick Equilibrium and Olefin Metathesis Catalyst Formation. Chem. Eur. J. 2018, 24, 4785 4789.

46 Mukherjee, N.; Marczyk, A.; Szczepaniak, G.; Sytniczuk, A.; Kajetanowicz, A.; Grela, K. A Gentler Touch: Synthesis of Modern Ruthenium Olefin Metathesis Catalysts Sustained by Mechanical Force. ChemCatChem. 2019, 11, 5362 - 5369.

47 Rozenberg, I.; Eivgi, O.; Frenklah, A.; Butilkov, D.; Kozuch, S.; Goldberg, I.; Lemcoff, N. G.. Synthesis and Catalytic Properties of Sulfur-Chelated Ruthenium Benzylidenes Bearing a Cyclic (Alkyl)(amino)carbene Ligand. ACS Catal. 2018, 8, 8182 - 8191.

48 Schanz, H.-J.; Jafarpour, L.; Stevens, E. D.; Nolan, S. P. Coordinatively Unsaturated 16-Electron Ruthenium Allenylidene Complexes: Synthetic, Structural, and Catalytic Studies. Organometallics 1999, 18, $5187-5190$ 
49 Dixneuf, H. P.; Bruneau, C. Ruthenium Indenylidene Catalysts for Alkene Metathesis in Handbook of Metathesis; 2nd ed.; Grubbs, R. H.; Wenzel, A. G. Eds.; Wiley-VCH: Weinheim, 2015; pp 389416.

50 Jafarpour, L.; Schanz, H.-J.; Stevens, E. D.; Nolan, S. P. Indenylidene-Imidazolylidene Complexes of Ruthenium as Ring- Closing Metathesis Catalysts. Organometallics 1999, 18, 5416 - 5419.

51 Mixed bis-carbenes have been obtained sequentially, for an example see: Keitz, B, K.; Bouffard, J.; Bertrand, G.; Grubbs, R. H. Protonolysis of a Ruthenium-Carbene Bond and Applications in Olefin Metathesis. J. Am. Chem. Soc. 2011, 133, 8498-8501.

52 Gawin, R. Kozakiewicz, A.; Gun'ka, P. A.; Da browski, P.; Skowerski, K. Bis(Cyclic Alkyl Amino Carbene) Ruthenium Complexes: AVersatile, Highly Efficient Tool for Olefin Metathesis. Angew. Chem. Int. Ed. 2017, 56, 981 - 986.

53 Note that Ru-43 is commercialized by Apeiron Synthesis as UltraCat under the CAS number: 2055540-61-7.

54 Weskamp, T.; Schattenmann, W. C.; Spiegler, M.; Herrmann, W. A. A Novel Class of Ruthenium Catalysts for Olefin Metathesis. Angew. Chem., Int. Ed. 1998, 37, 2490-2493.

55 Kamal, F.; Colombel-Rouen, S.; Dumas, A.; Guégan, J.-P.; Roisnel, T.; Dorcet, V.; Baslé, O.; Rouen, S.; Mauduit, M. Activation of olefin metathesis complexes containing unsymmetrical unsaturated Nheterocyclic carbenes by copper and gold transmetalation. Chem. Commun. 2019, 55, 11583-11586.

56 Grela, K.; Harutyunyan, S.; Michrowska, A. A Highly Efficient Ruthenium Catalyst for Metathesis Reactions. Angew. Chem. Int. Ed. 2002, 41, 4038-4040.

57 Gawin, R.; Tracz, A.; Chwalba, M.; Kozakiewicz, A.; Trzaskowski, B.; Skowerski, K. Cyclic Alkyl Amino Ruthenium Complexes Efficient Catalysts for Macrocyclization and Acrylonitrile Cross Metathesis. ACS Catal. 2017, 7, 5443 - 5449.

58 Note that Ru-50 is commercialized by Apeiron Synthesis as UltraNitroCat under the CAS number: 2106819-64-9.

59 Patent: Skowerski, K.; Rafal, G. Process for producing ruthenium complexes and intermediates thereof and their use in olefin metathesis. WO 2017/055945 A1, April 6, 2017

60 Endo, K.; Grubbs, R. H. Chelated Ruthenium Catalysts for Z-Selective Olefin Metathesis. J. Am. Chem. Soc., 2011, 133, 8525 - 8527.

61 Khan, R. K. M.; O'Brien, R. V.; Torker, S.; Li, B.; Hoveyda, A. H. Z- and Enantioselective RingOpening/Cross metathesis with Enol Ethers Catalyzed by Stereogenic-at-Ru Carbenes: Reactivity, Selectivity, and Curtin-Hammett Kinetics. J. Am. Chem. Soc. 2012, 134, 12774 - 12779.

62 Bronner, S. M.; Herbert, M. B.; Patel, P. R.; Marx, V. M.; Grubbs, R. H. Ru-based Z-selective metathesis catalysts with modified cyclometalated carbene ligands. Chem. Sci. 2014, 5, 4091 - 4098. 
63 Hartung, J.; Grubbs, R. H. Highly Z-Selective and Enantioselective Ring-Opening/Cross metathesis Catalyzed by a Resolved Stereogenic-at-Ru Complex. J. Am. Chem. Soc. 2013, 135, 10183 - 10185.

64 Manzini, S.; Poater, A.; Nelson, D.J.; Cavallo, L.; Slawin, A.M.Z.; Nolan, S.P. Insights into the Decomposition of Olefin Metathesis Precatalysts. Angew. Chem. Int. Ed. 2014, 53, 8995 - 8999.

65 For a recent review on the topic. Jawiczuk, M.; Marczyk, A.; Trzaskowski, B. Decomposition of Ruthenium Olefin Metathesis Catalyst. Catalysts, 2020, 10, 887.

66 Integrating Activity with Accessibility in Olefin Metathesis: An Unprecedentedly Reactive Ruthenium-Indenylidene Catalyst DanielL. Nascimento, AnnaGawin, Rafał Gawin, Piotr A.Gunḱa, Janusz Zachara, Krzysztof Skowerski, and Deryn E. Fogg. J. Am. Chem. Soc. 2019, 141, 10626 10631

67 Weskamp, T.; Kohl, F. J.; Hieringer, W.; Gleich, D.; Herrmann, W. A. Highly Active Ruthenium Catalysts for Olefin Metathesis: The Synergy of N-Heterocyclic Carbenes and Coordinatively Labile Ligands. Angew. Chem., Int. Ed. 1999, 38, 2416 - 2419.

68 Keitz, B. K.; Grubbs, R. H. Probing the Origin of Degenerate Metathesis Selectivity via Characterization and Dynamics of Ruthenacyclobutanes Containing Variable NHCs. J. Am. Chem. Soc. 2011, 133, 16277-16284

69 Romero, P. E.; Piers, W. E.; McDonald, R. Rapidly Initiating Ruthenium Olefin-Metathesis Catalysts. Angew. Chem., Int. Ed. 2004, 43, 6161-6165.

70 Nascimento; D. L.; Fogg, D. E. Origin of the Breakthrough Productivity of Ruthenium-Cyclic Alkyl Amino Carbene Catalysts in Olefin Metathesis. J. Am. Chem. Soc. 2019, 141, 19236-19240

71 Wang, F.; Liu, L.-J.; Wang, W.; Li, S.; Shi, M. Chiral NHC-Metal-Based Asymmetric Catalysis. Coord. Chem. Rev. 2012, 256, 804-853.

72 Janssen-Müller, D.; Schlepphorst, C.; Glorius, F. Privileged Chiral N-Heterocyclic Carbene Ligands for Asymmetric Transition-Metal Catalysis. Chem. Soc. Rev., 2017, 46, 4845-4854.

73 Selected book chapter on Ru-AOM, see: Stenne, B.; Collins, S. K. Enantioselective Olefin Metathesis in Olefin Metathesis: Theory and Pratice; Grela, K. Ed; Wiley-VCH: Weinheim, 2014; pp 233-267.

74 Okamoto, Y.; Ikai, T. Chiral HPLC for efficient resolution of enantiomers. Chem. Soc. Rev. 2008, 37, 2593-2608.

75 Morvan, J.; Vermersch, F.; Zhang, Z.; Falivene, L.; Vives, T.; Dorcet, V.; Roisnel, T.; Crévisy, C.; Cavallo, L.; Vanthuyne, N.; Bertrand, G.; Jazzar, R.; Mauduit, M. Optically Pure C1-Symmetric Cyclic(alkyl)(amino)carbene (CAAC) Ruthenium-Complexes for Asymmetric Olefin Metathesis. $J$. Am. Chem. Soc. 2020, 142, 19895-19901. 
76 Michrowska, A.; Bujok, R.; Harutyunyan, S.; Sashuk, V.; Dolgonos, G.; Grela, K. Nitro-Substituted Hoveyda-Grubbs Ruthenium Carbenes: En- hancement of Catalyst Activity through Electronic Activation. J. Am. Chem. Soc. 2004, 126, 9318-9325.

77 Dinger, M. B.; Mol, J. C. High Turnover Numbers with Ruthenium-Based Metathesis Catalysts. Adv. Synth. Catal. 2002, 344, 671-677.

78 Chatterjee, A. K.; Choi, T.-L.; Sanders, D. P.; Grubbs, R. H. A General Model for Selectivity in Olefin Cross Metathesis. J. Am. Chem. Soc. 2003, 125, 11360-11370.

79 Butilkov, D.; Frenklah, A.; Rozenberg, I.; Kozuch, S.; Lemcoff, N. G. Highly Selective Olefin Metathesis with CAAC-Containing Ruthenium Benzylidenes. ACS Catal. 2017, 7, 7634-7637

80 Bell, M.; Hester, H. G.; Gallman, A. N.; Gomez, V.; Pribyl, J.; Rojas, G.; Riegger, A.; Weil, T.; Watanabe, H.; Chujo, Y; Wagener, K. B. Bulk Acyclic Diene Metathesis Polycondensation. Macromol. Chem. Phys. 2019, 220, 1900223.

81 Grubbs, R. H. Handbook of Metathesis; Wiley-VCH: Weinheim, 2003.

82 Montgomery, T. P.; Ahmed, T. S.; Grubbs, R. H. Stereoretentive Olefin Metathesis: An Avenue to Kinetic Selectivity. Angew. Chem. Int. Ed. 2017, 56, 11024 - 11036

83 Hulatt, C. J.; Berecz, O.; Egeland, E. S.; Wijffels, R. H.; Kiron, V. Polar snow algae as a valuable source of lipids? Bioresour. Technol. 2017, 235, 338-347.

84 Hess, S. K.; Lepetit, B.; Kroth, P. G.; Stefan, M. Production of chemicals from microalgae lipids status and perspectives. Eur. J. Lipid Sci. Technol. 2018, 120, 1700152.

85 McClennan, W. L.; Rufh, S. A.; Lummiss, J. A. M.; Fogg, D. E. A General Decomposition Pathway for Phosphine-Stabilized Metathesis Catalysts: Lewis Donors Accelerate Methylidene Abstraction. $J$. Am. Chem. Soc. 2016, 138, 14668-14677.

86 Malacea, R.; Fischmeister, C.; Bruneau, C.; Dubois, J.-L.; Couturier, J.-L.; Dixneuf, P. H. Renewable materials as precursors of linear nitrile-acid derivatives viacross metathesis of fatty esters and acids with acrylonitrile and fumaronitrile. Green Chem. 2009, 11, 152-155.

87 Bidange, J.; Fischmeister, C.; Bruneau, C.; Dubois, J.-L.; Couturier, J.-L. Ruthenium-Benzylidenes and Ruthenium-Indenylidenes as Efficient Catalysts for the Hydrogenation of Aliphatic Nitriles into Primary Amines. Monatsh. Chem. 2015, 146, 1107-1113.

88 Patent: Dubois, J.-L.; Couturier, J.-L. Cross metathesis process. U.S. Patent 9,512,051 B2, December 6, 2015.

89 Jawiczuk, M; Młodzikowska-Pienḱo, K.; Osella, S.; Trzaskowski, B. Molecular Modeling of Mechanisms of Decomposition of Ruthenium Metathesis Catalysts by Acrylonitrile. Organometallics 2020, 39, 239-246. 
90 Patent: Skowerski, K.; Gawin, R. Chwalba, M. P. Use of ruthenium complexes in olefin metathesis reaction. WO 2018/087678 A1, May, 17, 2018.

91 Prunet, J.; Grimaud, L. Cross metathesis in Natural Products Synthesis in Metathesis in Natural Product Synthesis: Strategies, Substrates, and Catalysts; Cossy, J., Arseniyadis, S., Meyer, C., Eds; Wiley-VCH: Weinheim, Germany, 2010.

92 Bailey, G. A.; Fogg, D. E. Acrylate Metathesis via the Second-Generation Grubbs Catalyst: Unexpected Pathways Enabled by a PСуз-Generated Enolate. J. Am. Chem. Soc. 2015, 137, 73187321

93 Santos, A. G.; Bailey, G. A.; dos Santos, E. N.; Fogg, D. E. Overcoming Catalyst Decomposition in Acrylate Metathesis: Polyphenol Resins as Enabling Agents for PCy3-Stabilized Metathesis Catalysts. ACS Catalysis, 2017, 7, 3181-3189

94 Kaczanowska, K.; Trzaskowski, B.; Peszczyńska, A.; Tracz, A.; Gawin, R.; Olszewski, T. K.; Skowerski, K. Cross metathesis with acrylates: N-heterocyclic carbene (NHC)- versus cyclic alkyl amino carbene (CAAC)-based ruthenium catalysts, an unanticipated influence of the carbene type on efficiency and selectivity of the reaction. ChemCatChem 2020, 12, 6366-6374.

95 Berlin, J. M.; Goldberg, S. D.; Grubbs, R. H. Highly Active Chiral Ruthenium Catalyst for Asymmetric Cross metathesis and Ring-Opening Cross metathesis. Angew. Chem. Int. Ed. 2006, 45, 7591-7595.

96 Z-selective ACM variant (35\% yield, 50\% ee) has been reported : Hartung, J.; Dornan, P. K.; Grubbs, R. H. Enantioselective Olefin Metathesis with Cyclometalated Ruthenium Complexes. J. Am. Chem. Soc. 2014, 136, 13029-13037.

97 Gułajski, Ł; Michrowska, A.; Bujok, R.; Grela, K. New tunable catalysts for olefin metathesis: Controlling the initiation through electronic factors. J. Mol. Catal. A: Chem. 2006, 254, 118-123

98 Ton, S. J.; Fogg, D. E. The Impact of Oxygen on Leading and Emerging Ru-Carbene Catalysts for Olefin Metathesis: An Unanticipated Correlation Between Robustness and Metathesis Activity. ACS Catal, 2019, 9, 11329-11334

99 Patent: Grela, K.; Czarnocka-Ka-Śniadała, S.; Sytniczuk, A.; Milewski, M.; Urban, M.; Banach, Ł.; Dabrrowski, M. Method of cyclic compounds production in olefine metathesis reaction and use of ruthenium catalysts in production of cyclic olefins in olefine metathesis reaction - WO 2018/197963 A1, November 01, 2018.

100 Sytniczuk, A.; Dabrowski, M.; Banach, Ł.; Urban, M.; Czarnocka-Ka-Śniadała, S.; Milewski, M.; Kajetanowicz, A.; Grela, K. J. Am. Chem. Soc. 2018, 140, 8895-8901. 
101 Breen, C. P.; Parrish, C.; Shangguan, N.; Majumdar, S.; Murnen, H.; Jamison, T. F.; Bio, M. M. A Scalable Membrane Pervaporation Approach for Continuous Flow Olefin Metathesis. Org. Process Res. Dev, 2020, 24, 2298-2303.

102 Forman, G. S.; McConnell, A. E.; Hanton, M. J.; Slawin, A. M. Z.; Tooze, R. P.; vanRensburg, W. J.; Meyer, W. H.; Dwyer, C.; Kirk, M. M.; Serfontein, D. W. A Stable Ruthenium Catalyst for Productive Olefin Metathesis. Organometallics 2004, 23, 4824- 4827.

103 Schrodi, Y.; Ung, T.; Vargas, A.; Mkrtumyan, G.; Lee, C. W.; Champagne, T. M.; Pederson R. L.; Hong, S. H. Ruthenium Olefin Metathesis Catalysts for the Ethenolysis of Renewable Feedstocks. Clean 2008, 36, 669-673

104 Park, C. P.; Van Wingerden, M. M.: Han, S.-Y.; Kim D.-P.; Grubbs, R. H. Low pressure ethenolysis of renewable methyl oleate in a microchemical system. Org. Lett. 2011, 13, 2398-2401

105 Patent: Mignani, G.; Pevere, V.; Olivier Bouribigou, H.; Vallée, C.; Berthod, M.; Citadelle, C. Compositions catalytiques pour la métathèse de corps gras insaturés avec des oléfines et procédés de métathèse les mettant en œuvre. FR 2,934,178 A1, July 25, 2008.

106 Patent: Zhan, Z.-Y. J. Recyclable Ruthenium Catalysts for Metathesis Reactions, U.S. patent 2007/0043180 A1, February 22, 2007.

107 Patent: Hagadorn, J. R.; Holtcamp, M. W.; Bedoya, M. S. Metathesis catalyst and process for use thereof. US 2011/0306815 A1, December 15, 2011.

108 Chen, M.; Chen, C. Direct and tandem routes for the copolymerization of ethylene with polar functionalized internal olefins. Angew. Chem. Int. Ed. 2020, 59, 1206 -1210.

109 Wyrebek, P.; Malecki, P.; Sytniczuk, A.; Kosnik, W.; Gawin, A.; Kostrzewa, J.; Kajetanowicz, A.; Grela, K. Looking for the Noncyclic(amino) (alkyl)carbene Ruthenium Catalyst for Ethenolysis of Ethyl Oleate: Selectivity Is on Target. ACS Omega 2018, 3, 18481-18488.

110 Kajetanowicz, A.; Chwalba, M.; Gawin, A.; Tracz, A.; Grela, K. Non-Glovebox Ethenolysis of Ethyl Oleate and FAME at Larger Scale Utilizing a Cyclic (Alkyl)(Amino)Carbene Ruthenium Catalyst. Eur. J. Lipid Sci. Technol. 2020, 122, 1900263.

111 Patent: Marx, V.; Virgil, S. C.; Grubbs, R. H. Reactions in the presence of Ruthenium complexes. WO 2015/157736 A1, October 15, 2015

112 (a) Clavier, H.; Caijo, F.; Borre', E.; Rix, D.; Boeda, F.; Nolan, S. P.; Mauduit, M. Towards LongLiving Metathesis Catalysts by Tuning the N-Heterocyclic Carbene (NHC) Ligand on Trifluoroacetamide-Activated Boomerang Ru Complexes Eur. J. Org. Chem. 2009, 2009, 4254-4265. (b) Doppiu, A.; Caijo, F.; Tripoteau, F.; Bompard, S.; Crévisy, C.; Mauduit, M. Synthesis Optimization and Catalytic Activity Screening of Industrially Relevant Ruthenium-Based Metathesis Catalysts. Top. Catal. 2014, 57, 1351-1358. (c) Schmid, T. E.; Dumas, A.; Colombel-Rouen, S.; 
Crévisy,C.; Basle', O.; Mauduit, M. From Environmentally Friendly Reusable Ionic-Tagged Ruthenium- Based Complexes to Industrially Relevant Homogeneous Catalysts: Toward a Sustainable Olefin Metathesis. Synlett 2017, 28, 773-798.

113 Pfister, K. F.; Baader, S.; Baader, M.; Berndt, S.; Goossen, L. J. Biofuel by isomerizing metathesis of rapeseed oil esters with (bio)ethylene for use in contemporary diesel engines. Sci. Adv. 2017, 3, e1602624.

114 Engl, P. S.; Tsygankov, A.; De Jesus Silva, J.; Lange, J.-P.; Copéret, C.; Togni, A.; Fedorov, A. Acrylate Esters by ethenolysis of maleate esters with Ru metathesis catalysts: an HTE and a technoeconomic study. Helv. Chim. Acta 2020, 103, e2000035.

115 For previous study, see: D. Schweitzer, D.; Snell, K. D. Acrylates via Metathesis of Crotonates. Org. Process Res. Dev. 2015, 19, 715-720.

116 Ulman, M.; Belderrain, T. R.; Grubbs, R. H. A series of ruthenium(II) ester-carbene complexes as olefin metathesis initiators: metathesis of acrylates. Tetrahedron Lett. 2000, 41, 4689-4693.

117 Dabrowski, M.; Wyrebek, P.; Trybinski, D.; Wozniak, K.; Grela, K. In a quest for selectivity paired with activity: A Ruthenium olefin metathesis catalyst bearing an unsymmetrical phenanthrene-based N-Heterocyclic Carbene. Chem. Eur. J. 2020, 26, 3782-3794.

118 Patent: Lee, C. W. Ring opening cross metathesis reaction of cyclic olefins with seed oils and the like. WO 2008/008440 A2, January 17, 2008.

119 For reviews on chiral NHC in catalysis, see: (a) Wang, F.; Liu, L.-J.; Wang, W.; Li, S.; Shi, M. Chiral NHC-Metal-Based Asymmetric Catalysis. Coord. Chem. Rev. 2012, 256, 804-853. (b) JanssenMüller, D.; Schlepphorst, C.; Glorius, F. Privileged Chiral N-Heterocyclic Carbene Ligands for Asymmetric Transition-Metal Catalysis. Chem. Soc. Rev., 2017, 46, 4845-4854. (c) Zhao, M.; Zhang, Y.-T.; Chen, J.; Zhou, L. Enantioselective Reactions Catalyzed by N-Heterocyclic Carbenes. Asian J. Org. Chem. 2018, 7, 54-69. (d) Montgomery, T. P.; Johns, A. M.; Grubbs, R. H. Recent Advancements in Stereoselective Olefin Metathesis Using Ruthenium Catalysts. Catalysts 2017, 7, 87. (e) Hoveyda, A. H. Evolution of Catalytic Stereoselective Olefin Metathesis: From Ancillary Trans- formation to Purveyor of Stereochemical Identity. J. Org. Chem. 2014, 79, 4763-4792.

(120) Selected examples of AROCM: (a) Berlin, J. M.; Goldberg, S. D.; Grubbs, R. H. Highly Active Chiral Ruthenium Catalyst for Asymmetric Cross metathesis and Ring-Opening Cross metathesis. Angew. Chem. Int. Ed. 2006, 45, 7591-7595. (b) Giudici, R. E.; Hoveyda, A. H. Directed Catalytic Asymmetric Olefin Metathesis. Selectivity Control by Enoate and Ynoate Groups in Ru-Catalyzed Asymmetric Ring-Opening/ Cross metathesis. J. Am. Chem. Soc. 2007, 129, 3824-3825. (c) Kannenberg, A.; Rost, D.; Eibauer, S.; Tiede, S.; Blechert, S. A Novel Ligand for the Enantioselective Ruthenium-Catalyzed Olefin Metathesis. Angew. Chem., Int. Ed. 2011, 50, 3299-3302. (d) Hartung, J.; Dornan, P. K.; Grubbs, R. H. Enantioselective Olefin Metathesis with Cyclometalated Ruthenium Complexes. J. Am. Chem. Soc. 2014, 136, 13029-13037. (e) Paradiso, V.; Bertolasi, V.; Costabile, 
C.; Grisi, F. Ruthenium olefin metathesis catalysts featuring unsymmetrical N-heterocyclic carbenes Dalton Trans., 2016, 45, 561-571. (f) Rais, E.; Flörke, U.; Wilhelm, R. Reactivity of GrubbsHoveyda II Complexes Including Extended N-Heterocyclic Carbenes with a Bicyclic Camphor-Based Framework. Synthesis. 2017, 49, 2852-2864.

121 Tiede, S.; Berger, A.; Schlesiger, D.; Rost, D.; Luhl, A.; Blechert, S. Highly Active Chiral RutheniumBased Metathesis Catalysts through a Monosubstitution in the N-Heterocyclic Carbene. Angew. Chem. Int. Ed. 2010, 49, 3972 -3975

122 Nguyen, S. T.; Johnson, L. K.; Grubbs, R. H.; Ziller, J. W. Ring-opening metathesis polymerization (ROMP) of norbornene by a Group VIII carbene complex in protic media. J. Am. Chem. Soc. 1992, 114, 3974-3975.

123 Yasir, M; Liu, P.; Tennie, I. K.; Kilbinger, A. F. M. Catalytic living ring-opening metathesis polymerization with Grubbs’ second- and third-generation catalysts. Nature Chem., 2019, 11, 488494.

124 Sutthasupa, S.; Shiotsuki, M.; Sanda, F. Recent advances in ring-opening metathesis polymerization, and application to synthesis of functional materials. Polym. J. 2010, 42, 905-915.

125 Kovacic, S.; Slugovc, C. Ring-opening Metathesis Polymerisation derived poly(dicyclopentadiene) based materials. Mater. Chem. Front., 2020, 4, 2235

126 Slugovc, C. Industrial Applications of Olefin Metathesis Polymerization in Olefin Metathesis: Theory and Practice, ed. K. Grela, John Wiley \& Sons, 2014, pp. 329-334.

127 Leroux, F.; Pascual, S.; Montembault, V.; Fontaine, L. 1,4-Polybutadienes with Pendant Hydroxyl Functionalities by ROMP: Synthetic and Mechanistic Insights. Macromolecules 2015, 48, 3843-3852.

128 Patent: Holtcamp, M .W.; Crowther, D. J.; Huff, C. P.; Brant, P.; Lovell, J. A. Functionalization of vinyl terminated polymers by ring opening cross metathesis. WO 2013/081726 A1, June 6, 2013.

129 Butilkov, D.; Lemcoff, N. G. Jojoba oil olefin metathesis: a valuable source for bio-renewable materials. Green Chem. 2014, 16, 4728-4733.

130 Mori, M. Recent Progress on Enyne Metathesis: Its Application to Syntheses of Natural Products and Related Compounds. Materials 2010, 3, 2087-2140.

131 Dragutan, V.; Dragutan, I.; Demonceau, A.; Delaude, L. Combining enyne metathesis with longestablished organic transformations: a powerful strategy for the sustainable synthesis of bioactive moleculesBeilstein J. Org. Chem. 2020, 16, 738-755.

132 Villar, H.; Frings M.; Bolm, C. Ring closing enyne metathesis: A powerful tool for the synthesis of heterocycles. Chem. Soc. Rev., 2007, 36, 55-66. 
133 Bantreil, X.; Poater, A.; Urbina-Blanco, C. A.; Bidal, Y. D.; Falivene, L.; Randall, R. A. M.; Cavallo, L. Slawin, A. M. Z.; Cazin, C. S. J. Synthesis and Reactivity of Ruthenium Phosphite Indenylidene Complexes. Organometallics 2012, 31, 7415-7426.

134 Nelson, D. J.; Queval, P.; Rouen, M.; Magrez, M.; Toupet, L.; Caijo, F.; Borre, E.; Laurent, I.; Crev́isy, C. ; Basle, O.; Mauduit, M.; Percy, J. M. Synergic Effects Between N-Heterocyclic Carbene and Chelating Benzylidene-Ether Ligands Toward the Initiation Step of Hoveyda- Grubbs Type Ru Complexes. ACS Catal. 2013, 3, 259-264

135 Stewart, I. C.; Keitz, B. K.; Kuhn, K. M.; Thomas, R. M.; Grubbs, R. H. Nonproductive events in ring-closing metathesis using ruthenium catalysts, J. Am. Chem. Soc. 2010, 132, 8534-8535.

136 Nascimoto, D. L.; Fogg, D. E. Origin of the Breakthrough Productivity of Ruthenium-Cyclic Alkyl Amino Carbene Catalysts in Olefin Metathesis, J. Am. Chem. Soc. 2019, 141, 19236-19240.

137 Chu, J., Munz, D., Jazzar, R., Melaimi, M., Bertrand, G. "Synthesis of Hemilabile Cyclic (Alkyl)(amino)carbenes (CAACs) and Applications in Organometallic Chemistry” J. Am. Chem. Soc. 2016, 138, 7884-7887.

138 Dumas, A.; Tarrieu, R.; Vives, T.; Roisnel, T.; Dorcet, V.; Baslé, O.; Mauduit, M. A versatile and highly Z-selective olefin metathesis ruthenium catalyst based on a readily accessible N-heterocyclic carbene. ACS Catal. 2018, 8, 3257-3262.

139 Xu, Y.; Wong, J. J.; Samkian, A. E.; Ko, J. H.; Chen, S.; Houk, K. N.; Grubbs, R. H. Efficient ZSelective Olefin-Acrylamide Cross metathesis Enabled by Sterically Demanding Cyclometalated Ruthenium Catalysts. J. Am. Chem. Soc. 2020, 142, 20987-20993.

140 Liu, Z.; Xu, C.; del Pozo, J.; Torker, S.; Hoveyda, A. H. Ru- based catechothiolate complexes bearing an unsaturated NHC ligand: effective cross metathesis catalysts for synthesis of (Z)- $\alpha, \beta$-unsaturated esters, carboxylic acids, and primary, secondary, and Weinreb amides. J. Am. Chem. Soc. 2019, 141, 7137-7146.

141 Eivgi, O.; Phatake, R. S.; Nechmad, N. B.; Lemcoff, N. G. Light-Activated Olefin Metathesis: Catalyst Development, Synthesis, and Applications. Acc. Chem. Res. 2020, 53, 2456-2471.

142 Eivgi, O.; Vaisman, A.; l Lemcoff, N. G. Latent, Yet Highly Active Photoswitchable Olefin Metathesis Precatalysts Bearing Cyclic Alkyl Amino Carbene (CAAC)/Phosphite Ligands. Acc. Chem. Res. 2021, 11, 703-709. 